University of Tennessee Health Science Center

UTHSC Digital Commons

\title{
$5-2018$
}

\section{Rheological Studies of Injectable Thermoresponsive Biodegradable Hydrogels and Porcine Ocular Tissues}

Chandana Reddy Damera

University of Tennessee Health Science Center

Follow this and additional works at: https://dc.uthsc.edu/dissertations

Part of the Pharmaceutics and Drug Design Commons

\section{Recommended Citation}

Damera, Chandana Reddy (http://orcid.org/0000-0002-2768-1948), "Rheological Studies of Injectable Thermoresponsive Biodegradable Hydrogels and Porcine Ocular Tissues" (2018). Theses and Dissertations (ETD). Paper 456. http://dx.doi.org/10.21007/etd.cghs.2018.0448. 


\title{
Rheological Studies of Injectable Thermoresponsive Biodegradable Hydrogels and Porcine Ocular Tissues
}

\begin{abstract}
This research has evaluated the rheological properties of two types of materials which include (i) semisynthetic polymer-based injectable hydrogels [P(NIPAAm-co-DEX-Lactate HEMA) and P(NIPAAm-co-HAAEMA)], and (ii) biological tissues (porcine ocular tissues).

A series of thermoresponsive and biodegradable in situ hydrogel based on $\mathrm{N}$-isopropyacrylamide (NIPAAm) monomer and hydrolytically degradable oligolactate Dextran-lactate-HEMA or Hyaluronic acid (HA)-AEMA macromer were investigated as encapsulation matrices (scaffolds) for DPSCs/ADSCs and assess their applicability in dental/retinal tissue engineering. The rheological properties of the hydrogels were strongly dependent on the reaction conditions and composition of the hydrogels. Both the hydrogels exhibited linear viscoelasticity, and the values of storage moludus ( $\left.\mathrm{G}^{\prime}\right)$ at $1 \mathrm{~Hz}$ appeared in the range of 15-35 Pa for P(NIPAAm-Co-DEX-Lactate HEMA) gels and 20-40 Pa for P(NIPAAm-Co-HA-AEMA) gels at 15 $\mathrm{mg} \cdot \mathrm{mL}-1$ concentration. No significant differences were found for the hydrogels prepared with the HA or dextran at the same concentration and monomer to macromer ratio (19:1). The hydrogels were nontoxic to DPSCs and ADSCs at a concentration up to $15 \mathrm{mg} \cdot \mathrm{mL}-1$, and in vitro survival studies using MTT and DAPI indicated that both DPSCs and ADSCs have favorably adhered and proliferated within the dextran and HA-based hydrogels. Survival of the DPSCs/ADSCs in the hydrogels, growth and morphology make these scaffolds a viable option for using as a biological scaffold for tissue engineering.
\end{abstract}

Since the functionality of the ocular tissues closely depends on their biomechanical properties, the rheological properties of the ocular tissues at different stages of development (preterm, neonatal and adult stage) is of therapeutic interest and has not been thoroughly investigated. This study has investigated the shear properties of porcine cornea, sclera and vitreous under strain and frequency sweep. All three tissue types at different stages have shown linear viscoelastic region under strain sweep. The $\mathrm{G}^{\prime}$ of cornea and vitreous weakly varied between neonatal and preterm, however, the adult cornea ( 1.3-fold) and vitreous ( 1.8-fold) showed significant higher moduli. On the other hand, the $\mathrm{G}^{\prime}$ of the sclera increased significantly with the developmental stage of the tissue, (preterm

\section{Document Type}

Thesis

\section{Degree Name}

Master of Science (MS)

\section{Program}

Pharmaceutical Sciences

\section{Research Advisor}

Tao L. Lowe, Ph.D.

\section{Keywords}

Hydrogels, Ocular Tissues, Rheology, Stem Cells, Thermoresponsive, Tissue Engineering

\section{Subject Categories}

Medicine and Health Sciences | Pharmaceutics and Drug Design | Pharmacy and Pharmaceutical Sciences 


\title{
Rheological Studies of Injectable Thermoresponsive Biodegradable Hydrogels
} and Porcine Ocular Tissues

\author{
A Thesis \\ Presented for \\ The Graduate Studies Council \\ The University of Tennessee \\ Health Science Center \\ In Partial Fulfillment \\ Of the Requirements for the Degree \\ Master of Science \\ From The University of Tennessee
}

By

Sri Chandana Reddy Damera

May 2018 
Copyright C 2018 by Sri Chandana Reddy Damera.

All rights reserved. 


\section{DEDICATION}

Dedicated to my loving family. 


\section{ACKNOWLEDGEMENTS}

First and foremost, I would like to express my sincere gratitude to my advisor, Dr. Tao Lowe for her continuous support and guidance throughout my graduate studies and related research. I would like to thank her for her patience, motivation, and immense knowledge. Her office was always open whenever I ran into a problem or had a question about my research or writing. Her writing and editing skills are superior to many and she was an irreplaceable mentor throughout the writing process. Her undeniable devotion to her students, research, and the future of science is inspiring and did not go unnoticed. Besides my advisor, I would like to thank Dr. George Huang for providing me with dental pulp stem cells and Dr. Rajashekhar Gangaraju for providing me with adiposederived stem cells for my project and for their scientific discussions.

I would like to thank my advisory committee members Dr. Bernd Meibohm, Dr. George Huang and Dr. David Hamilton, for their time and academic support they have offered me.

Thank you to my fellow lab members, Dr. Fitsum Sahle, Dr. Muhammad Gulfam, Darren Will, Niloy Kumar and Sangyoon Kim whom I have come to know as friends. Your quirks and charms made coming to the lab every day an adventure. I'm very thankful to Dr. Steven Davison and Dr. Cameron Fili for providing me with porcine ocular tissues. I would also like to thank my friends and colleagues at the University of Tennessee Health Science Center. Especially I would like to thank Diwa Koirala, Santosh Wagh, Pallabita Chowdhury and Saini Setua for providing me with exceptional accompany over the course of my studies.

I would like to thank my family (Mom, Dad, and my Brother) for always encouraging me academically and setting me up with the inquisitive attitude that led me to science. Your support both financially and emotionally has kept me on track.

Last but not least, I owe thanks to a very special person, my husband, Dileep Janagam for his continued and unfailing love, support, and understanding during my pursuit of Master's degree. Your encouragement and emotional support have helped me in so many ways. Special thanks to you for being my lab member and familiarizing me with basic lab techniques. 


\begin{abstract}
This research has evaluated the rheological properties of two types of materials which include (i) semi-synthetic polymer-based injectable hydrogels [P(NIPAAm-coDEX-Lactate HEMA) and P(NIPAAm-co-HA-AEMA)], and (ii) biological tissues (porcine ocular tissues).

A series of thermoresponsive and biodegradable in situ hydrogel based on Nisopropyacrylamide (NIPAAm) monomer and hydrolytically degradable oligolactate Dextran-lactate-HEMA or Hyaluronic acid (HA)-AEMA macromer were investigated as encapsulation matrices (scaffolds) for DPSCs/ADSCs and assess their applicability in dental/retinal tissue engineering. The rheological properties of the hydrogels were strongly dependent on the reaction conditions and composition of the hydrogels. Both the hydrogels exhibited linear viscoelasticity, and the values of storage moludus $\left(\mathrm{G}^{\prime}\right)$ at $1 \mathrm{~Hz}$ appeared in the range of 15-35 Pa for P(NIPAAm-co-DEX-Lactate HEMA) gels and 20$40 \mathrm{~Pa}$ for P(NIPAAm-co-HA-AEMA) gels at $15 \mathrm{mg} \cdot \mathrm{mL}^{-1}$ concentration. No significant differences were found for the hydrogels prepared with the HA or dextran at the same concentration and monomer to macromer ratio (19:1). The hydrogels were nontoxic to DPSCs and ADSCs at a concentration up to $15 \mathrm{mg} \cdot \mathrm{mL}^{-1}$, and in vitro survival studies using MTT and DAPI indicated that both DPSCs and ADSCs have favorably adhered and proliferated within the dextran and HA-based hydrogels. Survival of the DPSCs/ADSCs in the hydrogels, growth and morphology make these scaffolds a viable option for using as a biological scaffold for tissue engineering.
\end{abstract}

Since the functionality of the ocular tissues closely depends on their biomechanical properties, the rheological properties of the ocular tissues at different stages of development (preterm, neonatal and adult stage) is of therapeutic interest and has not been thoroughly investigated. This study has investigated the shear properties of porcine cornea, sclera and vitreous under strain and frequency sweep. All three tissue types at different stages have shown linear viscoelastic region under strain sweep. The $\mathrm{G}^{\prime}$ of cornea and vitreous weakly varied between neonatal and preterm, however, the adult cornea ( $\sim 1.3$-fold) and vitreous ( $\sim 1.8$-fold) showed significant higher moduli. On the other hand, the $\mathrm{G}^{\prime}$ of the sclera increased significantly with the developmental stage of the tissue, (preterm $<$ neonatal $(\sim 1.9$-fold $)<$ adult $(17.4$-fold $))$. Thus, the rheological properties of the porcine ocular tissues varied with the developmental stage of the tissue. 


\section{TABLE OF CONTENTS}

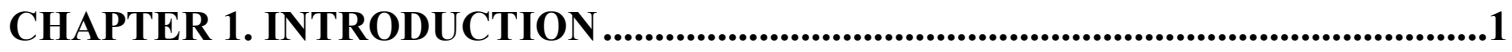

PNIPAAm-Based (Thermoresponsive) Injectable Hydrogels .........................................1

Hypothesis and Specific Aims ................................................................................

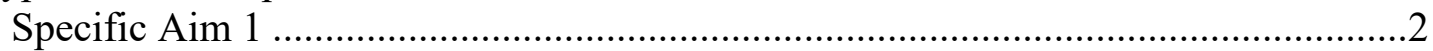

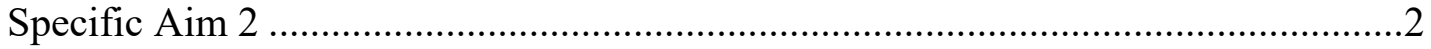

Rheological Studies of Porcine Ocular Tissues ..............................................................

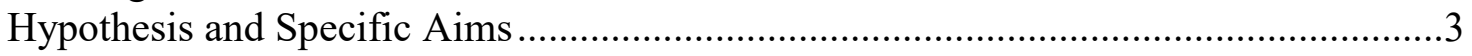

Specific Aim 1 ....................................................................................

Specific Aim 2 ......................................................................................

\section{CHAPTER 2. SYNTHESIS AND CHARACTERIZATION OF INJECTABLE THERMORESPONSIVE AND BIODEGRADABLE HYDROGELS FOR STEM CELL-BASED TISSUE ENGINEERING ......................................................5}

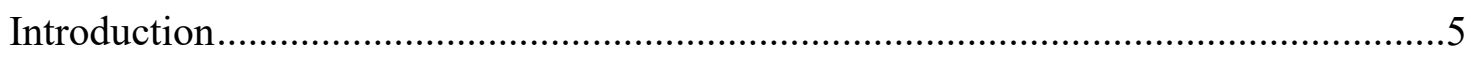

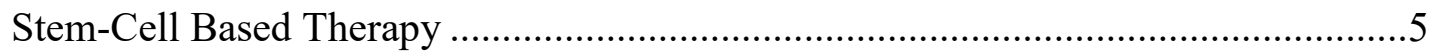

Tissue Engineering........................................................................................

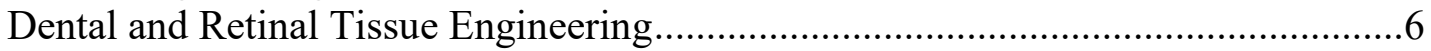

Injectable Hydrogel Biomaterials ............................................................................

PNIPAAm-Based (Thermoresponsive) Injectable Hydrogels ......................................

Hypothesis and Specific Aims ...........................................................................10

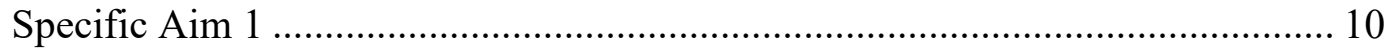

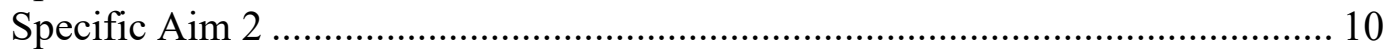

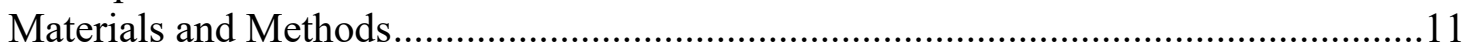

Chemicals and Reagents .......................................................................................11

Synthesis of DEX-Lactate-HEMA and HA-AEMA Macromers.................................11

Synthesis of P(NIPAAm-co-DEX-Lactate-HEMA) and P(NIPAAm-co-HA-

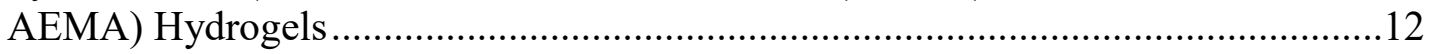

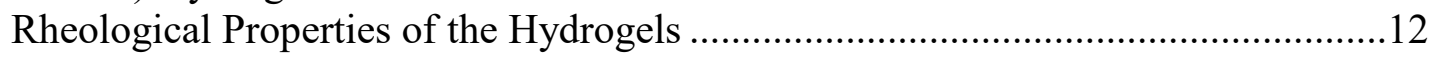

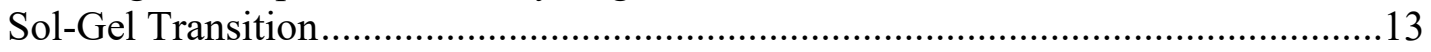

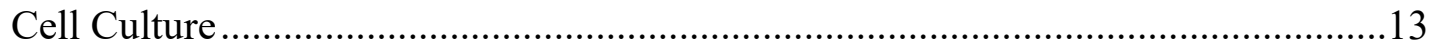

In Vitro Cytotoxicity of Hydrogels to Stem Cells ...................................................13

DPSCs (or) ADSCs Cell Survival Study by MTT and DAPI.....................................13

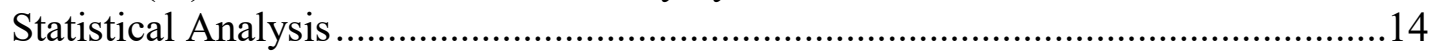

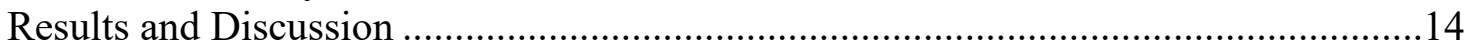

Synthesis and Characterization of Hydrogels .........................................................14

Synthesis and Comparison of Hydrogels Based on HA-AEMA Macromer...............18

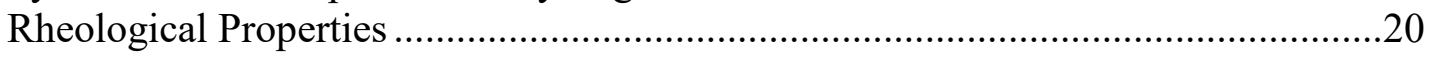

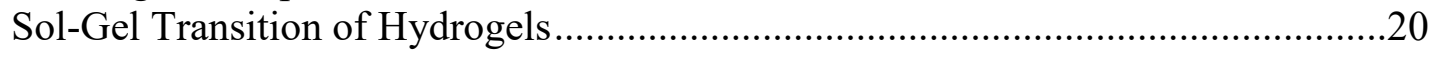

Cell Survival in Hydrogels..............................................................................2.

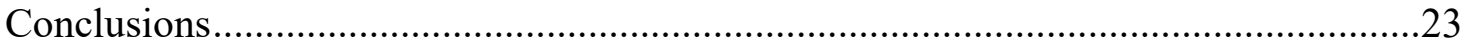




\section{CHAPTER 3. RHEOLOGICAL PROPERTIES OF THE PORCINE OCULAR}

TISSUES AT DIFFERENT STAGES OF DEVELOPMENT ...............................29

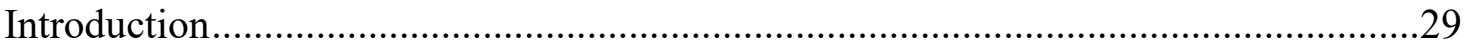

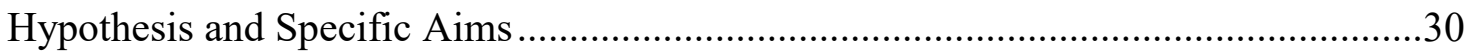

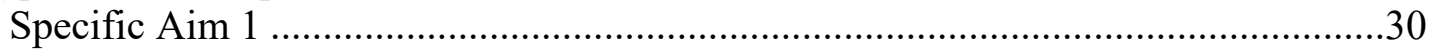

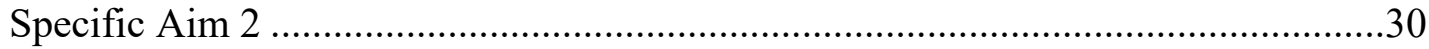

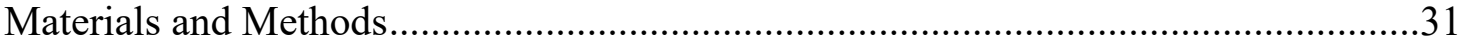

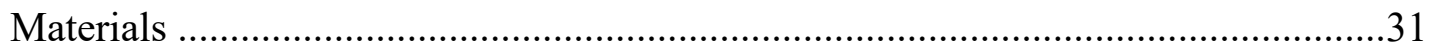

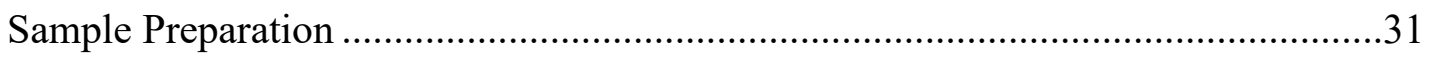

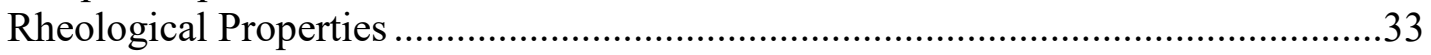

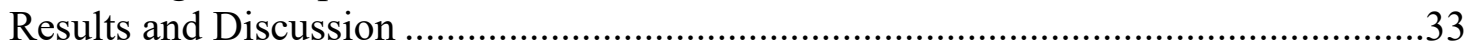

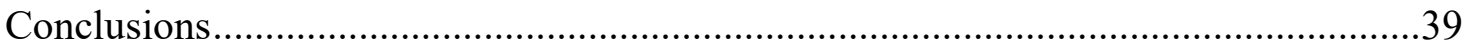

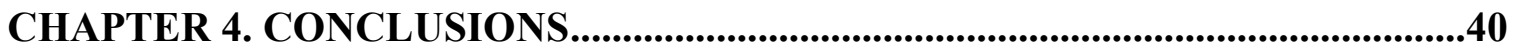

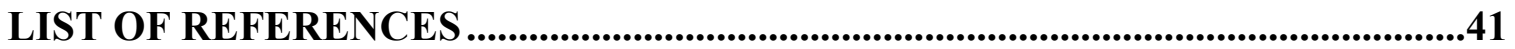

APPENDIX. RHEOLOGY DATA OF HYDROGELS AND PORCINE

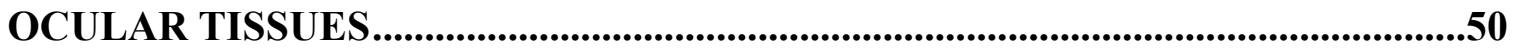

VITA 


\section{LIST OF TABLES}

Table 2-1. Effect of NIPAAM/DEX-Lactate-HEMA macromer ratio, UV intensity, precursor concentration, initiator concentration on the formation of P(NIPAAM-co-DEX-Lactate-HEMA) gels .......................................... 17

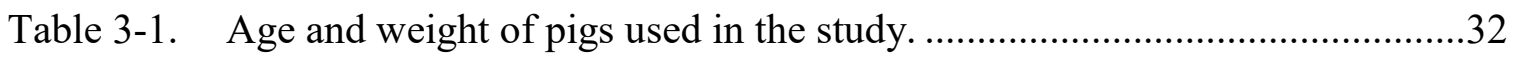




\section{LIST OF FIGURES}

Figure 2-1. FTIR spectrum of hydrogels

Figure 2-2. Cell viability of the P(NIPAAM-co-DEX-LactateHEMA) gels to DPSCs.

Figure 2-3. Representative shear storage modulus $\left(\mathrm{G}^{\prime}\right)$ and shear loss modulus $\left(\mathrm{G}^{\prime \prime}\right)$ as a function of oscillatory strain sweep for the hydrogels.

Figure 2-4. Representative shear storage modulus $\left(\mathrm{G}^{\prime}\right)$ and shear loss modulus $\left(\mathrm{G}^{\prime \prime}\right)$ as a function of frequency for the hydrogels.

Figure 2-5. The thermoresponsive sol-gel transition of the hydrogels

Figure 2-6. Thermoresponsive phase transition and representative change in shear storage modulus $\left(\mathrm{G}^{\prime}\right)$ and shear loss modulus $\left(\mathrm{G}^{\prime \prime}\right)$ as a function of temperature ramp for the hydrogels.

Figure 2-7. Cell viability of DPSCs \& ADSCs in injectable NIPAAm-DEX-LactateHEMA hydrogels using MTT assay.

Figure 2-8. Cell viability of DPSCs \& ADSCs in injectable NIPAAm-HA-AEMA hydrogels using MTT assay.

Figure 2-9. DPSCs growth and morphology in injectable P(NIPAAm-co-DEX-

Lactate-HEMA ) and P(NIPAAm-co-HA-AEMA) hydrogels. .25

Figure 2-10. ADSCs growth and morphology in injectable P(NIPAAm-co-DEXLactate-HEMA) and P(NIPAAm-co-HA-AEMA) hydrogels. .26

Figure 2-11. Cell count of DPSCs \& ADSCs in injectable NIPAAm-DEX-LactateHEMA hydrogels by DAPI staining.

Figure 2-12. Cell count of DPSCs \& ADSCs in Injectable NIPAAm-HA-AEMA Hydrogels by DAPI staining.

Figure 3-1. Storage and loss moduli of corneal tissues at preterm, neonatal and adult stages of development under strain-sweep.

Figure 3-2, Storage and loss moduli of scleral tissues at preterm, neonatal and adult stages of development under strain-sweep.

Figure 3-3. Storage and Loss moduli of vitreous humor at preterm, neonatal and adult stages of development under strain-sweep.

Figure 3-4. Storage and loss moduli of corneal tissues at preterm, neonatal and adult stages of development under frequency-sweep. 
Figure 3-5. Storage and loss moduli of scleral tissues at preterm, neonatal and adult stages of development under frequency-sweep.

Figure 3-6. Storage and Loss moduli of vitreous humor at preterm, neonatal and adult stages of development under frequency-sweep.

Figure 3-7. The viscosity of vitreous humor with the shear rate at preterm, neonatal and adult stages of development.

Figure A-1. Representative shear storage modulus $\left(\mathrm{G}^{\prime}\right)$ and shear loss modulus $\left(\mathrm{G}^{\prime \prime}\right)$ as a function of oscillatory strain sweep for the HA-based $15 \mathrm{mg} \cdot \mathrm{mL}^{-1}$ hydrogel.

Figure A-2. Representative shear storage modulus $\left(\mathrm{G}^{\prime}\right)$ and shear loss modulus $\left(\mathrm{G}^{\prime \prime}\right)$ as a function of oscillatory strain sweep for the HA-based $10 \mathrm{mg} \cdot \mathrm{mL}^{-1}$ hydrogel.

Figure A-3. Representative shear storage modulus $\left(\mathrm{G}^{\prime}\right)$ and shear loss modulus $\left(\mathrm{G}^{\prime \prime}\right)$ as a function of oscillatory strain sweep for the Dex-based $15 \mathrm{mg} \cdot \mathrm{mL}^{-1}$ hydrogel.

Figure A-4. Representative shear storage modulus $\left(\mathrm{G}^{\prime}\right)$ and shear loss modulus $\left(\mathrm{G}^{\prime \prime}\right)$ as a function of oscillatory strain sweep for the Dex-based $10 \mathrm{mg} \cdot \mathrm{mL}^{-1}$ hydrogel.

Figure A-5. Representative shear storage modulus $\left(\mathrm{G}^{\prime}\right)$ and shear loss modulus $\left(\mathrm{G}^{\prime \prime}\right)$ as a function of frequency for the HA-based $15 \mathrm{mg} \cdot \mathrm{mL}^{-1}$ hydrogel.

Figure A-6. Representative shear storage modulus $\left(\mathrm{G}^{\prime}\right)$ and shear loss modulus $\left(\mathrm{G}^{\prime \prime}\right)$ as a function of frequency for the HA-based $10 \mathrm{mg} \cdot \mathrm{mL}^{-1}$ hydrogel.

Figure A-7. Representative shear storage modulus $\left(\mathrm{G}^{\prime}\right)$ and shear loss modulus $\left(\mathrm{G}^{\prime \prime}\right)$ as a function of frequency for the Dex-based $15 \mathrm{mg} \cdot \mathrm{mL}^{-1}$ hydrogel.

Figure A-8. Representative shear storage modulus $\left(\mathrm{G}^{\prime}\right)$ and shear loss modulus $\left(\mathrm{G}^{\prime \prime}\right)$ as a function of frequency for the Dex-based $10 \mathrm{mg} \cdot \mathrm{mL}^{-1}$ hydrogel.

Figure A-9. Thermoresponsive phase transition and representative change in shear storage modulus $\left(\mathrm{G}^{\prime}\right)$ and shear loss modulus $\left(\mathrm{G}^{\prime \prime}\right)$ as a function of temperature ramp for the HA-based $15 \mathrm{mg} \cdot \mathrm{mL}^{-1}$ hydrogel.

Figure A-10. Thermoresponsive phase transition and representative change in shear storage modulus $\left(\mathrm{G}^{\prime}\right)$ and shear loss modulus $\left(\mathrm{G}^{\prime \prime}\right)$ as a function of temperature ramp for the HA-based $10 \mathrm{mg} \cdot \mathrm{mL}^{-1}$ hydrogel.

Figure A-11. Thermoresponsive phase transition and representative change in shear storage modulus $\left(\mathrm{G}^{\prime}\right)$ and shear loss modulus $\left(\mathrm{G}^{\prime \prime}\right)$ as a function of temperature ramp for the Dex-based $15 \mathrm{mg} \cdot \mathrm{mL}^{-1}$ hydrogel. 
Figure A-12. Thermoresponsive phase transition and representative change in shear storage modulus $\left(\mathrm{G}^{\prime}\right)$ and shear loss modulus $\left(\mathrm{G}^{\prime \prime}\right)$ as a function of temperature ramp for the Dex-based $10 \mathrm{mg} \cdot \mathrm{mL}^{-1}$ hydrogel.

Figure A-13. Storage and loss moduli of corneal tissues at preterm stage of development under strain-sweep.

Figure A-14. Storage and loss moduli of corneal tissues at neonatal stage of development under strain-sweep.

Figure A-15. Storage and loss moduli of corneal tissues at adult stage of development under strain-sweep

Figure A-16. Storage and loss moduli of scleral tissues at preterm stage of development under strain-sweep.

Figure A-17. Storage and loss moduli of scleral tissues at neonatal stage of development under strain-sweep. .66

Figure A-18. Storage and loss moduli of scleral tissues at adult stage of development under strain-sweep.

Figure A-19. Storage and Loss moduli of vitreous humor at preterm stage of development under strain-sweep.

Figure A-20. Storage and Loss moduli of vitreous humor at neonatal stage of development under strain-sweep.

Figure A-21. Storage and Loss moduli of vitreous humor at adult stage of development under strain-sweep.

Figure A-22. Storage and loss moduli of corneal tissues at preterm stage of development under frequency-sweep.

Figure A-23. Storage and loss moduli of corneal tissues at neonatal stage of development under frequency-sweep.

Figure A-24. Storage and loss moduli of corneal tissues at adult stage of development under frequency-sweep.

Figure A-25. Storage and loss moduli of scleral tissues at preterm stage of development under frequency-sweep.

Figure A-26. Storage and loss moduli of scleral tissues at neonatal stage of development under frequency-sweep.

Figure A-27. Storage and loss moduli of scleral tissues at adult stage of development under frequency-sweep. 
Figure A-28. Storage and Loss moduli of vitreous humor at preterm stage of development under Frequency-sweep.

Figure A-29. Storage and Loss moduli of vitreous humor at neonatal stage of development under Frequency-sweep........................................................78

Figure A-30. Storage and Loss moduli of vitreous humor at adult stage of development under Frequency-sweep.........................................................79

Figure A-31. The viscosity of vitreous humor with the shear rate at preterm stage of

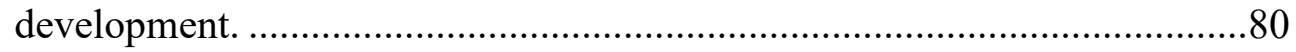

Figure A-32. The viscosity of vitreous humor with the shear rate at neonatal stage of development.

Figure A-33. The viscosity of vitreous humor with the shear rate at adult stage of development. 


\section{LIST OF ABBREVIATIONS}

$\begin{array}{ll}\text { ADSCs } & \text { Adipose-Derived Stem Cells } \\ \text { AEMA } & \text { Aminoethyl methacrylate } \\ \text { CaCl2 } & \text { Calcium Chloride } \\ \text { CDI } & \text { N,N'-carbonyl diimidazole } \\ \text { DAPI } & \text { (4',6-diamidino-2-phenylindole) } \\ \text { DMAP } & \text { 4-(N,N-dimethylamino) pyridine } \\ \text { DMSO } & \text { Dimethyl Sulfoxide } \\ \text { DP } & \text { Degree of Polymerization } \\ \text { DPSCs } & \text { Dental Pulp Stem Cells } \\ \text { DS } & \text { Degree of Substitution } \\ \text { ECM } & \text { Extra Cellular Matrix } \\ \text { ESB } & \text { European Society of Biomaterials } \\ \text { G" } & \text { Loss modulus } \\ \text { G' } & \text { Storage Modulus } \\ \text { HA } & \text { Hyaluronic Acid } \\ \text { HA } & \text { Hydroxyapatite } \\ \text { HEMA } & \text { 2-hydroxyethyl methacrylate } \\ \text { KCl } & \text { Potassium Chloride } \\ \text { MgCl2 } & \text { Magnesium Chloride } \\ \text { MTT } & \text { 3-(4,5-dimethylthiazol-2-yl)-2,5-diphenyltetrazolium bromide } \\ \text { NaCl } & \text { Sodium Chloride } \\ \text { NaH2PO4 } & \text { Sodium dihydrogen phosphate } \\ \text { NaHCO3 } & \text { Sodium Bicarbonate } \\ \text { PCL } & \text { Polycaprolactone } \\ \text { PCLA } & \text { Poly(caprolactone-co-lactide) } \\ \text { PLA } & \text { Polylactide } \\ \text { PLG } & \text { Polyglycolide } \\ \text { PLGA } & \text { Polylactide-co-glycolide } \\ \text { PNIPAAM } & \text { Poly-N-isopropylacrylamide } \\ \text { RGCs } & \text { Retinal Ganglion Cells } \\ \text { SnOct2 } & \text { Stannous octoate } \\ \text { TCP } & \text { Tri-calcium Phosphate } \\ \text { TEMED } & \text { Tetramethylethylenediamine } \\ \text { THF } & \text { Tetrahydrofuran } \\ & \\ & \end{array}$




\section{CHAPTER 1. INTRODUCTION}

This research has evaluated the rheological properties of two types of materials which include (i) semi-synthetic polymer-based injectable hydrogels [P(NIPAAm-coDEX-Lactate HEMA) and P(NIPAAm-co-HA-AEMA)], and (ii) biological tissues (porcine ocular tissues).

\section{PNIPAAm-Based (Thermoresponsive) Injectable Hydrogels}

Among the injectable hydrogels, in situ hydrogels formed by thermoresponsive phase transition have gained extensive attention because the gelation can be triggered as the temperature rises above the lower critical solution temperature (LCST) of the polymer [1]. LCST can be designed below body temperature so that the sol-gel phase transition of injectable systems get triggered at the physiological condition $\left(37^{\circ} \mathrm{C}\right)$ [2]. PNIPAAm is a typical thermosensitive polymer used in the synthesis of various hydrogels [3]. Below LCST, PNIPAAm is hydrophilic and remains in a soluble state in aqueous solution, but with an increase in the temperature above LCST it undergoes a phase transition and forms a hydrogel [4]. Several studies have shown that the phase behavior and mechanical properties of PNIPAAm hydrogels can be modified by the addition of hydrophobic or hydrophilic monomers to impart desired properties into the material $[2,5,6]$. Various composite hydrogel systems were reported in the literature by modifying the PNIPAAm with poly(ethylene glycol), chitosan, hyaluronic acid, chondroitin sulfate or other polymers to alter its physicochemical/ biological/mechanical properties such as to preserve the viability and phenotypic morphology of the cells, improve proliferation, differentiation and extracellular matrix secretion of the cells entrapped within the hydrogel, provide mechanical properties for providing ambient environment for supporting the cell growth [5-11].

Although promising, the thermoresponsive NIPAAm homopolymer are not biodegradable. It is more advantageous to introduce degradable property into the PNIPAAm-based scaffolds as degradation of the hydrogel matrix not only circumvents removal of the empty device but also can be used to modulate space in response to the tissue regeneration and nutrient diffusion. Also, when the polymer slowly degrades, the cells will be able to produce their own ECM and generate successful cell-polymer graft. Therefore, in this study, we designed and synthesized injectable thermoresponsive and biodegradable hydrogels by copolymerizing NIPAAm monomer with dextran-lactate-2hydroxyethyl methacrylate (DEX-Lactate-HEMA) or HA-aminoethylmethacrylate (HAAEMA) macromer using the synthetic technique. Because of the existence of a hydrolyzable/enzymatically degradable DEX-Lactate/HA in the prepolymer mixture, biodegradable crosslinks can be formed within the PNIPAAm hydrogel systems, resulting in biodegradable thermoresponsive systems. Dextran and HA used in the study for modifying PNIPAAm are naturally occurring biodegradable polymers. Dextran is a natural polysaccharide that is enzymatically degradable by dextranases [12]. Dextran is commercially available in wide range of MWs with relatively narrow MW distribution. It 
has been successfully used for various tissue engineering applications because of its excellent biocompatibility, biodegradability, hydrophilicity, stability under slightly acidic and basic conditions, and surface hydroxyl functionality for conjugation [13-16]. Several reports have been published on altering the dextran properties to make various dextran graft polymers via various chemical modifications for various applications [12]. HA is one of the major glycosaminoglycan polysaccharides in the ECM of the newly developed dentin, pulp tissues, and vitreous humor, and is enzymatically degradable by hyaluronidase. The biocompatible structure, biodegradation rate of HA and the flexibility to modify structurally and chemically has suggested its suitability as a scaffold for DPSCs/ADSCs in tissue engineering applications [5, 17-20].

\section{Hypothesis and Specific Aims}

The long-term goal of the project is to develop biomaterials for dental and retinal tissue engineering. The short-term goal of this project was to design and develop injectable thermoresponsive and biodegradable hydrogels P(NIPAAm,-co-DEX-LactateHEMA) and P(NIPAAm-co-Hyaluronic acid AEMA) as scaffolds for encapsulating DPSCs/ADSCs for dental and retinal tissue engineering applications. Also, to investigate whether the scaffold material properties can be controlled by polymer modification and whether cell viability and growth could be improved. The hypothesis of this research was that the injectable biodegradable P(NIPAAm-co-DEX-Lactate-HEMA) and P(NIPAAmco-HA-AEMA) hydrogels were nontoxic to DPSCs and ADSCs cells and promote their growth inside the matrices.

\section{Specific Aim 1}

To synthesize and characterize P(NIPAAm-co-DEX-Lactate-HEMA) and P(NIPAAm-co-HA-AEMA) hydrogels by UV polymerization and FTIR. A series of biodegradable P(NIPAAm-co-DEX-Lactate-HEMA) and p(NIPAAm-co-HA-AEMA) hydrogels were synthesized with varying monomer/macromer ratios, initiator concentration, UV intensity, and reaction times. The hydrogels were characterized for sol-gel transition and rheological properties.

\section{Specific Aim 2}

To evaluate in vitro cytotoxicity and encapsulation capabilities of P(NIPAAm-coDEX-Lactate-HEMA) and P(NIPAAm-co-HA-AEMA) hydrogels. In vitro cytotoxicity of hydrogels to DPSCs and ADSCs was tested at various concentrations of the hydrogel in cell growth medium by MTT assay. The growth of DPSCs/ADSCs inside the hydrogel matrix was examined using MTT and DAPI assays. 


\section{Rheological Studies of Porcine Ocular Tissues}

The proper vision of the eye strongly depends on its ability to maintain optical clarity and structural integrity under routine variations in pressure, changes in humidity and temperature, constant muscular stress/strain and rapid sudden movements. Thus the proper functioning of the eye is dependent on its physical and mechanical properties, and altered chemical and mechanical states of ocular tissues could lead to abnormalities and may result in complete loss of the functionality. Various age-related changes in composition and structure of the eye tissues affect the biomechanical properties and performance of the eye tissues and could contribute to the predisposition of various eye abnormalities [21-26]. For example, aging results in stiffening of the cornea tissue which could be because of the additional age-related non-enzymatic cross-linking affecting the stromal collagen fibrils $[24,25]$. It is reported in the literature that age-related variations affect the biomechanical characteristics of the sclera [21], and aging results in the microstructural changes in the sclera and contribute to the predisposition to primary open-angle glaucoma [22]. With age, collagen networks in the vitreous begin to break down and pockets of liquid form in the eye, the process of liquefaction in which the liquid volume increases and gel volume decreases [23, 26]. These age-related changes could lead to structural and mechanical differences between vitreous at various stages of development, and in about $25-30 \%$ of the population, these age-related degenerative changes eventually result in posterior vitreous detachment [27]. Given the importance of the viscoelastic properties of the ocular tissues, to its function and to pathology, detailed rheological characterization of these tissues is crucial to appreciate the normal functions and quantitative understanding of disease pathophysiology of these tissues at various stages of development. The objective of this project was to characterize the rheological properties of the ocular tissues (cornea, sclera and vitreous) at different stages (preterm, neonatal and adult) of development. Though several measurements could be measured in vivo, such as topography, thickness distribution, but the attempts to investigate the biomechanical properties of the tissues still depend on ex-vivo experiments involving human or other animal tissues [28]. Because of the difficulties in obtaining human donor tissues in sufficient numbers for the research and experimental needs, it had been necessary to use animal ocular tissues as approximate models for human ocular tissues for performing various evaluations including the mechanical property characterization studies. Several investigations used porcine tissues for ocular related experiments [2830], although other animal's rabbit and bovine tissues a common practice. Therefore, the current rheological characterization also contributes to the literature for identifying and assessing the important similarities and significant differences between the rheological behaviors of porcine ocular tissues and human and other animal tissues and evaluating the suitability of the porcine eye tissues as a model of the human tissues.

\section{Hypothesis and Specific Aims}

The hypothesis of this project was that the storage and loss modulus of the porcine ocular tissues differ at different stages of development (preterm, neonatal and adult). There were two specific aims: 


\section{Specific Aim 1}

To conduct the shear-sweep experiments and identify the linear viscoelastic region of the porcine ocular tissues (cornea, sclera, vitreous) at different stages of development (preterm, neonatal, adult).

\section{Specific Aim 2}

To conduct the frequency sweep experiment and analyze the gel-like behaviors of the porcine ocular tissues (cornea, sclera, vitreous) at different stages of development (preterm, neonatal, adult). 


\title{
CHAPTER 2. SYNTHESIS AND CHARACTERIZATION OF INJECTABLE THERMORESPONSIVE AND BIODEGRADABLE HYDROGELS FOR STEM CELL-BASED TISSUE ENGINEERING
}

\author{
Introduction
}

\section{Stem-Cell Based Therapy}

Organ failure disorders and several of neurodegenerative diseases characterized by death of cells are leading to the irreversible loss of tissues and functions. For many of the neurodegenerative diseases, particularly in those conditions where an extensive cell loss was occurred prior to molecular level diagnosis of their gene defects, just the drug and/or gene therapy may not be enough to resolve the issues [31]. In such instances, the strategies were focused on cellular or tissue replacement, and based on recent studies, it was found that these strategies were beneficial [31-33]. Cell-based therapy involves the use of exogenous cells obtained from either autologous or allogenic source [34]. In such cases, use of stem/progenitor cells presents major advantages over differentiated cells as they can proliferate to the required amounts before or after transplantation [34].

Even though the stem-cell based therapies are promising, still they need an

effective transplantation system. Current direct delivery methods could result in massive cell loss and limited cellular integration following transplantation [31]. For example, studies indicated that after bolus injection of photoreceptor cells, less than $0.01 \%$ of transplanted cells survive and even fewer actually integrate within the host retina [35, 36]. Therefore, there is a need for efficient delivery methods that could minimize the cell loss and assist in the growth and cell integration into the host system, and tissue engineering scaffolds are the alternative option that has shown to help in addressing the above-mentioned issues [37-39].

\section{Tissue Engineering}

Since its first use as a term in the mid-1980s, tissue engineering has moved from 'science-fiction' concept to 'science fact' and emerged as a significant multidisciplinary field in the biotechnological area, with the research-oriented acceptance of its potential to regulatory approvals and market availability for the treatment [40]. Especially, with a more significant advancement of biomaterials, tissue engineering is emerging as a great potential alternative or complementary solution for restoring, maintaining or improving tissue or organ functions [41]. A general tissue engineering paradigm involves the use of a highly porous artificial extracellular matrix or 'scaffold' as a temporary support matrix for cell growth, differentiation, and matrix production, and the resulting tissue engineering construct is then grafted back in vivo into the subject. These constructs are either fully functional or they grow into the required functionality $[41,42]$. Thus, tissue 
engineering has the promising potential to revolutionize methods in medical treatment and can offer a long-term solution for many age-related conditions.

In simple terms, scaffolds are porous artificial materials functioning as an extracellular matrix that accommodates and guides the growth and proliferation of cells in the 3D environment $[39,42]$. The native extracellular matrix (ECM) not only provides physical support or appropriate architecture to the cells but also functions as a substrate for cell adhesion, migration and controls cellular proliferation and supplies with various growth factors and nutrients. In order to guide the formation of tissues with a required structural and functional characteristics, it is essential to provide a dynamic in vitro microenvironment with a proper quantity of physical strength such as shear and mechanical forces that promote their development [43]. Therefore, the key objective of a scaffold is to closely mimic the native ECM environment in terms of physical structure, chemical composition, and biological functions and play a similar role for promoting tissue regeneration in vitro as native ECM does in vivo [41]. Overall, the desirable physical characteristics of biomaterial scaffold for tissue engineering applications include nontoxic/non-inflammatory, hydrophilicity, high porosity with uniformly distributed interconnected pores throughout the matrix, large surface area, large pore size, and the ability to degrade in response to tissue repair and growth progresses, ideal shear and mechanical support as native environment [44-46].

\section{Dental and Retinal Tissue Engineering}

Data on tooth loss showed that at least 20 million people in the US have missed all of their teeth, and more than 100 million have lost 11-15 teeth [47]. Dental tissue engineering, to regenerate the dental pulp or dentin tissues in the pulp space of teeth, has grown tremendously as a new option in the area of endodontics for preserving and restoring the teeth $[34,48]$. Although dentine can regenerate, the pulp has a limited capability for regeneration as it is encased in dentine and has limited apical blood supply [49]. Dental pulp stem cells (DPSCs) are an accessible multipotent stem cell source with therapeutic applicability in repair and regeneration of damaged tissues [50]. Dr. Huang's group has demonstrated that DPSCs are a promising source for dental tissue regeneration (dentin-pulp like tissues, bioroot) [51]. Also because of their angiogenic and angioinductive property, they are a good source for non-dental (bonelike tissues, neurogenic, angiogenic) tissue engineering applications as well [34]. Studies conducted on dental pulp tissue regeneration, utilizing the DPSCs seeded PLGA-based synthetic preformed scaffolds, have shown the formation of pulp-like tissue in both in vitro and in vivo models. However, due to the smaller size and encasement of the dental pulp inside the root canal, utilizing an injectable scaffold that can be administered into the enclosed area could complement the efficiency of the DPSCs-based therapy for engineering the dentine-pulp complex by minimizing the cell loss and assisting in the growth and cell integration into the host system upon administration.

Retinal degenerations are a group of conditions that can lead to permanent visual loss and affect millions of people worldwide [52]. Clinically, there are no neuroprotective 
nor axogenic therapies are available that can restore lost visual functionality in retinal degenerative diseases [53]. Current therapeutic strategies such as anti-angiogenic drugs, anti-inflammatory, and gene therapy can delay the disease progression but not effective in permanent cure. Several studies are in progress aiming to regenerate the diseased retina by stem-cell transplantation for the replacement of lost retinal ganglion cells (RGCs) and photoreceptors. Currently, there are many ongoing clinical trials which aim to test the safety and efficacy of stem cell transplantation in the eye [52]. Several reports in the literature have suggested that the retinal tissue can be replaced and some degree of functional recovery can be regained following the delivery of stem-cells [54]. Adiposederived stem cells (ADSCs) are progenitor cells that can easily be isolated from adipose tissue [55]. They have the capability of self-renewal and multilineage differentiation and can be transplanted to either autologous or allogeneic body safely with less implant migration and foreign body reaction [20]. The ADSCs have functional and phenotypic overlap and plays a key role in providing vascular protection $[20,56,57]$. ADSCs are also known to produce angiogenic and antiapoptotic factors [55]. Recent findings from Dr. Gangaraju's group on the regenerative therapeutic potential of ADSCs and showed that a single direct intravitreal injection of ADSCs significantly limited the development of diabetic ocular complications [55]. Intravitreal injection of ADSCs has shown to stabilize the retinal microvasculature, thereby enabling repair and regeneration of damaged capillaries in vivo [58]. The results suggested that ADSCs have great potential to be developed into a cell-based therapy to address both retinal capillary and neurodegeneration [55]. Earlier retinal transplantation studies involved direct injection of the cells into the vitreous or subretinal space with the assumption that the injected cells would migrate to the degenerated site of the retina, integrate within the host retina and restore vision functionality [52]. Despite promising outcomes of cell-based therapies to regenerate the degenerating retina, they also demonstrated that the direct bolus injection of stem cells in vivo could result in disorganized and poorly localized tissue grafts [59]. The resulted outcomes of low rates of cell survival due to poor donor cell integration and injection reflux are primarily related to the transplantation procedure [59]. Use of injectable hydrogel scaffolds for seeding and delivering the stems cells into the retina could be an attractive alternative to direct injection as they can potentially limit donor cell death due to injection reflux and help in improving the integration of the donor cells into host system [60].

Therefore, new biomaterials, injectable thermoresponsive and biodegradable hydrogel scaffolds, have been evaluated in this project for seeding DPSCs/ADSCs for dental/retinal tissue engineering applications.

\section{Injectable Hydrogel Biomaterials}

Biomaterials have been proved to significantly affect the proliferation and differentiation potential of stem cells by controlling physicochemical properties (e.g., surface charge, source, mechanical properties and microstructural patterns) [61]. In the

recent years, significant efforts have been made to develop several biocompatible scaffolds for tissue engineering based on synthetic and natural polymers and studied to 
improve the cell attachment, viability/proliferation, differentiation and growth of the DPSCs/ADSCs [44, 46, 62-65]. The synthetic polymers (polyglycolide (PLG) [66, 67], polylactide (PLA) [68, 69], polylactide-co-glycolide (PLGA) [70-72], polycaprolactone (PCL) [73], PNIPAAm-based possess much flexibility in terms of tailoring the architecture (scaffold shape, porosity, mechanical properties), controlling the degradation rate and have shown much success [74-76]. But the limitations include the risk of rejection rate due to cell and tissue necrosis due to degradation products of polymers [44, 77]. Unlike synthetic polymer-based scaffolds, natural polymers (polysaccharides (e.g., chitin [78], chitosan [79-81], hyaluronic acid (HA) [17-19], alginate [82-85]) proteins (collagen [17, 86, 87], gelatin [84], fibrin [76]) are bioactive and promote cell growth and cell adhesion. Further, they are biodegradable thus can allow the host cells to grow and produce their own ECM and replace the degraded scaffold over time. Thus advantages of these single type of polymers have motivated the researchers to investigate combinatorial systems/composite scaffolds comprising multiple types of biomaterials [44]. Such examples include combining synthetic polymers with natural polymers $[88,89]$, for enhancing their biological capacity. These combinational systems can have controlled degradation, have a wide range of mechanical properties that enable them to be used in various tissue engineering applications. Since human tissue ranges in terms of mechanical properties, control of mechanical properties of the materials using a composite scaffold of synthetic and natural polymers will be greatly advantageous.

Among various biomaterials, hydrogels represent an important class of scaffolds that have been explored for tissue engineering applications. These are 3-dimensionalcrosslinked hydrophilic polymeric networks that absorb and retain large amounts of water or biological fluids [90]. They possess several unique properties such as 3-dimensional network, tissue compatibility and similarity to native ECM, support cell proliferation and migration, controlled release of growth factors and nutrient diffusion [91]. They have gained significant attention for tissue engineering applications because of their attractive physicochemical properties such as hydrophilicity, water imbibing nature, softness, nutrient diffusion, and synthetic flexibility [91-93]. However, the traditional pre-formed hydrogel scaffold needs invasive procedures for administration and may have improper adaptation to the defect site which could lead to scaffold failure. Therefore, injectable biodegradable hydrogel biomaterials, which are liquids before injection and transform to a gel at the site of injection in response to external stimuli, have been extensively investigated as cell scaffolds owing to their advantages such as ease of administration with minimal invasiveness, less discomfort and less scarring, complete filling of the defect area with better adaptation and good permeability [94]. In addition, cells can be easily incorporated in the solution by mixing prior to injection under appropriate conditions, and after injection, they can take the shape of the cavity and fill irregular defects $[92,93]$. Eliminating highly invasive procedures could lower the healthcare costs and improve the recovery time for the patients.

Various physical and chemical mechanisms can be used to trigger this phase transition [94, 95]. Various types of injectable hydrogels have been investigated for the regeneration of i) cartilage tissues (using chondrocytes in: collagen [96], chitosanhyaluronic acid (HA) [97], methacrylated glycol chitosan-HA [98], gelatin-hydroxy 
phenylpropionic acid [99], HA-PEG [100], PEG-based [101], dextran-tyramine [13], HA-g-dextran-tyramine [15]), ii) intervertebral discs (using chondrocytes in: amidic alginate [102]; using mesenchymal stem cells in: HA-PNIPAAm [103], PHEMA-coaminopropyl methacrylamide (APMA))-graft-poly(amido amine) [104], HA-PEG [105]), iii) bone (using calvarial osteoblasts in: alginate hydrogels along with poly(aldehyde glucoronate) [106], RGD peptide modified alginate [107]; using human mesenchymal stem cells in: PCLA-PEG-PCLA [108], acrylated HA-PEG [109]; using osteoblasts in: RGD modified PEG hydrogel [110]; using marrow mesenchymal stem cells in: chitosan [111], chitin-PCL-nanoHAp [111], chitosan-alginate [112]); iv) adipose tissue (using adipose-derived stem cells in: PNIPAAM-HA [5], modified PEG [5], alginate-Ocarboxymethyl chitosan-fibrin [113]; using preadipocytes in: alginate hydrogels linked with RGD peptide $[114,115]$ ), v) muscle tissues (using skeletal myoblasts in: fibrin [116, 117], poly(d-valerolactone) (PVL)-PEG-PVL [118]; using cardiosphere derived cells in combination polymers PNIPAAm-PCL-HEMA-DBLA, Dex-PCL-HEMA/PNIPAAm $[119,120]$, using satellite cells in photo-crosslinkable HA [121], chitosan/betaglycerolphosphate/collagen [122]; using mesoangioblasts in: PEG-fibrinogen [123]; using ischaemic progenitor cells in: collagen, alginate, HA, chitosan [124, 125]); v) dental (using DPSCs in Puramatrix [126]).

\section{PNIPAAm-Based (Thermoresponsive) Injectable Hydrogels}

Among the injectable hydrogels, in situ hydrogels formed by thermoresponsive phase transition have gained extensive attention because the gelation can be triggered as the temperature rises above the lower critical solution temperature (LCST) of the polymer [1]. LCST can be designed below body temperature so that the sol-gel phase transition of injectable systems get triggered at the physiological condition $\left(37^{\circ} \mathrm{C}\right)$ [2]. PNIPAAm is a typical thermosensitive polymer used in the synthesis of various hydrogels [3]. Below LCST, PNIPAAm is hydrophilic and remains in a soluble state in aqueous solution, but with an increase in the temperature above LCST it undergoes a phase transition and forms a hydrogel [4]. Several studies have shown that the phase behavior and mechanical properties of PNIPAAm hydrogels can be modified by the addition of hydrophobic or hydrophilic monomers to impart desired properties into the material $[2,5,6]$. Various composite hydrogel systems were reported in the literature by modifying the PNIPAAm with poly(ethylene glycol), chitosan, hyaluronic acid, chondroitin sulfate or other polymers to alter its physicochemical/ biological/mechanical properties such as to preserve the viability and phenotypic morphology of the cells, improve proliferation, differentiation and extracellular matrix secretion of the cells entrapped within the hydrogel, provide mechanical properties for providing ambient environment for supporting the cell growth [5-11].

Although promising, the thermoresponsive NIPAAm homopolymer are not biodegradable. It is more advantageous to introduce degradable property into the PNIPAAm-based scaffolds as degradation of the hydrogel matrix not only circumvents removal of the empty device but also can be used to modulate space in response to the tissue regeneration and nutrient diffusion. Also, when the polymer slowly degrades, the 
cells will be able to produce their own ECM and generate successful cell-polymer graft. Therefore, in this study, we designed and synthesized injectable thermoresponsive and biodegradable hydrogels by copolymerizing NIPAAm monomer with dextran-lactate-2hydroxyethyl methacrylate (DEX-Lactate-HEMA) or HA-aminoethylmethacrylate (HAAEMA) macromer using the synthetic technique. Because of the existence of a hydrolyzable/enzymatically degradable DEX-Lactate/HA in the prepolymer mixture, biodegradable crosslinks can be formed within the PNIPAAm hydrogel systems, resulting in biodegradable thermoresponsive systems. Dextran and HA used in the study for modifying PNIPAAm are naturally occurring biodegradable polymers. Dextran is a natural polysaccharide that is enzymatically degradable by dextranases [12]. Dextran is commercially available in wide range of MWs with relatively narrow MW distribution. It has been successfully used for various tissue engineering applications because of its excellent biocompatibility, biodegradability, hydrophilicity, stability under slightly acidic and basic conditions, and surface hydroxyl functionality for conjugation [13-16]. Several reports have been published on altering the dextran properties to make various dextran graft polymers via various chemical modifications for various applications [12]. HA is one of the major glycosaminoglycan polysaccharides in the ECM of the newly developed dentin, pulp tissues, and vitreous humor, and is enzymatically degradable by hyaluronidase. The biocompatible structure, biodegradation rate of HA and the flexibility to modify structurally and chemically has suggested its suitability as a scaffold for DPSCs/ADSCs in tissue engineering applications [5, 17-20].

\section{Hypothesis and Specific Aims}

The long-term goal of the project is to develop biomaterials for dental and retinal tissue engineering. The short-term goal of this project was to design and develop injectable thermoresponsive and biodegradable hydrogels P(NIPAAm,-co-DEX-LactateHEMA) and P(NIPAAm-co-Hyaluronic acid AEMA) as scaffolds for encapsulating DPSCs/ADSCs for dental and retinal tissue engineering applications. Also, to investigate whether the scaffold material properties can be controlled by polymer modification and whether cell viability and growth could be improved. The hypothesis of this research was that the injectable biodegradable P(NIPAAm-co-DEX-Lactate-HEMA) and P(NIPAAmco-HA-AEMA) hydrogels were nontoxic to DPSCs and ADSCs cells and promote their growth inside the matrices.

Specific Aim 1. To synthesize and characterize P(NIPAAm-co-DEX-LactateHEMA) and P(NIPAAm-co-HA-AEMA) hydrogels by UV polymerization and FTIR. A series of biodegradable P(NIPAAm-co-DEX-Lactate-HEMA) and p(NIPAAm-co-HAAEMA) hydrogels were synthesized with varying monomer/macromer ratios, initiator concentration, UV intensity, and reaction times. The hydrogels were characterized for sol-gel transition and rheological properties.

Specific Aim 2. To evaluate in vitro cytotoxicity and encapsulation capabilities of P(NIPAAm-co-DEX-Lactate-HEMA) and P(NIPAAm-co-HA-AEMA) hydrogels. In

vitro cytotoxicity of hydrogels to DPSCs and ADSCs was tested at various concentrations 
of the hydrogel in cell growth medium by MTT assay. The growth of DPSCs/ADSCs inside the hydrogel matrix was examined using MTT and DAPI assays.

\section{Materials and Methods}

\section{Chemicals and Reagents}

Dextran (MW -15,000 $\left.\mathrm{g} \cdot \mathrm{mol}^{-1}\right)$ was purchased from Polysciences, Inc., Warrington, PA. Hyaluronic Acid (HA) was provided by Bloomage Freda Biopharm Co., Ltd., Jinan, China. The following materials were obtained from Sigma-Aldrich, Inc (St. Louis, MO): N-isopropylacrylamide (NIPAAm), 2-hydroxyethyl methacrylate (HEMA), 4-(N,N-dimethylamino) pyridine (DMAP), N,N'-carbonyl diimidazole (CDI), L-lactide, stannous octoate ( $\left.\mathrm{SnOct}_{2}\right)$, tetrahydrofuran (THF), irgacure 2959, dimethyl sulfoxide (DMSO), 3-(4,5-dimethylthiazol-2-yl)-2,5-diphenyltetrazolium bromide (MTT), 4',6diamidino-2-phenylindole (DAPI). Dialysis tubing of 50,000 molecular weight cut off (MWCO) was purchased from Spectrum Laboratories. DPSCs were obtained from Dr. Huang's Lab and ADSCs were obtained from Dr. Gangaraju Rajashekar's Lab. All the chemicals were used as received. Deionized distilled water was used in all the experiments.

\section{Synthesis of DEX-Lactate-HEMA and HA-AEMA Macromers}

DEX-Lactate-HEMA macromer with a theoretical degree of polymerization 4 (DP) and degree of substitution 10\% (DS) was synthesized according to the previously published procedure [4]. Briefly, at first, L-lactide (4.32 g, $0.02 \mathrm{~mol})$ and HEMA (1.8 g, $0.01 \mathrm{~mol})$ were reacted in the presence of nitrogen and catalyst SnOct2 $(0.05 \mathrm{~g}, 0.00013$ mol) at $110^{\circ} \mathrm{C}$ for $1 \mathrm{~h}$. HEMA-lactate product was collected by dissolving the cooled reaction mixture in THF, precipitating in ice-cold water, dissolving in ethyl acetate, drying over $\mathrm{MgSO}_{4}$, and concentrating under reduced pressure. The yield of the above reaction was 35\%. Next, CDI (2.59 g, $0.015 \mathrm{~mol})$ was dissolved in THF (100 mL) in a nitrogen atmosphere and reacted with the above HEMA-lactate $(4.454 \mathrm{~g}, 0.01 \mathrm{~mol})$ at room temperature for $16 \mathrm{~h}$. The resulting HEMA-lactate-imidazolyl carbamate (HEMAlactateCI) was obtained by solvent evaporation under reduced pressure, and the reaction yield was 95\%. Finally, dextran (4 g, $0.024 \mathrm{~mol}$ of glucopyranose residues) was dissolved in DMSO $(90 \mathrm{~mL})$ in a nitrogen atmosphere. After the dissolution of DMAP $(2.0 \mathrm{~g})$, HEMA- lactate-CI (1.62 g, $0.002 \mathrm{~mol})$ was added, and the mixture was stirred at room temperature for 4 days. The DEX-Lactate-HEMA product was obtained by precipitating the reaction mixture in a large excess volume of cold dry 2-propanol, washed several times with 2-propanol, and dried in a vacuum for at least $24 \mathrm{~h}$. The yield of the final reaction was $85 \%$.

HA-AEMA macromer of molecular weight 18k and 25\% AEMA substitution used in thesis work was synthesized by previous lab member Mr. K.B. Compton and 
reported in his thesis [127].

\section{Synthesis of P(NIPAAm-co-DEX-Lactate-HEMA) and P(NIPAAm-co-HA-AEMA) Hydrogels}

P(NIPAAm-co-DEX-Lactate-HEMA or DEX-based gels) and P(NIPAAm-coHA-AEMA or HA-based gels) hydrogels were synthesized by photopolymerization of NIPAAm monomer and hydrolytically degradable oligolactate 2-hydroxyethyl methacrylate (DEX-Lactate-HEMA) macromer or HA-AEMA macromer. The variables that were studied and optimized during the synthesis of hydrogels include: NIPAAm to macromer ratio, the concentration of the pre-polymer mixture, initiator concentration, UV intensity, reaction time, distance of the tip of the probe from the surface of the liquid, and dialysis time. Different weight ratios of NIPAAm:DEX-Lactate-HEMA or NIPAAm:HAAEMA (19:1 16:4, w:w) were used for the synthesis. Irgacure 2959, a biocompatible photoinitiator was used in different amounts relative to prepolymer mixture weight, $0.0125,0.025,0.05 \mathrm{w} \%$ for the initiation of the crosslinking. Different UV intensities $\left(100,250,375,500,750,1000 \mathrm{~mW} \cdot \mathrm{cm}^{-2}\right)$, and different reaction time $(3,10 \mathrm{~min})$ are used for synthesizing the hydrogels. DEX-Lactate-HEMA (or) HA-AEMA macromers were dissolved in $25 \%$ ethanol. The concentration of the pre-polymer mixture used was $0.5,1,2 \mathrm{mg} \cdot \mathrm{mL}^{-1}$. To the dissolved macromer solution, NIPAAm was added and vortexed to get a uniform solution. Initiator in different amounts $(0.05,0.025,0.0125$ $\mathrm{w} \%$ ) were added to the above solution. $50 \mu \mathrm{L}$ of the pre-polymer mixture was placed into a 96 well plate and exposed to UV at different intensities of $100-750 \mathrm{~mW} \cdot \mathrm{cm}^{-2}$ for 3 (or) $10 \mathrm{~min}$. The distance of the tip of the probe from the surface of a mold used was 0.5 or 0 $\mathrm{cm}$. The obtained hydrogels were dialyzed against DI water for 4-6 $\mathrm{h}$ with changing the water every half an hour in a $2 \mathrm{~L}$ beaker. After dialysis, the contents were collected and freeze-dried to get the dried polymer, and characterized by FTIR. The yield of the DEXbased gels was $52,75,91 \%$ with $0.0125,0.025,0.05 \mathrm{wt} \%$ initiator respectively and the yield of HA-based gels was 55, 79, $94 \%$ with $0.0125,0.025,0.05 \mathrm{wt} \%$ initiator, respectively.

\section{Rheological Properties of the Hydrogels}

The rheological properties of hydrogels were tested using an AR-G2 Rheometer (TA Instruments, New Castle, Delaware) with $8 \mathrm{~mm}$ parallel plate geometry. Specifically, the hydrogels were subjected from 0.01 to 100 percent strain, while maintaining a normal force to $0.01-0.03 \mathrm{~N}$, the temperature at $37^{\circ} \mathrm{C}$, and a constant $1 \mathrm{~Hz}$ frequency of oscillation to determine linear viscoelastic region. $50 \mu \mathrm{L}$ of hydrogel was used in each run and the gap of $500 \mu \mathrm{m}$ was maintained between the top plate and bottom Peltier plate. The software for the rheometer was set up to take 15 sample points per decade of strain, for the strain sweep and 10 sample points per decade of frequency in a frequency sweep, and a resulting graph of the storage modulus over the range of percent strain or frequency was created at the termination of the procedure. Strain sweep was conducted to determine the linear viscoelastic region of the gels where $\mathrm{G}^{\prime}$ and $\mathrm{G}^{\prime \prime}$ are independent of \% strain. For 
the temperature ramp, $\mathrm{G}^{\prime}$ and $\mathrm{G}^{\prime \prime}$ were measured with an increase in temperature from 15 to $45^{\circ} \mathrm{C}$ at the rate of $1{ }^{\circ} \mathrm{C} / \mathrm{min}$.

\section{Sol-Gel Transition}

The dried DEX-Lactate-HEMA was dissolved at concentration 10 or $20 \mathrm{mg} / \mathrm{mL}$ in the dental pulp stem cell (DPSC) medium and transferred to Eppendorf tubes. Then the tubes were heated to $37^{\circ} \mathrm{C}$ from room temperature to test the gelation.

\section{Cell Culture}

The DPSCs were cultured in DPSCs medium containing a-MEM $500 \mathrm{~mL}$, FBS 55 $\mathrm{mL}$ (final content: 10\%-15\%), 2mM L-glutamine $5.5 \mathrm{~mL}$ (final: $200 \mathrm{mM}$ ), $1 \%$ antibiotics and $100 \mu \mathrm{g} \cdot \mathrm{mL}-1 \mathrm{~b}$-FGF $20 \mu \mathrm{L}$ (final: $4 \mathrm{ng} \cdot \mathrm{mL}-1$ ) at $37^{\circ} \mathrm{C}$ in a humidified incubator containing 5\% CO2. The ADSCs were cultured in DMEM/F-12 medium containing 10\% FBS (Fetal Bovine Serum) and 1\% antibiotics.

\section{In Vitro Cytotoxicity of Hydrogels to Stem Cells}

The cytotoxicity of P(NIPAAm-co-DEX-Lactate-HEMA) and P(NIPAAm-coHA-AEMA) against DPSCs were performed by MTT assay. The cells were seeded in 96well plate at a density of 7500 cells/well. After the incubation in $150 \mu \mathrm{L}$ of DPSCs medium for $48 \mathrm{~h}$, with replacing $100 \mu \mathrm{L}$ of medium after $24 \mathrm{~h}$, the medium was replaced with an assigned amount of p(NIPAAm-co-DEX-Lactate-HEMA) dissolved in DPSCs medium, respectively, and the cells were incubated at $37{ }^{\circ} \mathrm{C}$ and $5 \% \mathrm{CO}_{2}$ for another 24 h. Hydrogel solution was added to each of the test wells at different concentrations $(0.5$, $\left.1,10 \mathrm{mg} \cdot \mathrm{mL}^{-1}\right)$. After $24 \mathrm{~h}$ of incubation, $20 \mu \mathrm{L}$ of MTT solution $\left(5 \mathrm{mg} \cdot \mathrm{mL}^{-1}\right.$ in PBS) was added to each well and the cells were further incubated for $4 \mathrm{~h}$. A solubilizing solution, dimethyl sulfoxide (DMSO) is added to dissolve the insoluble purple formazan product into a colored solution and shaken for 10-15 minutes. The absorbance of this colored solution was quantified by measuring at a wavelength of $570 \mathrm{~nm}$ using a microplate reader (BioTek Instruments, Inc., Winooski, VT, USA). The relative percent cell viability was plotted.

\section{DPSCs (or) ADSCs Cell Survival Study by MTT and DAPI}

The materials used for this study was synthesized from macromer DEX-LactateHEMA (or) HA-AEMA (18k-25), NIPAAm:macromer was used in the ratio of 19:1 (w:w). Irgacure 2959 was used as initiator at the concentration of $0.05 \mathrm{w} \%$ of total monomer and macromer. No gap was maintained between the tip of UV probe and mold. $\mathrm{UV}$ intensity at $750 \mathrm{~mW} \cdot \mathrm{cm}^{-2}$ for $10 \mathrm{~min}$ was used. The product obtained was then dialyzed against $4 \mathrm{~L}$ of distilled water for $6 \mathrm{~h}$ by changing the water every half an hour and 
freeze-dried. DPSCs (or) ADSCs were grown to confluence and encapsulated in hydrogels with cell seeding density of $5 \times 10^{4}$ cells $\cdot \mathrm{mL}^{-1}$. Incubated at $37{ }^{\circ} \mathrm{C}, 5 \% \mathrm{CO}_{2}$ for $24 \mathrm{~h}$. Concentrations of the hydrogels used were 10,15 and $20 \mathrm{mg} \cdot \mathrm{mL}^{-1}$. After $24 \mathrm{~h}$ the hydrogels with the cells were centrifuged and the hydrogels were replaced with the medium. Then the medium with cells is seeded in a 96 well plate $(200 \mu \mathrm{L} /$ well $)$ and 24 well plate $(250 \mu \mathrm{L} /$ well $)$ for MTT and DAPI assays respectively and incubated at $37{ }^{\circ} \mathrm{C}$, $5 \% \mathrm{CO}_{2}$ for $24 \mathrm{~h}$. Then the following procedure was followed for the cell survival study by MTT. $26 \mu \mathrm{L}$ of $5 \mathrm{mg} \cdot \mathrm{mL}^{-1}$ MTT was added to each well and incubated at $37{ }^{\circ} \mathrm{C}, 5 \%$ $\mathrm{CO}_{2}$ for $4 \mathrm{~h}$. Then $200 \mu \mathrm{L}$ of DMSO was added to each well, and shaken for 15 minutes. The absorbance was measured at $570 \mathrm{~nm}$. For the cell survival study by DAPI assay, the following procedure was followed. After incubation for $24 \mathrm{~h}$ at $37{ }^{\circ} \mathrm{C}, 5 \% \mathrm{CO}_{2}$, the cells were washed with PBS 2-3 times and fixed by using 4\% paraformaldehyde for $15 \mathrm{~min}$. Then the cells were washed with PBS for 2-3 times and incubated with DAPI at concentration $1 \mu \mathrm{g} \cdot \mathrm{mL}^{-1}$ for $15-20 \mathrm{~min}$. After incubation, the cells were again washed with PBS for 2-3 times and then the images were taken at 10x.

\section{Statistical Analysis}

Data were reported as the mean \pm standard deviation (SD) or mean \pm standard error (SE) from at least $n=3$. Two-tailed Student's t-test was used to analyze the differences between groups. A statistically significant difference was reported if $p=0.05$ or less.

\section{Results and Discussion}

\section{Synthesis and Characterization of Hydrogels}

UV initiated photo emulsion polymerization, using Irgacure 2959 as an initiator, offered the flexibility of fabricating the hydrogels under mild conditions such as low temperature (room temperature) and short reaction times ( $<10 \mathrm{mins})$. Also, the initiator Irgacure 2959 solution has been widely used for in situ polymerization in vivo and does not cause irritation [128]. The synthesis was successful and confirmed by FTIR spectra of hydrogels 19:1 - NIPAAm to macromer are shown in Figure 2-1. The hydrogels contain characteristic peaks from both PNIPAAm and DEX-Lactate-HEMA or HA-AEMA macromer, namely, the absorbance of the carbonyl group at $1640 \mathrm{~cm}^{-1}, \mathrm{~N}-\mathrm{H}$ bending at $1538 \mathrm{~cm}^{-1}$ and N-H stretching at $3300 \mathrm{~cm}^{-1}$ are the characteristic peaks of NIPAAm. The divided bands of symmetric $\mathrm{C}-\mathrm{H}$ bending from the $-\mathrm{CH}\left(\mathrm{CH}_{3}\right)_{2}$ group $\left(1369\right.$ and $1367 \mathrm{~cm}^{-}$

$\left.{ }^{1}\right)$ are attributed to PNIPAAm, C-OH stretching $\left(\sim 1020 \mathrm{~cm}^{-1}\right)$ due to the abundant hydroxyl groups of dextran backbone and C-H asymmetric stretching at $2974 \mathrm{~cm}^{-1}$. All the $\mathrm{OH}$ and $\mathrm{NH}$ stretching were confined b/w $3000-3500 \mathrm{~cm}^{-1}$. The presence of more hydroxyl groups in dextran gives rise to the high-intensity peaks in the spectrum of DEXLac-HEMA. 


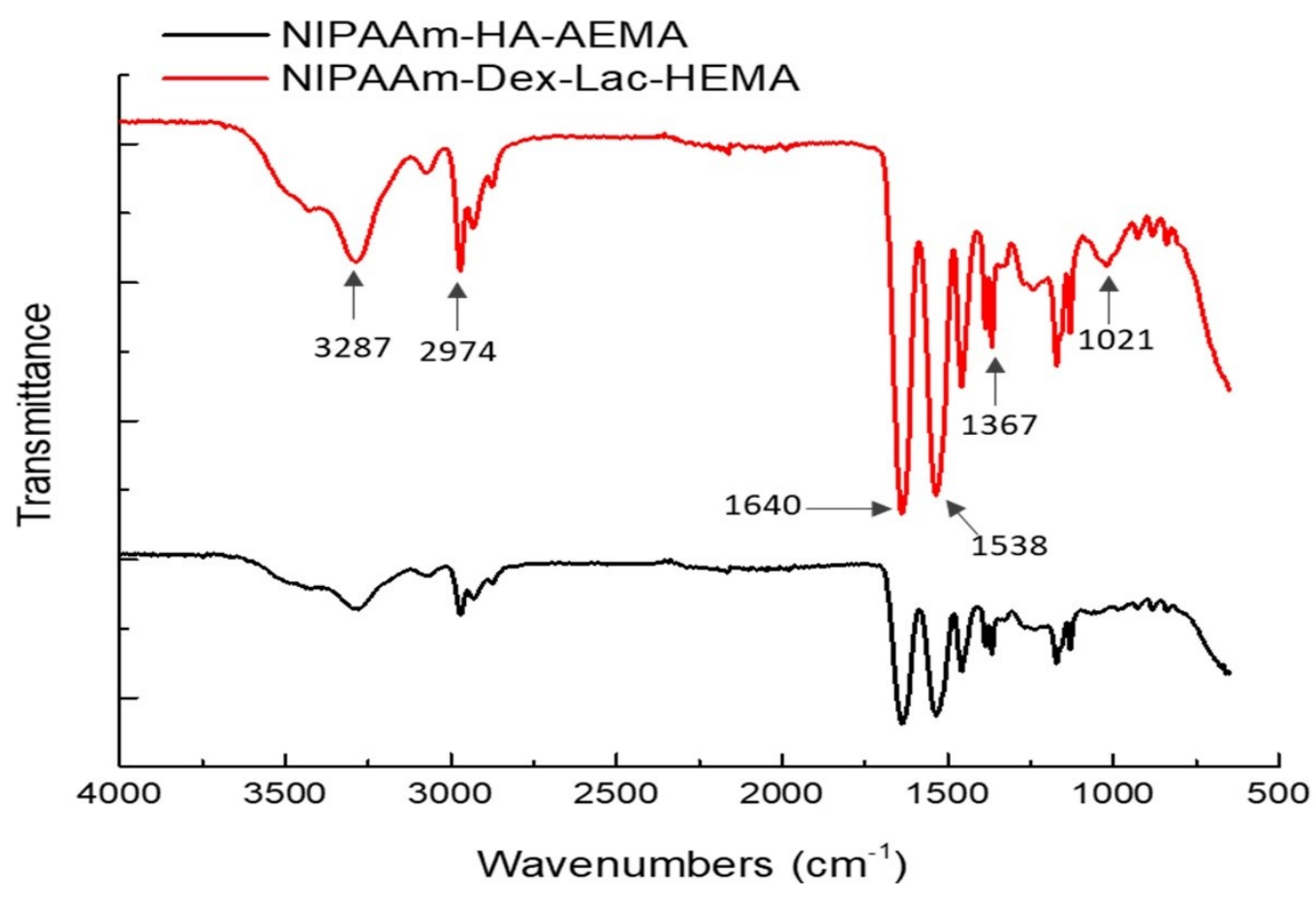

Figure 2-1. FTIR spectrum of hydrogels

Notes: N-H stretching at $3287 \mathrm{~cm}^{-1}, \mathrm{C}-\mathrm{H}$ asymmetric stretching at $2974 \mathrm{~cm}^{-1}$, absorbance of amide-carbonyl group at $1640 \mathrm{~cm}^{-1}, \mathrm{~N}-\mathrm{H}$ bending at $1538 \mathrm{~cm}^{-1}$, symmetric $\mathrm{C}-\mathrm{H}$ bending from the $-\mathrm{CH}\left(\mathrm{CH}_{3}\right)_{2}$ group at $1367 \mathrm{~cm}^{-1}$ and $\mathrm{C}-\mathrm{OH}$ stretching at $1021 \mathrm{~cm}^{-1}$ 
The early stage of optimization of the variables was primarily focused on P(NIPAAm-co-DEX-Lactate-HEMA) hydrogels. The endpoints or the observations that were monitored during the synthesis optimization include: i) State or physical appearance of the reaction mixture after photopolymerization if it is a liquid or solid gel, ii) State or physical appearance of the reaction mixture after heating at $37^{\circ} \mathrm{C}$. The ideal characteristics of the gel include: being liquid at room temperature and turning into solid/gel upon heating to $37^{\circ} \mathrm{C}$. The observations/comparisons of the formation of gels with the changes in parameters and the trends are mentioned in Table 2-1. When the DEX-Lactate-HEMA macromer concentration was increased from 5 to $20 \%$, strong insoluble gels were formed, and this could be attributed to higher crosslinking in case of 16:4 hydrogels compared to 19:1.

The polymerization is proportional to the monomer concentration and inversely related to the initiator concentration. The higher the concentration of the polymer, stronger the polymer with higher molecular weight and more insoluble it could become. Similar results were observed when the prepolymer mixture concentration was increased, the gelation increased and the gel becomes more insoluble and resulted in a solid gel. However, the gels formed at $1 \mathrm{mg} \cdot \mathrm{mL}^{-1}$ concentration showed favorable results as they exhibited viscous liquid behavior and turned solid upon heating. Table 2-1 also presents the gelation process of the hydrogels with an increase in the initiator concentration as well. The size of the solid gels formed was same for 0.05 and 0.025 irgacure $\mathrm{w} \%$ but it decreased with the 0.0125 irgacure $w \%$, however, the yield was less with the decrease in the initiator concentration to 0.025 and $0.0125 \mathrm{wt} \%$. Overall, with the decrease in the initiator (irgacure), the size of the solid gels obtained decreased and this could be attributed to the formation of insoluble higher chain length polymer at higher initiator concentration. The optimum concentration was found to be $0.05 \mathrm{w} \%$. Based on the results from Table 2-1, it can also be observed that the gelation process increased with increase in UV intensity. $500 \mathrm{~mW} \cdot \mathrm{cm}^{-2}$ was selected and continued to characterize further.

In vitro cytotoxicity testing of the $\mathrm{P}(\mathrm{NIPAAm}-\mathrm{co}$-DEX-Lactate-HEMA) gels (synthesized at $1 \mathrm{mg} \cdot \mathrm{mL}^{-1}, 500 \mathrm{~mW} \cdot \mathrm{cm}^{-2}, 0.5 \mathrm{~cm}$ distance. $3 \mathrm{~min}$ reaction time) showed toxicity and had low percentage cell viability values (below 50\%). In case of 19:1, the gels made at $0.0125 \mathrm{wt} \%$ initiator showed higher cytotoxicity ( 1.6 fold) than gels made at 0.05 and $0.025 \mathrm{wt} \%$ initiator. However, 16:4 gels showed a different behavior where the gels made at 0.05 and $0.0125 \mathrm{wt} \%$ were toxic than that of gels made at $0.025 \mathrm{wt} \%$. Overall, all the gels were cytotoxic to the DPSCs, which could be attributed to lack of complete polymerization of the monomer/macromer mixture, and presence of any unreacted monomer/macromers that were toxic to the cells. In order to complete the polymerization, the reaction time (time of UV exposure) was increased from 3 to $10 \mathrm{~min}$. and the resulted polymeric gels were compared with raw materials (PNIPAAm and DEXLactate-HEMA macromer) in terms of cytotoxicity to DPSCs. The raw materials were found to be toxic (\%cell viabilities 40-80) to the DPSCs at all the studied concentrations $0.1,10,20 \mathrm{mg} \cdot \mathrm{mL}^{-1}$. However, after polymerization P(NIPAAm-co-DEX-LactateHEMA) gels were found to be non-toxic at $0.1 \mathrm{mg} \cdot \mathrm{mL}^{-1}$ concentration, still, the cell 
Table 2-1. Effect of NIPAAM/DEX-Lactate-HEMA macromer ratio, UV intensity, precursor concentration, initiator concentration on the formation of P(NIPAAM-co-DEX-Lactate-HEMA) gels.

\begin{tabular}{|c|c|c|c|c|c|c|}
\hline $\begin{array}{c}\text { Precursor } \\
\text { concentration } \\
(\mathrm{mg} / \mu \mathrm{L})\end{array}$ & $\begin{array}{c}\text { UV } \\
\text { intensity } \\
\left(\mathbf{m W} \cdot \mathbf{c m}^{-2}\right)\end{array}$ & Macromer* & $\begin{array}{l}\text { NIPAAm/ } \\
\text { macromer } \\
(\mathbf{w} / \mathbf{w})\end{array}$ & $\begin{array}{l}\text { Irgacure } \\
(\mathbf{w} \%)\end{array}$ & $\begin{array}{l}\text { Distance between } \\
\text { tip of UV probe } \\
\text { and surface of } \\
\text { liquid }(\mathrm{cm})\end{array}$ & Product appearance \\
\hline 1 & 100 & DEX & $19: 1$ & 0.05 & 0.5 & Liquid \\
\hline 1 & 250 & DEX & $19: 1$ & 0.05 & 0.5 & Liquid \\
\hline 1 & 375 & DEX & $19: 1$ & 0.0125 & 0.5 & $\begin{array}{c}\text { Liquid }+ \text { small soft } \\
\text { gel }\end{array}$ \\
\hline 1 & 375 & DEX & $19: 1$ & 0.025 & 0.5 & Liquid + soft gel \\
\hline 0.5 & 375 & DEX & $19: 1$ & 0.05 & 0.5 & Soft gel \\
\hline 1 & 375 & DEX & $19: 1$ & 0.05 & 0.5 & Liquid + soft gel \\
\hline 2 & 375 & DEX & $19: 1$ & 0.05 & 0.5 & Soft gel \\
\hline 1 & 500 & DEX & $19: 1$ & 0.05 & 0 & Soft gel \\
\hline 1 & 250 & DEX & $16: 4$ & 0.05 & 0.5 & Liquid \\
\hline 1 & 375 & DEX & $16: 4$ & 0.0125 & 0.5 & $\begin{array}{l}\text { Liquid }+ \text { small soft } \\
\text { gel }\end{array}$ \\
\hline 1 & 375 & DEX & $16: 4$ & 0.025 & 0.5 & Liquid + soft gel \\
\hline 0.5 & 375 & DEX & $16: 4$ & 0.05 & 0.5 & Soft gel \\
\hline 1 & 375 & DEX & $16: 4$ & 0.05 & 0.5 & Liquid \\
\hline 2 & 375 & DEX & $16: 4$ & 0.05 & 0.5 & Soft gel \\
\hline 1 & 500 & DEX & $16: 4$ & 0.05 & 0.5 & Soft gel \\
\hline 1 & 750 & DEX & $19: 1$ & 0.05 & 0 & Soft gel \\
\hline 1 & 750 & DEX & $19: 1$ & 0.05 & 0 & Soft gel \\
\hline 1 & 750 & HA & $19: 1$ & 0.05 & 0 & Soft gel \\
\hline 1 & 750 & HA & $19: 1$ & 0.05 & 0 & Soft gel \\
\hline 1 & 750 & HA & $19: 1$ & 0.05 & 0 & Soft gel \\
\hline 1 & 1000 & DEX & $19: 1$ & 0.05 & 0 & Strong soft gel \\
\hline 1 & 1000 & DEX & $19: 1$ & 0.05 & 0 & Strong soft gel \\
\hline 1 & 1000 & DEX & $19: 1$ & 0.05 & 0 & Strong soft gel \\
\hline 1 & 1000 & HA & $19: 1$ & 0.05 & 0 & Strong soft gel \\
\hline 1 & 1000 & HA & $19: 1$ & 0.05 & 0 & Strong soft gel \\
\hline 1 & 1000 & HA & $19: 1$ & 0.05 & 0 & Strong soft gel \\
\hline
\end{tabular}

Notes: Macromer* : DEX: DEX-Lactate-HEMA; HA: HA-AEMA; NIPAAm :

Macromer $=19: 1$ (or) 16:4 (w:w), Concentration : $0.5,1,2 \mathrm{mg} \cdot \mathrm{mL}^{-1}$; UV intensity : 100, 250,375, 500, 750, $1000 \mathrm{~mW} / \mathrm{cm}^{2}$ Distance between tip of the UV probe and mold : 0 , $0.5 \mathrm{~cm}$ 
viability values decreased with increased polymer concentration. Increasing the reaction time alone did not result in reduced cytotoxicity of the hydrogels. The synthetic conditions used might have resulted in partial or incomplete polymerization and presence of any unreacted starting materials, because of these the gels were found to be toxic. Therefore, the gel synthesis parameters needed more optimization.

To further optimize the gels to improve the polymerization and to lower the cytotoxicity, the variables that are altered during the synthesis include i) distance between the UV probe and the tip of the liquid surface. Instead of using $0.5 \mathrm{~cm}$ distance, the gap between the UV probe and the mold surface was completely eliminated and kept at $0 \mathrm{~cm}$ distance; ii) the UV intensity was increased from $500 \mathrm{~mW} \cdot \mathrm{cm}^{-2}$ to $750 \mathrm{~mW} \cdot \mathrm{cm}^{-2}$; and iii) the dialysis time was increased from $4 \mathrm{~h}$ to $6 \mathrm{~h}$ to remove any unreacted raw materials. The gels obtained were exposed to DPSCs to estimate the in vitro cytotoxicity. Figure 2-2 illustrates the cell viability of gels (synthesized at different initiator levels) to DPSCs at three different concentrations $0.5,1$ and $10 \mathrm{mg} \cdot \mathrm{mL}^{-1}$. Independent of the initiator percentages $(0.05,0.025,0.0125 \mathrm{wt} \%)$ used in the synthesis, elimination of gap, increase in UV intensity and dialysis time had shown a drastic improvement in the cell viability values of the gels. The cell viabilities improved from $40-60 \%$ to $90-100 \%$. Removing the gap and increasing the UV intensity might have increased the polymerization, and increasing the dialysis time might have led to the removal of any unreacted starting materials, and this could have resulted in the improved cell viability of the gels. Overall, the gels made with $0.05 \mathrm{w} \%$ initiator concentration has shown relatively higher yield when compared with the 0.025 and $0.0125 \mathrm{w} \%$. Increased initiator concentration could lead to higher polymer chain length and as result, the hydrogels with $0.05 \mathrm{w} \%$ initiator concentration could have formed the gels with higher yield when compared with lower initiator concentration.

\section{Synthesis and Comparison of Hydrogels Based on HA-AEMA Macromer}

After optimizing the synthetic parameters of the injectable hydrogels, another macromer based on hyaluronic acid was investigated for synthesizing the hydrogels and compared the properties with dextran-based hydrogels. The P(NIPAAm-co-HA-AEMA) hydrogels were synthesized at NIPAAm/Macromer of 19:1 (w:w) with prepolymer concentration of $1 \mathrm{mg} \cdot \mathrm{mL}^{-1}$ by direct exposure to UV probe (without gap) at two different intensities $\left(750\right.$ and $\left.1000 \mathrm{~mW} \cdot \mathrm{cm}^{-2}\right)$ and three different initiator concentrations $(0.05$, $0.025,0.0125 \mathrm{w} \%)$. The gels synthesized were observed for their physical appearance and compared with P(NIPAAm-co-DEX-Lactate-HEMA). The observations are mentioned in Table 2-1. When observed for the overall trend, both the gels formed at higher intensity resulted in a stronger solid gel formation before dialysis. However, all the gels (polymerization mixture) after dialysis yielded a viscous gel. No other significant differences were found in terms of the physical appearance of the gels. 


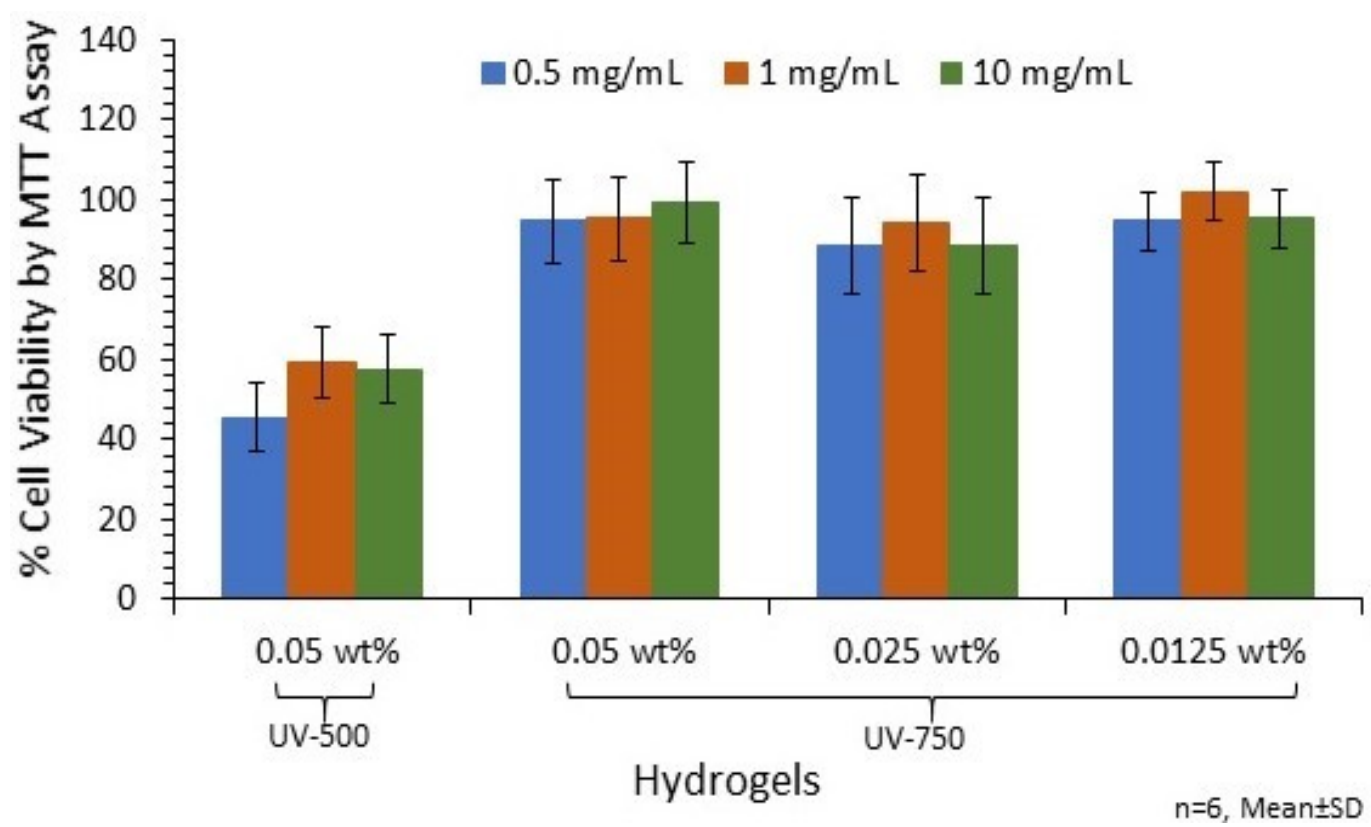

Figure 2-2. Cell viability of the P(NIPAAM-co-DEX-LactateHEMA) gels to DPSCs.

Notes: Macromer: DEX: DEX-Lactate-HEMA; NIPAAm: Macromer = 19:1 (w:w), Concentration : $1 \mathrm{mg} \cdot \mathrm{mL}^{-1}$; UV intensity : $500,750 \mathrm{~mW} / \mathrm{cm}^{2}$; Distance between tip of the UV probe and mold : $0 \mathrm{~cm}$. 


\section{Rheological Properties}

The rheological property of hydrogels needs to be evaluated for their rheological behavior within their range of linear viscoelastic region to ensure their stability [129]. Figure 2-3 illustrates the linear viscoelastic region of the P(NIPAAm-co-DEX-LactateHEMA) and P(NIPAAm-co-HA-AEMA) gels under oscillatory strain ramp. The $\mathrm{G}^{\prime}$ of hydrogels remains unaffected by strain amplitude (linear viscoelastic region) for $2-20 \%$ and $2-100 \%$ (Figure 1-3) for every Dextran-based and HA-based gels respectively. The gels exhibited similar behavior at both 10 and $15 \mathrm{mg} \cdot \mathrm{mL}^{-1}$ concentrations. In case of strain sweep, when the concentration of the hydrogels was increased from 10 to 15 $\mathrm{mg} \cdot \mathrm{mL}^{-1}$, the $\mathrm{G}^{\prime}$ was increased about 2.4 fold for dextran-based hydrogels and 3.2 fold for HA-based hydrogels. At $15 \mathrm{mg} \cdot \mathrm{mL}^{-1}$, the value of $\mathrm{G}^{\prime}$ at $1 \mathrm{~Hz}$ appears in the range of 20-40 Pa for HA-based gels and 15-35 Pa for dextran-based gels. Since both the hydrogels have shown linear viscoelasticity at $10 \%$ strain, in order to ensure that measurements are done within the linear viscoelastic region, all subsequent rheological characterization was performed at $10 \%$ strain. Frequency sweep studies were conducted to determine the characteristic gel behavior $\left(G^{\prime}>G^{\prime \prime}\right)$. Figure 2-4 shows the $G^{\prime}$ and $G^{\prime \prime}$ of the hydrogels as a function of frequency. The $\mathrm{G}^{\prime}$ was always higher than $\mathrm{G}^{\prime \prime}$ suggesting that the elastic behavior dominates the viscous behavior in these hydrogels, which is the typical characteristic of a hydrogel. After about $2 \mathrm{~Hz}$ frequency, both the $\mathrm{G}^{\prime}$ and $\mathrm{G}^{\prime \prime}$ increased linearly with increasing frequency, suggesting that both types of hydrogels were in the glass transition stage and became stiffer with increasing frequency. In case of HA-or Dextran-based hydrogels, increase in concentration from 10 to $15 \mathrm{mg} \cdot \mathrm{mL}^{-1}$ has resulted in a significant increase in $\mathrm{G}^{\prime}$ and $\mathrm{G}^{\prime \prime}$ values (2-4 fold). No significant differences were found for the hydrogels prepared with the HA or dextran at the same concentration, as the majority of the polymer is NIPAAm (95\%). The individual figures of strain sweep, frequency sweep and temperature ramp for each hydrogel are given in the Appendix (Figure A-1 through Figure A-12).

\section{Sol-Gel Transition of Hydrogels}

The feasibility of P(NIPAAm-co-DEX-Lactate-HEMA) hydrogels for using as injectable in situ hydrogels for tissue engineering, a sol-gel transition study was conducted to evaluate their behavior in presence of stem cells. The solutions of gels (10 $\mathrm{mg} / \mathrm{mL}$ and $20 \mathrm{mg} \cdot \mathrm{mL}^{-1}$ ) encapsulated with DPSCs were immediately transformed (gelation time $<2 \mathrm{~min}$ ) into solid gels when exposed to $37^{\circ} \mathrm{C}$ (Figure 2-5). The temperature-dependent transition of hydrogels was studied by monitoring the storage modulus values as a function of temperature on a rheometer. Followed by a plateau regime, rapid buildup regime was observed in $\mathrm{G}^{\prime}$ (Figure 2-6), and this fast increase in $\mathrm{G}^{\prime}$ was attributable to gelling (sol to gel transition) or 3D crosslink network formation of the polymeric chains. Because of the strong hydrophobic interactions between the PNIPAAm chains above LCST, the PNIPAAm exhibit a phase transition or thermoresponsive behavior. The midpoint temperature $\left(\sim 35^{\circ} \mathrm{C}\right)$ of the transition is about the same for all samples. 


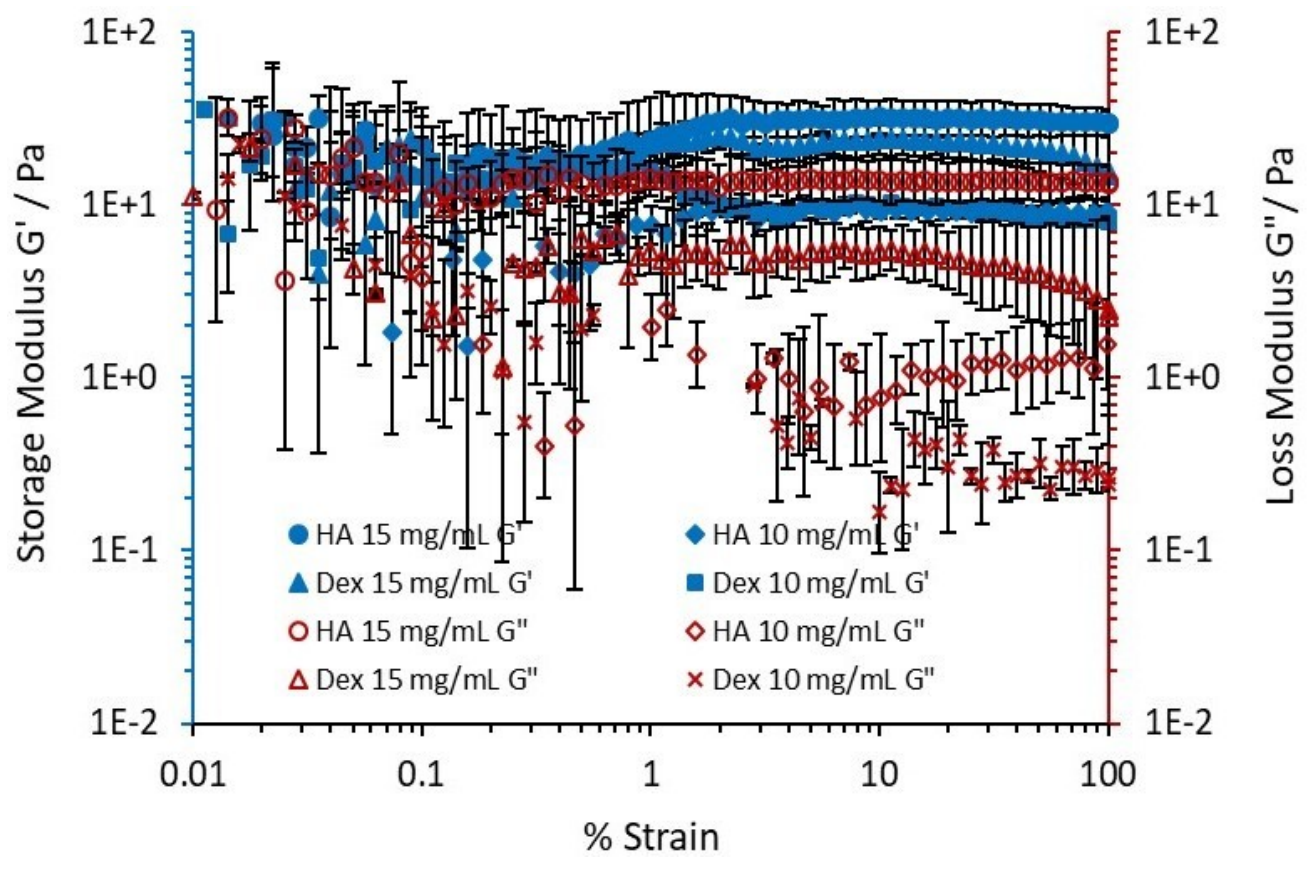

Figure 2-3. Representative shear storage modulus $\left(G^{\prime}\right)$ and shear loss modulus $\left(G^{\prime \prime}\right)$ as a function of oscillatory strain sweep for the hydrogels.

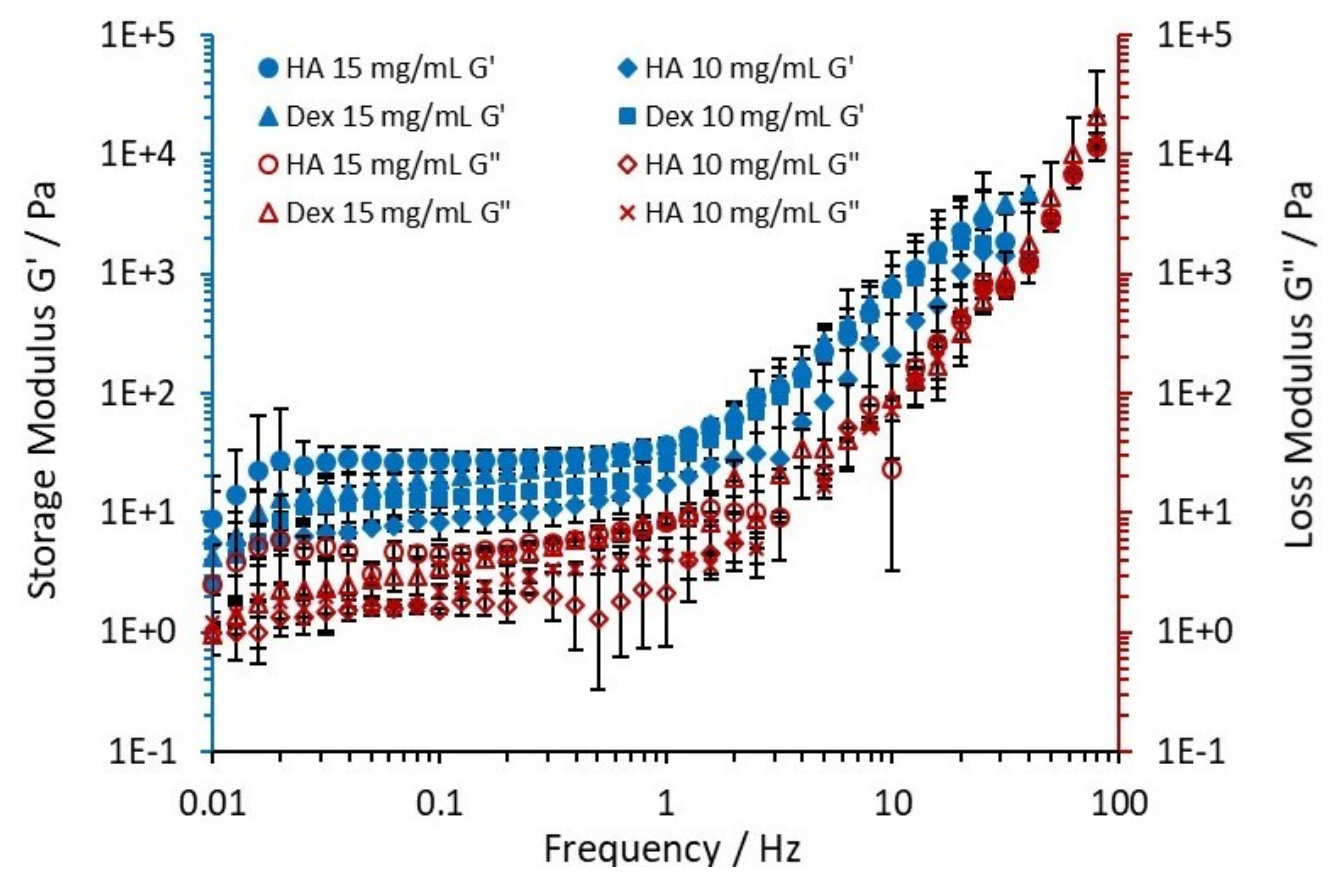

Figure 2-4. Representative shear storage modulus $\left(G^{\prime}\right)$ and shear loss modulus $\left(G^{\prime \prime}\right)$ as a function of frequency for the hydrogels. 
A
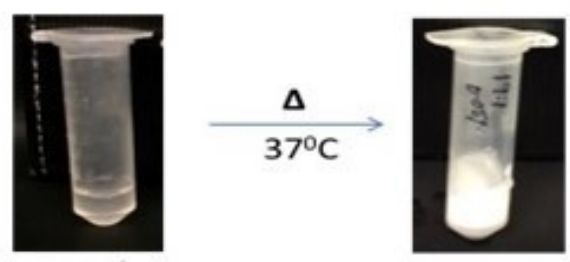

$20 \mathrm{mg} / \mathrm{mL}$

$20 \mathrm{mg} / \mathrm{mL}$

B
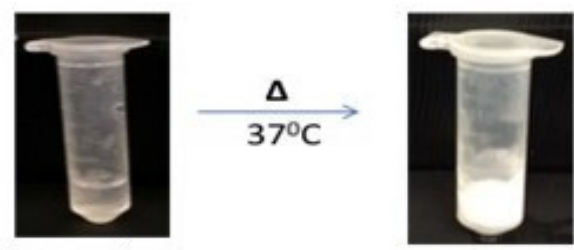

$10 \mathrm{mg} / \mathrm{mL}$

$10 \mathrm{mg} / \mathrm{mL}$

Figure 2-5. The thermoresponsive sol-gel transition of the hydrogels.

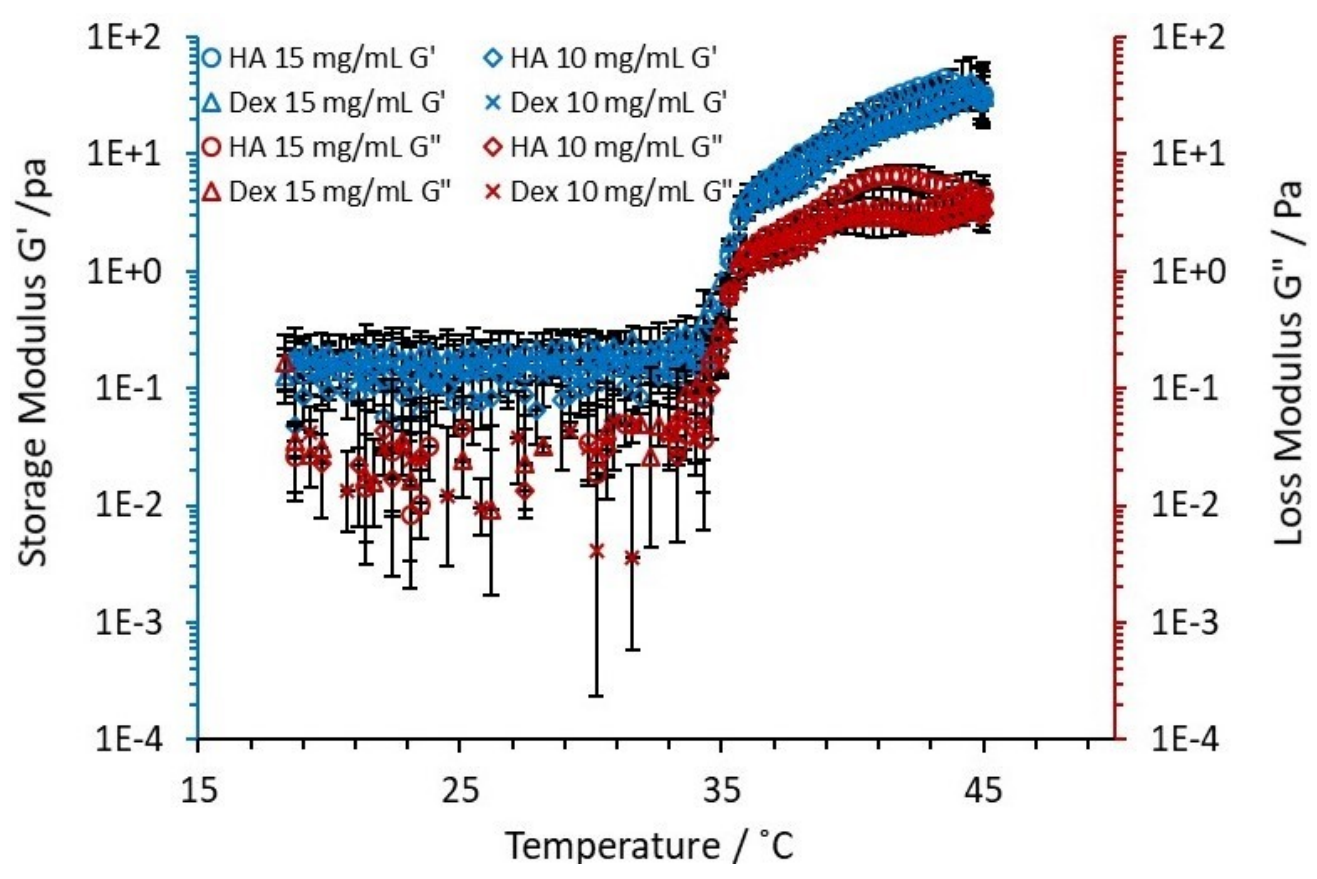

Figure 2-6. Thermoresponsive phase transition and representative change in shear storage modulus $\left(G^{\prime}\right)$ and shear loss modulus $\left(G^{\prime \prime}\right)$ as a function of temperature ramp for the hydrogels. 


\section{Cell Survival in Hydrogels}

To assess the cytotoxicity of DPSCs and ADSCs encapsulated in Dex and HAbased hydrogels in vitro, the MTT assay was utilized. The DPSCs \& ADSCs viability in Dex-based hydrogels with a concentration of $10,15,20 \mathrm{mg} \cdot \mathrm{mL}^{-1}$ was about $117 \pm 7.4$, $106 \pm 7.8,79 \pm 5.3 \& 110 \pm 7.8,99 \pm 6.6,80 \pm 7.3 \%$ respectively (Figure 2-7). The DPSCs \& ADSCs viability in HA-based hydrogels with a concentration of $10,15,20 \mathrm{mg} \cdot \mathrm{mL}^{-1}$ was about $122 \pm 6.6,103 \pm 12.8,91 \pm 7.1 \& 143 \pm 9.7,132 \pm 9.1,90 \pm 9.4 \%$ respectively (Figure 2-8). There was a statistically significant decrease in the cell viability for the Dex-based hydrogels between concentrations of 10 and 15,15 and $20 \mathrm{mg} / \mathrm{mL}$ for the ADSCs $(\mathrm{p}<0.05)$. DPSCs cell viabilities in Dex-based hydrogels decreased significantly between 15 and $20 \mathrm{mg} / \mathrm{mL}(\mathrm{p}<0.01)$. In HA-based hydrogels the ADSC viabilities decreased significantly between the concentrations 10 and $15(\mathrm{p}<0.05), 15$ and $20 \mathrm{mg} / \mathrm{mL}(\mathrm{p}<0.01)$. In addition to the cell viability by MTT, the percentage live cell number of the DPSCs and ADSCs after 24hrs of encapsulation in the hydrogels was determined using DAPI (Figure 2-9 and Figure 2-10). The DPSCs \& ADSCs percent cell number compared to control in Dex-based hydrogels with a concentration of $10,15,20 \mathrm{mg} \cdot \mathrm{mL}^{-1}$ was about $112 \pm 1.58,102 \pm 1.22,80 \pm 0.71 \& 121 \pm 2.92,97 \pm 1.41,89 \pm 0.71 \%$ respectively (Figure 2-11). The DPSCs \& ADSCs percent cell number in HA-based hydrogels with a concentration of $10,15,20 \mathrm{mg} \cdot \mathrm{mL}^{-1}$ was about $127 \pm 3.39,107 \pm 0.71,82 \pm 1.22 \&$ $134 \pm 3.67,97 \pm 0.71,89 \pm 1.87 \%$ respectively (Figure 2-12). There was a statistically significant decrease in the ADSCs number for the Dex-based hydrogels between $10 \& 15$, $15 \& 20 \mathrm{mg} / \mathrm{mL}(\mathrm{p}<0.01)$. In Dex and HA-based hydrogels the DPSCs number decreased significantly between the concentrations 10 and $15(\mathrm{p}<0.05), 15$ and $20 \mathrm{mg} / \mathrm{mL}(\mathrm{p}<0.01)$. In HA-based hydrogels the ADSC viabilities decreased significantly between 10 and 15 $\mathrm{mg} / \mathrm{mL}(\mathrm{p}<0.01)$. Cell survival studies based on MTT and DAPI live cell counting demonstrated that both DEX-based and HA-based based hydrogels showed promising cell viability and cell number values ( $\sim 100 \%$ and above) at concentrations of 10 and 15 $\mathrm{mg} / \mathrm{mL}$ for DPSCs and ADSCs. The results from the MTT assay and cell number studies by DAPI staining were in accordance with each other and confirm that the Dex \& HA hydrogels are suitable for the encapsulation of ASDSCs \& DPSCs at 10 and $15 \mathrm{mg} / \mathrm{ml}$ concentrations.

\section{Conclusions}

A series of biodegradable hydrogels were synthesized by photopolymerization of NIPAAm monomer and hydrolytically degradable oligolactate DEX-Lactate-HEMA or HA-AEMA macromers. The thermoresponsive, rheological and biodegradable properties of the hydrogels were strongly dependent on the reaction conditions and composition of the hydrogels. The higher the amount of the Irgacure 2959 initiator, the higher the UV intensity, the longer the reaction time, and the higher amounts of crosslinker used for the synthesis, the higher the yield of the synthesized hydrogels. The hydrogels were not cytotoxic to DPSCs and ADSCs at a concentration up to at least $15 \mathrm{mg} \cdot \mathrm{mL}^{-1}$, and have appropriate mechanical and biodegradable properties to promote DPSCs and ADSCs growth. Based on in vitro studies it was observed that DEX-gels and HA-gels appear to 


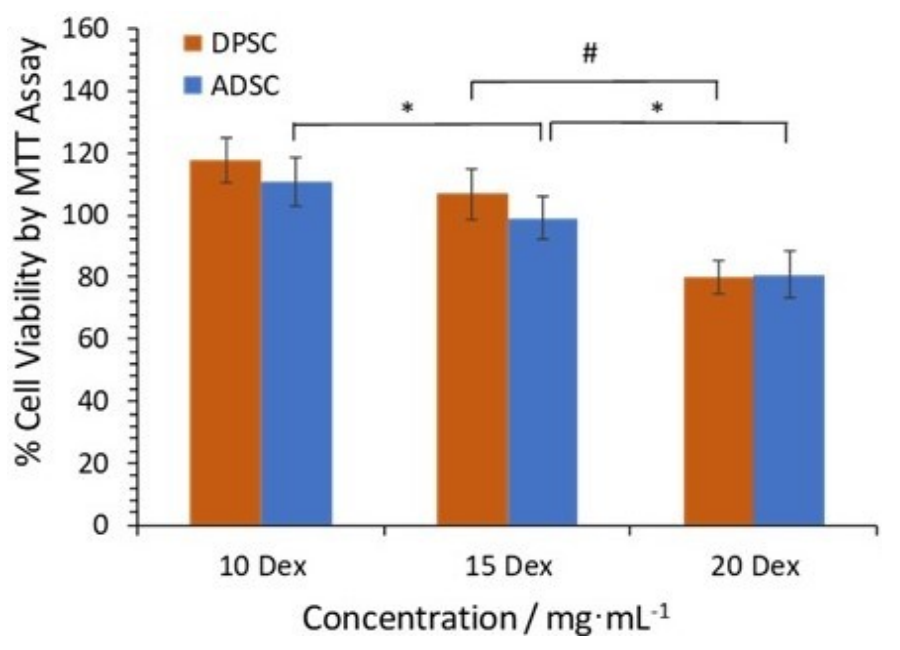

Figure 2-7. Cell viability of DPSCs \& ADSCs in injectable NIPAAm-DEXLactate-HEMA hydrogels using MTT assay.

Notes: NIPAAm:DEX-Lactate-HEMA - 19:1, Initiator - 0.05\%, UV - 750mW·cm-2, UV exposure time - $10 \mathrm{~min}$, Distance of UV probe from the mold $-0 \mathrm{~cm}$. (Mean $\pm \mathrm{SD}, \mathrm{n}=3$; *: p-value $<0.05$, \#: p-value $<0.01)$

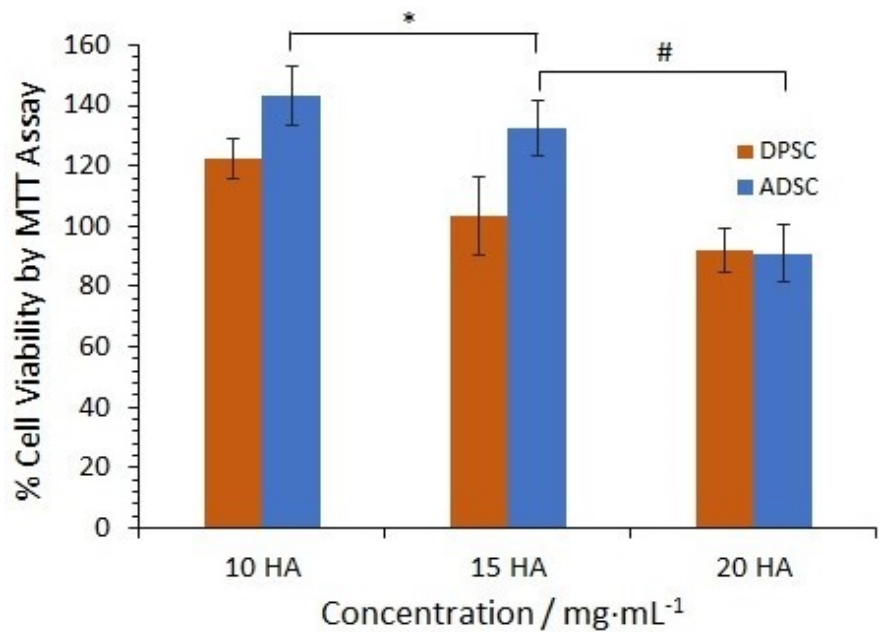

Figure 2-8. Cell viability of DPSCs \& ADSCs in injectable NIPAAm-HA-AEMA hydrogels using MTT assay.

Notes: NIPAAm:HA-AEMA - 19:1, Initiator $-0.05 \%$, UV $-750 \mathrm{~mW} \cdot \mathrm{cm}^{-2}$, UV exposure time - 10 min, Distance of UV probe from the mold $-0 \mathrm{~cm}$. (Mean $\pm \mathrm{SD}, \mathrm{n}=3 ; *$ : $\mathrm{p}$-value $<0.05$, \#: p-value $<0.01$ ) 


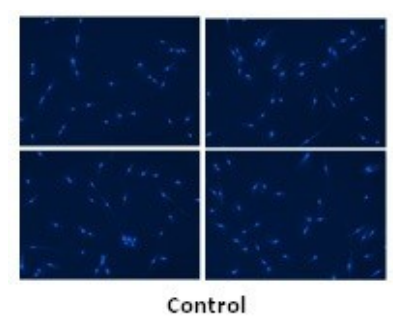

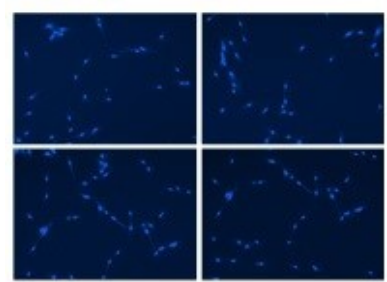

Dex-10 $\mathrm{mg} / \mathrm{mL}$

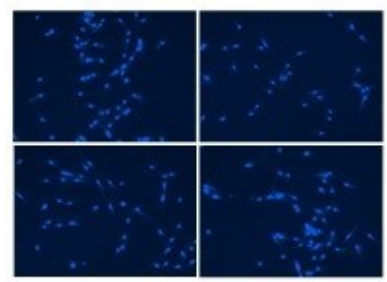

$\mathrm{HA}-10 \mathrm{mg} / \mathrm{mL}$

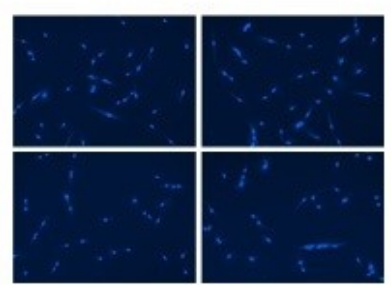

Dex-15 mg/mL

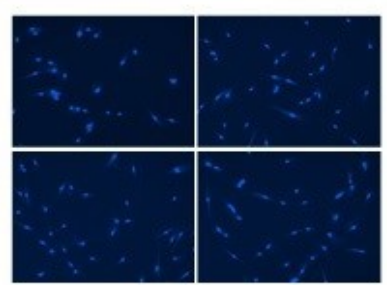

$\mathrm{HA}-15 \mathrm{mg} / \mathrm{mL}$

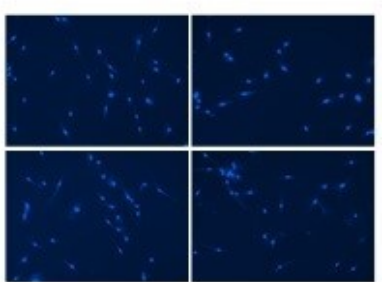

Dex-20 mg/mL

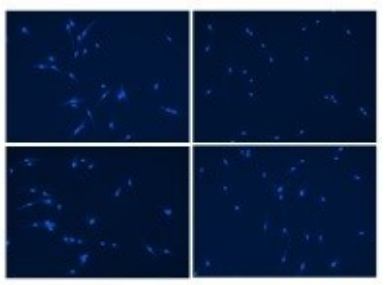

$\mathrm{HA}-20 \mathrm{mg} / \mathrm{mL}$

Figure 2-9. DPSCs growth and morphology in injectable P(NIPAAm-co-DEXLactate-HEMA ) and P(NIPAAm-co-HA-AEMA) hydrogels.

Notes: P(NIPAAm-co-DEX-Lactate-HEMA) - represented as DEX in Figure (Synthetic conditions: NIPAAm:DEX-Lactate-HEMA-19:1, Initiator $-0.05 \%$, UV $-750 \mathrm{~mW} \cdot \mathrm{cm}^{-2}$, UV exposure time - $10 \mathrm{~min}$, Distance of UV probe from the mold - $0 \mathrm{~cm}$; Cells staining DAPI);

P(NIPAAm-co-HA-AEMA) - represented as HA in Figure (NIPAAm:HA-AEMA-19:1, Initiator $-0.05 \%, \mathrm{UV}-750 \mathrm{~mW} \cdot \mathrm{cm}^{-2}$, UV exposure time - $10 \mathrm{~min}$, Distance of UV probe from the mold - 0cm; Cells staining - DAPI) 


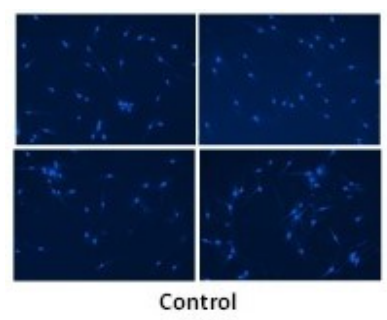

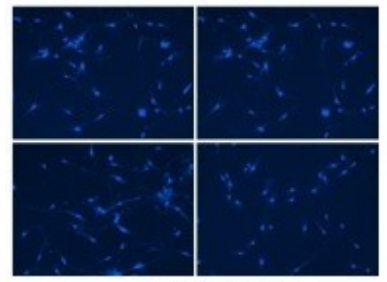

Dex $-10 \mathrm{mg} / \mathrm{mL}$

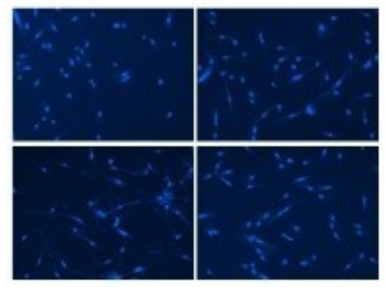

$\mathrm{HA}-10 \mathrm{mg} / \mathrm{mL}$

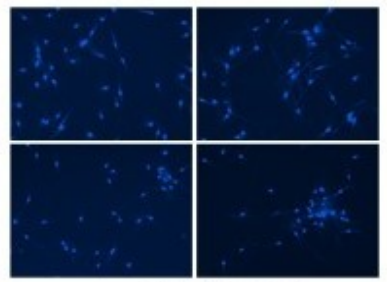

Dex $-15 \mathrm{mg} / \mathrm{mL}$

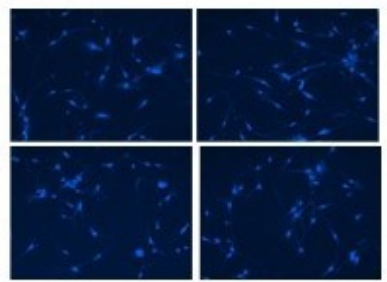

$\mathrm{HA}-15 \mathrm{mg} / \mathrm{mL}$

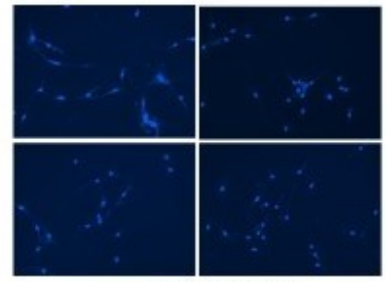

Dex- $20 \mathrm{mg} / \mathrm{mL}$

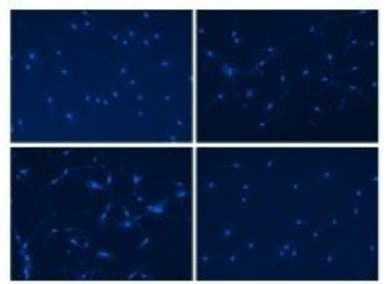

$\mathrm{HA}-20 \mathrm{mg} / \mathrm{mL}$

Figure 2-10. ADSCs growth and morphology in injectable P(NIPAAm-co-DEXLactate-HEMA) and P(NIPAAm-co-HA-AEMA) hydrogels.

Notes: P(NIPAAm-co-DEX-Lactate-HEMA) - represented as DEX in Figure (Synthetic conditions: NIPAAm:DEX-Lactate-HEMA-19:1, Initiator $-0.05 \%, \mathrm{UV}-750 \mathrm{~mW} \cdot \mathrm{cm}^{-2}$, UV exposure time - $10 \mathrm{~min}$, Distance of UV probe from the mold - $0 \mathrm{~cm}$; Cells staining DAPI);

P(NIPAAm-co-HA-AEMA) - represented as HA in Figure (NIPAAm:HA-AEMA-19:1, Initiator $-0.05 \%, \mathrm{UV}-750 \mathrm{~mW} \cdot \mathrm{cm}^{-2}$, UV exposure time - $10 \mathrm{~min}$, Distance of UV probe from the mold - 0cm; Cells staining - DAPI) 


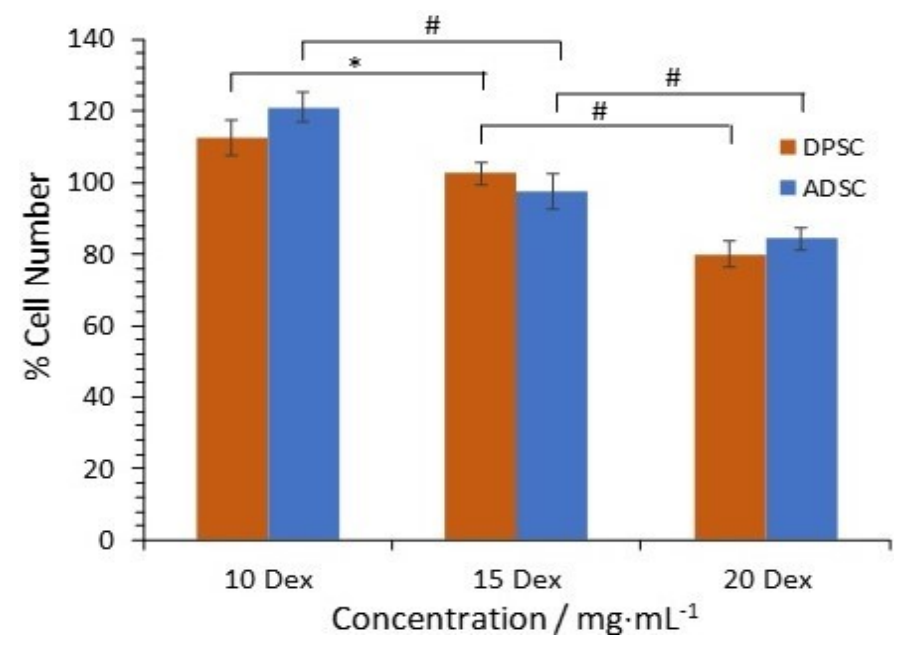

Figure 2-11. Cell count of DPSCs \& ADSCs in injectable NIPAAm-DEX-LactateHEMA hydrogels by DAPI staining.

Notes: NIPAAm: DEX-Lactate-HEMA - 19:1, Initiator $-0.05 \%$, UV $-750 \mathrm{~mW} \cdot \mathrm{cm}^{-2}$, UV exposure time - $10 \mathrm{~min}$, Distance of UV probe from the mold $-0 \mathrm{~cm}$. (Mean $\pm \mathrm{SD}, \mathrm{n}=4$; $*$ : p-value $<0.05$, \#: p-value $<0.01$ )

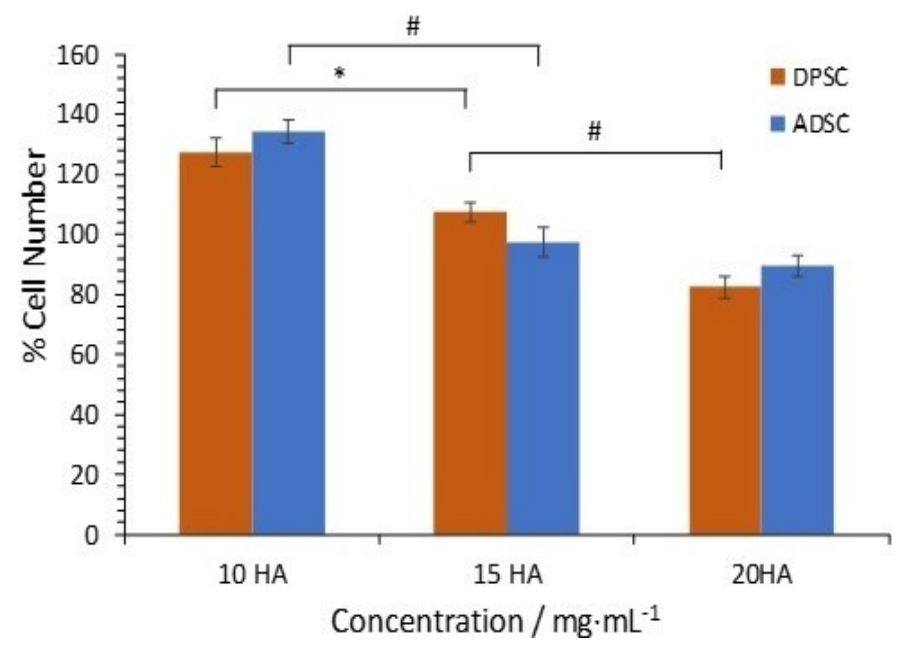

Figure 2-12. Cell count of DPSCs \& ADSCs in Injectable NIPAAm-HA-AEMA Hydrogels by DAPI staining.

Notes: NIPAAm: HA-AEMA - 19:1, Initiator $-0.05 \%, \mathrm{UV}-750 \mathrm{~mW} \cdot \mathrm{cm}^{-2}$, UV exposure time - 10 min, Distance of UV probe from the mold $-0 \mathrm{~cm}$. (Mean $\pm \mathrm{SD}, \mathrm{n}=4$; *: p-value $<0.05$, \#: p-value $<0.01$ ) 
be suitable for encapsulation of DPSCs/ADSCs at optimum hydrogel concentration. The data confirmed that both DPSCs and ADSCs favorably adhered and proliferated within the biomaterials in vitro. Additionally, the current study confirmed that DPSCs and ADSCs have superior growth properties in HA-AEMA hydrogels compared to DEXLactate-HEMA hydrogels. The developed hydrogels have shown promising potential for encpaulsating DPSCs/ADSCs for tissue engineering aplications. However, further optimization is needed to have apropriate mechanical and degradation properties to cater as per DPSCs or ADSCs growth inside their matrices, and successful completion of this project will have a significant impact on dental and retinal tissue engineering fields. 


\section{CHAPTER 3. RHEOLOGICAL PROPERTIES OF THE PORCINE OCULAR TISSUES AT DIFFERENT STAGES OF DEVELOPMENT}

\section{Introduction}

The eye is a complex and delicate organ being divided into two anatomical segments called the anterior (comprises of cornea, conjunctiva, iris, lens, ciliary body, and the anterior part of the sclera) and posterior (comprises of vitreous humor, retina, choroid, and posterior part of the sclera) segments [130]. Cornea, sclera and vitreous humor are the three tissues that were investigated in this study for the rheological properties. The cornea is a specialized transparent tough tissue covering the front portion of the eye and protects the sensitive internal contents of the eye and is responsible for refracting the light [131]. The tissue is under constant stress because of various forces such as external (eye rubbing, poking, eyelid closure) and internal (intraocular pressure because of aqueous/vitreous flow dynamics). Cornea's mechanical behavior, fundamental for maintaining its dimensional stability, refractability and vision, depends on the thickens, topography and biomechanical properties of the tissue [28]. The extracellular matrix of the cornea called the stroma forming the bulk of the corneal thickness primarily contributes to its biomechanical properties [131]. The sclera is a dense connective tissue covering the five-sixths of the eye. The sclera is a strong and firm tissue and maintains the shape of the globe. It helps in the maintenance of intraocular pressure, provides attachment sites for the external eye muscles, and provides the internal eye structures from injuries and mechanical displacement. The vitreous body/vitreous humor is a transparent and gelatinous substance that fills the inner posterior cavity (space between the lens and the retina) of the eye. Vitreous humor is highly hydrated and comprised of $99 \%$ of water, avascular, and nearly acellular. The unique extracellular matrix of the vitreous humor, composed of a complex network of collagen fibers and hyaluronic acid (glycosaminoglycan), significantly contributes to the viscoelastic nature of the vitreous [132]. Vitreous plays a significant role in metabolic nutrient supply to the lens, coordinating eye growth (developmental) allows light to reach the retina (optical), providing support to the retina, maintain the shape of the eyeball and protects eye tissues from high-frequency stresses (mechanical) $[132,133]$.

The proper vision of the eye strongly depends on its ability to maintain optical clarity and structural integrity under routine variations in pressure, changes in humidity and temperature, constant muscular stress/strain and rapid sudden movements. Thus the proper functioning of the eye is dependent on its physical and mechanical properties, and altered chemical and mechanical states of ocular tissues could lead to abnormalities and may result in complete loss of the functionality. Various age-related changes in composition and structure of the eye tissues affect the biomechanical properties and performance of the eye tissues and could contribute to the predisposition of various eye abnormalities [21-26]. For example, aging results in stiffening of the cornea tissue which could be because of the additional age-related non-enzymatic cross-linking affecting the stromal collagen fibrils $[24,25]$. It is reported in the literature that age-related variations affect the biomechanical characteristics of the sclera [21], and aging results in the 
microstructural changes in the sclera and contribute to the predisposition to primary open-angle glaucoma [22]. With age, collagen networks in the vitreous begin to break down and pockets of liquid form in the eye, the process of liquefaction in which the liquid volume increases and gel volume decreases $[23,26]$. These age-related changes could lead to structural and mechanical differences between vitreous at various stages of development, and in about $25-30 \%$ of the population, these age-related degenerative changes eventually result in posterior vitreous detachment [27]. Given the importance of the viscoelastic properties of the ocular tissues, to its function and to pathology, detailed rheological characterization of these tissues is crucial to appreciate the normal functions and quantitative understanding of disease pathophysiology of these tissues at various stages of development. The objective of this project was to characterize the rheological properties of the ocular tissues (cornea, sclera and vitreous) at different stages (preterm, neonatal and adult) of development. Though several measurements could be measured in vivo, such as topography, thickness distribution, but the attempts to investigate the biomechanical properties of the tissues still depend on ex-vivo experiments involving human or other animal tissues [28]. Because of the difficulties in obtaining human donor tissues in sufficient numbers for the research and experimental needs, it had been necessary to use animal ocular tissues as approximate models for human ocular tissues for performing various evaluations including the mechanical property characterization studies. Several investigations used porcine tissues for ocular related experiments [2830], although other animal's rabbit and bovine tissues a common practice. Therefore, the current rheological characterization also contributes to the literature for identifying and assessing the important similarities and significant differences between the rheological behaviors of porcine ocular tissues and human and other animal tissues and evaluating the suitability of the porcine eye tissues as a model of the human tissues.

\section{Hypothesis and Specific Aims}

The hypothesis of this project was that the storage and loss modulus of the porcine ocular tissues differ at different stages of development (preterm, neonatal and adult). There were two specific aims:

\section{Specific Aim 1}

To conduct the shear-sweep experiments and identify the linear viscoelastic region of the porcine ocular tissues (cornea, sclera, vitreous) at different stages of development (preterm, neonatal, adult).

\section{Specific Aim 2}

To conduct the frequency sweep experiment and analyze the gel-like behaviors of the porcine ocular tissues (cornea, sclera, vitreous) at different stages of development (preterm, neonatal, adult). 


\section{Materials and Methods}

\section{Materials}

Sodium Chloride $(\mathrm{NaCl})$, potassium chloride $(\mathrm{KCl})$, calcium chloride $\left(\mathrm{CaCl}_{2}\right)$, magnesium chloride $\left(\mathrm{MgCl}_{2}\right)$, sodium dihydrogen phosphate $\left(\mathrm{NaH}_{2} \mathrm{PO}_{4}\right)$, sodium bicarbonate $\left(\mathrm{NaHCO}_{3}\right)$, sodium hydroxide $(\mathrm{NaOH})$ and Hydrochloric acid $(\mathrm{HCl})$ were bought from Sigma Aldrich. Porcine eyes tissues were obtained from Dr. Steven Davison and Dr. Cameron Fili.

\section{Sample Preparation}

Fresh porcine eyeball tissues were provided by Dr. Steven Davison and Dr. Cameron Fili. A circular trephine punch from Katena was used to punch specimens of diameter $8 \mathrm{~mm}$ from the central region of the cornea and from the region below optic nerve in the sclera. AR-G2 TA Instruments Rheometer with accompanying Rheology Advantage Instrument Control software was used to perform the experiments. Prior to testing, the specimens were equilibrated in GBR solution (bicarbonate-Ringer's solution (BR) containing reduced glutathione) $\left(\mathrm{NaCl}, 6.2 \mathrm{~g} / \mathrm{L} ; \mathrm{KCl}, 0.358 \mathrm{~g} / \mathrm{L} ; \mathrm{CaCl}_{2}, 0.115 \mathrm{~g} / \mathrm{L}\right.$; $\mathrm{MgCl}_{2}, 0.159 \mathrm{~g} / \mathrm{L} ; \mathrm{NaH}_{2} \mathrm{PO}_{4}, 0.103 \mathrm{~g} / \mathrm{L} ; \mathrm{NaHCO}_{3}, 2.454 \mathrm{~g} / \mathrm{L} ;$ glucose, $0.90 \mathrm{~g} / \mathrm{L} ;$ reduced glutathione, $0.92 \mathrm{gm} . / \mathrm{L}$ and $\mathrm{pH}$ was adjusted to 7.4 using Sodium hydroxide $(\mathrm{NaOH})$ and Hydrochloric acid $(\mathrm{HCl})$ [134], which has been shown to maintain endothelial function for up to $6 \mathrm{hr}$., was added to the immersion cell bathing either side of the cornea tissue. The thickness of the specimens was measured using screw gauge. The sample was placed on the lower geometry, and then the upper geometry was lowered to contact the sclera. The gap between the parallel plates was maintained at the thickness of the sample tissues used and the experiments were done. In this experimental method, circular specimens of sclera and cornea tissues are sheared between two parallel plates. In order to characterize the shear viscoelastic properties, two types of oscillatory tests, i.e. the strain and frequency sweep experiments, were conducted. Although, it is known that the cornea and sclera tissues have an inhomogeneous microstructure through the thickness, and the present study did not consider these inhomogeneities and its findings should only be considered as the macroscale (effective) shear properties of the tissue. However, care was taken while sample preparation to be consistent. For characterizing the range of linear viscoelasticity, the strain sweep experiments (4 samples) were done at frequency $1 \mathrm{~Hz}$ and force $0.01 \mathrm{~N}$. For frequency sweep experiments (4 samples), the frequency of $0.01-100$ $\mathrm{Hz}$ and a shear strain magnitude of $0.05 \%$ (which was within the region of linear viscoelasticity) were selected. The age and weight of pigs are mentioned in Table 3-1. 
Table 3-1. Age and weight of pigs used in the study.

\begin{tabular}{ccc}
\hline Pig & Age & Weight \\
\hline Preterm Pig & 10 days prior & $0.5-1.5 \mathrm{Kg}$ \\
Neonatal Pig & 20 days & $2.5-3.5 \mathrm{Kg}$ \\
Adult Pig & 1 year & $80-100 \mathrm{Kg}$ \\
\hline
\end{tabular}




\section{Rheological Properties}

Strain sweep oscillation was performed to determine the limit of linear viscoelasticity. Four preconditioned specimens were tested at $1 \mathrm{~Hz}$ frequency. For the determination of linear viscoelastic region (where $\mathrm{G}^{\prime}$ and $\mathrm{G}^{\prime \prime}$ remain constant), strain sweep oscillation was performed at constant frequency with varying strain amplitude from 0.01 to $100 \%$. Unlike the conventional solid mechanical definition, strain here is defined as the excursion of the circumference of the disk-shaped specimen divided by its thickness. Rheological properties such as $\mathrm{G}^{\prime}$ and $\mathrm{G}^{\prime \prime}$ remain constant within the limit of linear viscoelasticity. After the determination of tissue's viscoelastic region by a strain sweep, the tissues were further characterized by a frequency sweep at a strain in the linear viscoelastic region to understand the gel behaviors of the tissues $\left(\mathrm{G}^{\prime}>\mathrm{G}^{\prime \prime}\right)$. The viscosity of the whole vitreous was measured at a shear rate 0.1 to $1000 \mathrm{~s}^{-1}$ under continuous flow mode.

\section{Results and Discussion}

Figures 3-1, 3-2 and 3-3 show the range of linear viscoelasticity of the porcine cornea, sclera and vitreous as a function of strain sweep (at $1 \mathrm{~Hz}$ frequency) at different ages. These figures confirm that the studied tissues, like other soft tissues, showed a viscoelastic behavior. The strain sweep experiments on all the tissues at different ages showed that the measured storage modulus was nearly constant over small amplitude shear strain (\%) and decreased nonlinearly with increasing percent strain after a turnover point, called critical shear strain level. Two different regions were clearly differentiated: a linear viscoelastic region where $\mathrm{G}^{\prime}$ and $\mathrm{G}^{\prime \prime}$ were practically constant (small deformation), and a nonlinear region, in which $\mathrm{G}^{\prime}$ and $\mathrm{G}^{\prime \prime}$ began to diminish with increasing strain (large deformations) [135]. Within the range of linear viscoelastic response, the viscoelastic parameters are independent of the shear strain amplitude. The strain independent region indicates that extent of strain applied is small enough not to cause any perturbance in the structure of the material, and in biological samples, these linear region includes normal physiological loads and represent normal in vivo response [136]. The individual figures of strain sweep, frequency sweep and viscosity for each tissue or vitreous are given in the Appendix (Figure A-13 through Figure A-33).

In the linear viscoelastic region (Figure 3-1), the values of $\mathrm{G}^{\prime}$ and $\mathrm{G}^{\prime \prime}$ for all corneal tissues were constant below $2 \%$ strain and decreased logarithmically with increasing strain ( $>2 \%$ strain). Linear region for the corneal samples was found to be 0.01 $-2 \%$ strain. The consistent linear regions of both $\mathrm{G}^{\prime}$ and $\mathrm{G}^{\prime \prime}$ were observed for all the corneal samples at different ages. Similar to the cornea, scleral tissues (Figure 3-2) also behaved as gel-like and exhibited linear viscoelastic region below 3\% strain in preterm and neonatal, and $0.1 \%$ strain in adult pigs, the critical strain related to the linear viscoelastic region in sclera tissues was different at different ages. Vitreous also exhibited gel-like behavior with a linear viscoelastic region (Figure 3-3). It was reported that the gel-like physical properties of vitreous are primarily derived from its chemical composition which includes a hydrated cross-linked network of fibrillar collagens (type) 


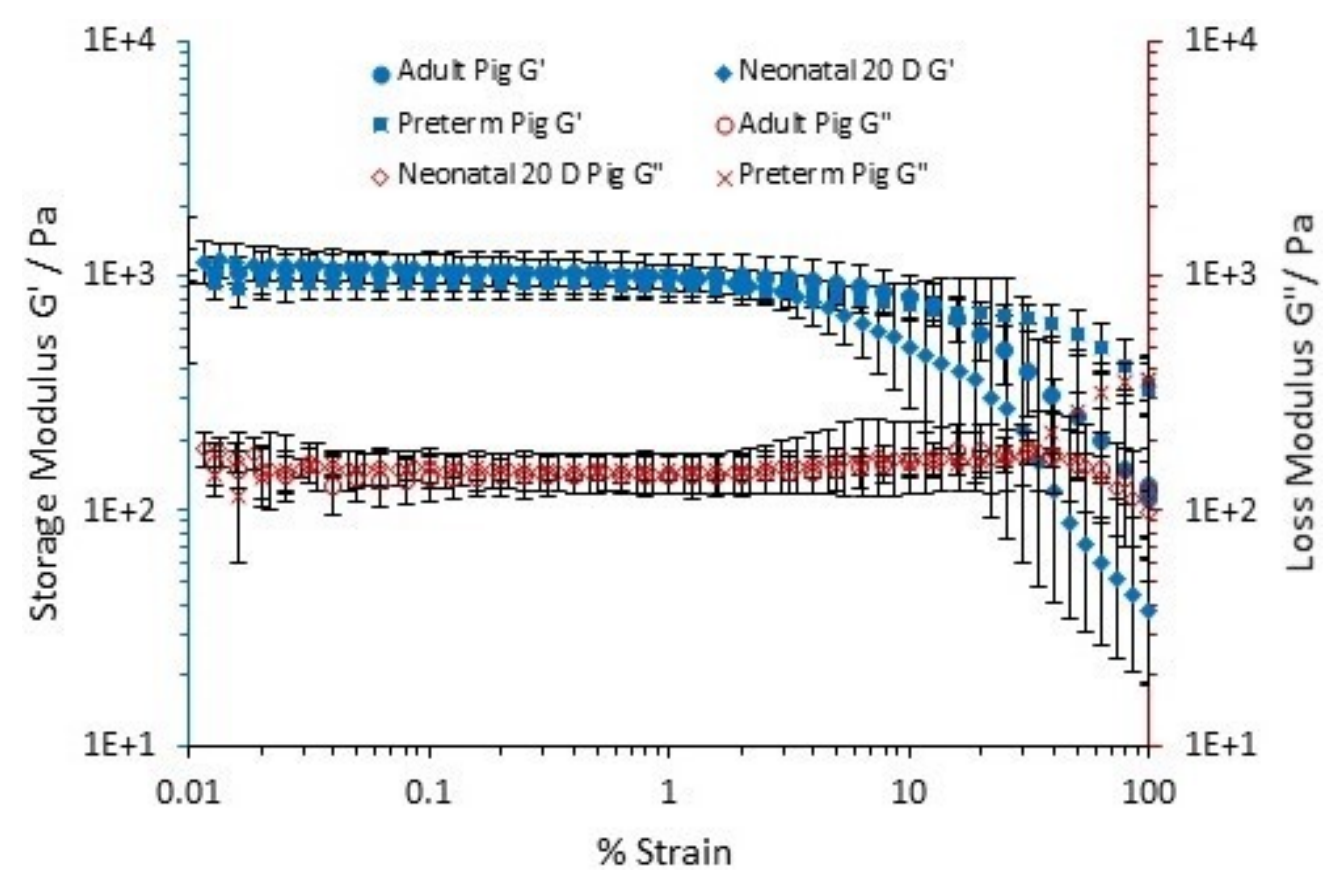

Figure 3-1. Storage and loss moduli of corneal tissues at preterm, neonatal and adult stages of development under strain-sweep.

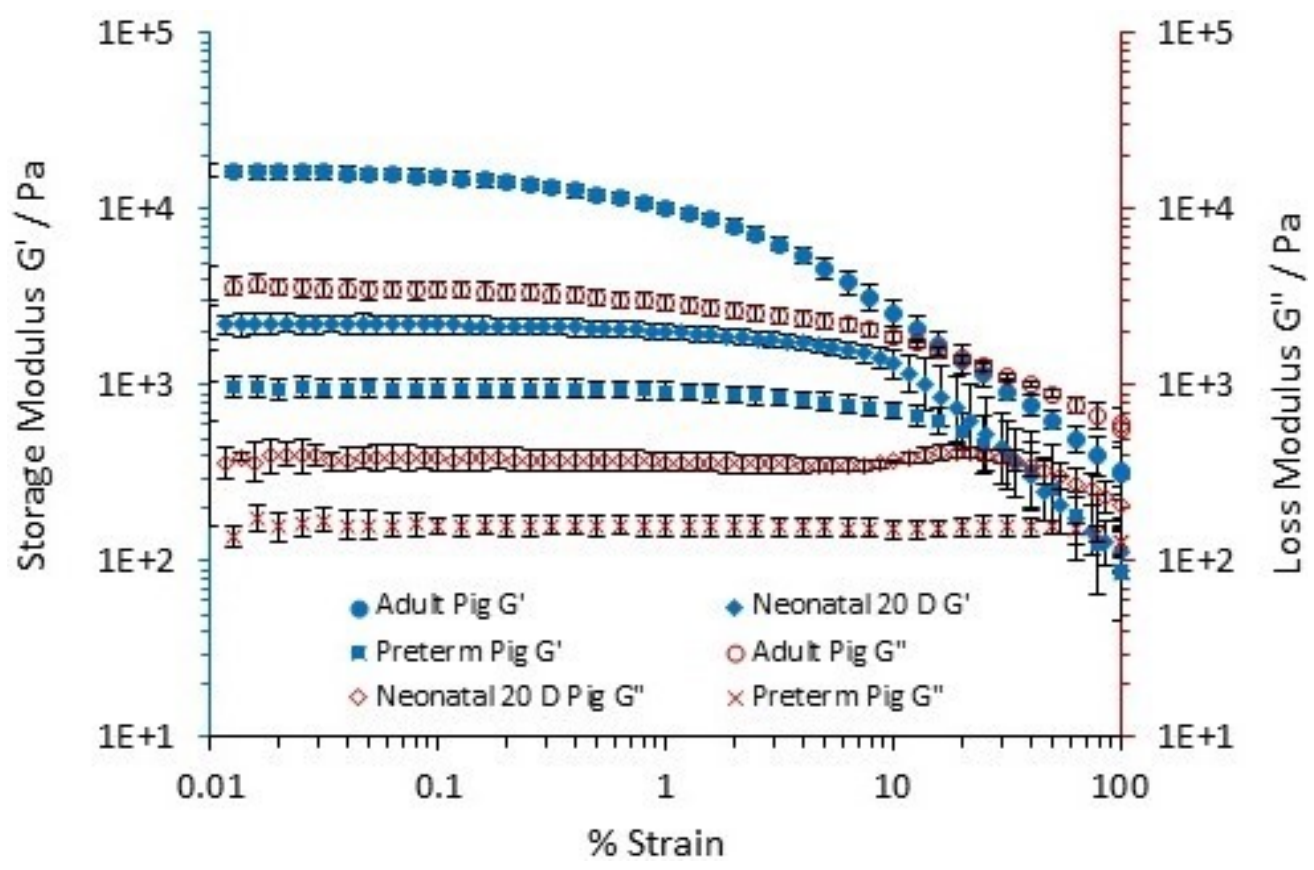

Figure 3-2, Storage and loss moduli of scleral tissues at preterm, neonatal and adult stages of development under strain-sweep. 


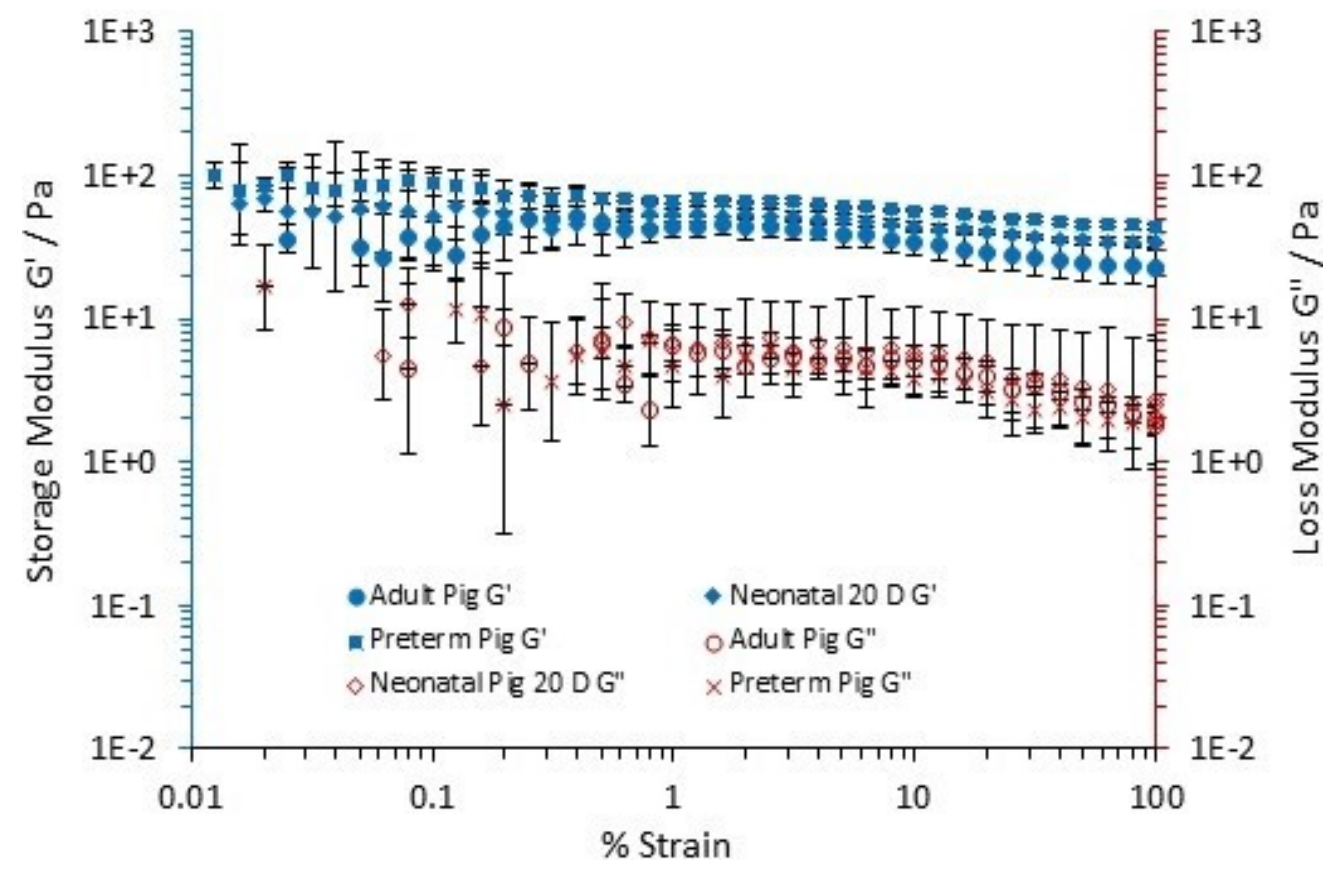

Figure 3-3. Storage and Loss moduli of vitreous humor at preterm, neonatal and adult stages of development under strain-sweep. 
and higher-molecular-weight polyanionic hyaluronan macromolecules, which is consistent with the literature [137].

Once the range of linear viscoelastic region was determined, frequency sweep experiments were performed on the samples with a strain amplitude that was within the range of linearity for each sample (Figures 3-4, 3-5 and 3-6). In corneal samples, the moduli increased weakly with increasing frequency (Figure 2-2a), and this trend was similar to the response of corneal stroma [131]. This behavior also related to other tissues such as articular cartilage, meniscus, and intervertebral disk [131, 138-140]. The magnitude of change (increase in storage modulus) increased significantly at a higher frequency $(>5 \mathrm{~Hz})$. Adult cornea tissue has shown higher $\mathrm{G}^{\prime}$ and $\mathrm{G}^{\prime \prime}$ compared to the preterm and neonatal corneal tissues. At $1 \mathrm{~Hz}$ frequency, the $\mathrm{G}^{\prime}$ values of preterm, neonatal and adult cornea were $\sim 0.89,0.97$ and $1.22 \mathrm{kPa}$, respectively. Similar to the cornea, scleral tissues (Figure 3-5) also showed a slight increase in moduli with an increase in the frequency in the low-frequency range $(<10 \mathrm{~Hz})$, and the magnitude of increase in the moduli changed significantly at a higher frequency $(>10 \mathrm{~Hz})$. The moduli values of sclera increased with increase in the age (preterm $<$ neonatal $<$ adult). At $1 \mathrm{~Hz}$ frequency, the $\mathrm{G}^{\prime}$ values of preterm, neonatal and adult sclera were $\sim 0.96,1.81$ and 16.8 $\mathrm{kPa}$, respectively. In frequency dependence studies, the storage modulus of vitreous varied weakly with frequency up to $\sim 0.4 \mathrm{~Hz}$ (Figure 3-6) and raised significantly thereafter. This frequency dependence behavior is characteristic of a lightly crosslinked amorphous network of macromolecules and is consistent with the literature [136]. The storage modulus of the adult vitreous was higher at low frequency $(<0.2 \mathrm{~Hz})$ but were similar thereafter to neonatal and preterm samples. At $1 \mathrm{~Hz}$ frequency, the $\mathrm{G}^{\prime}$ values of preterm, neonatal and adult vitreous were $\sim 4.5,4.8$ and $8.8 \mathrm{~Pa}$, respectively.

In frequency dependence studies, all three types of tissues showed a similar behavior of weak variation in moduli with increased frequency. Also, it can be observed that irrespective of the age, all tissue samples showed $\mathrm{G}^{\prime}>\mathrm{G}^{\prime \prime}$, which represents that elastic properties of the materials dominate the viscous portion and the samples exhibited solid-like behavior. The difference between $\mathrm{G}^{\prime}$ and $\mathrm{G}^{\prime \prime}$ of corneal and scleral samples is much higher compared to the vitreous humor, and the magnitude of $\mathrm{G}^{\prime} / \mathrm{G}^{\prime \prime}$ among the tissues was in the order of cornea $>$ sclera $>>$ vitreous. Thus, the cornea and sclera are more gel-like than the vitreous humor, as the elastic character of the tissue is manifested in the storage modulus.

When the vitreous was ran under shear rate-controlled experiments (Figure 3-7), the viscosity of the vitreous decreased with increasing shear-rate exhibiting a shearthinning behavior (non-Newtonian) with a value around $39.5 \pm 2.7,40.3 \pm 9.1,54.8 \pm 1.2$ for a share rate of $0.93 \mathrm{~s}^{-1}$ and reaching a value around $3.2 \pm 0.1,3.4 \pm 0.8,4.1 \pm 0.1$ for shear rate of $100 \mathrm{~s}^{-1}$ for preterm, neonatal, and adult porcine vitreous, respectively. At low shear rates $\left(\sim 1 \mathrm{~s}^{-1}\right)$, the viscosity of the adult vitreous was significantly higher than the neonatal and preterm porcine vitreous. The shear-thinning behavior of the vitreous was consistent with the literature [141]. It is reported that this behavior could be attributed to the presence of HA (primary component) in the liquid portion of the vitreous [141]. HA solutions exhibit this shear thinning behavior [142]. 


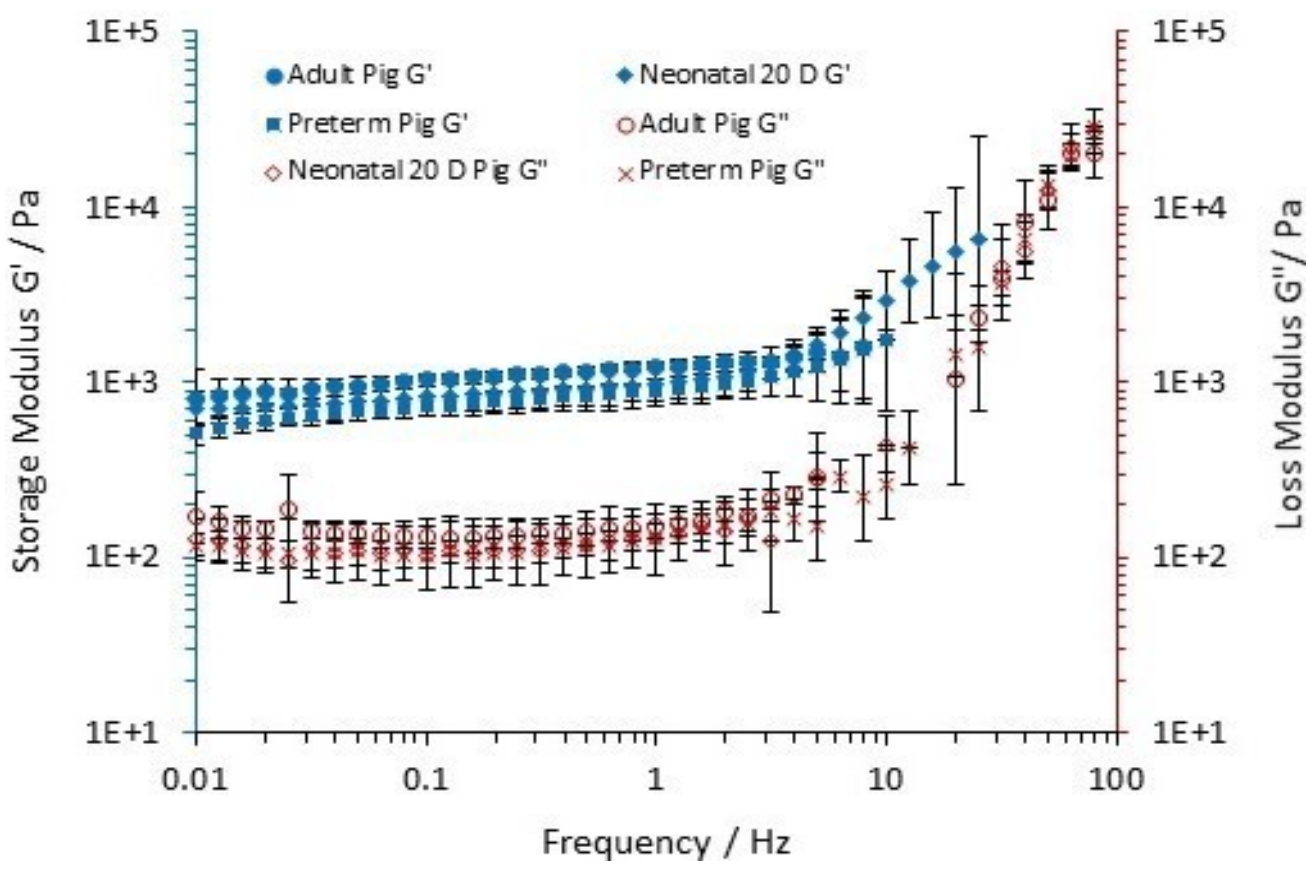

Figure 3-4. Storage and loss moduli of corneal tissues at preterm, neonatal and adult stages of development under frequency-sweep.

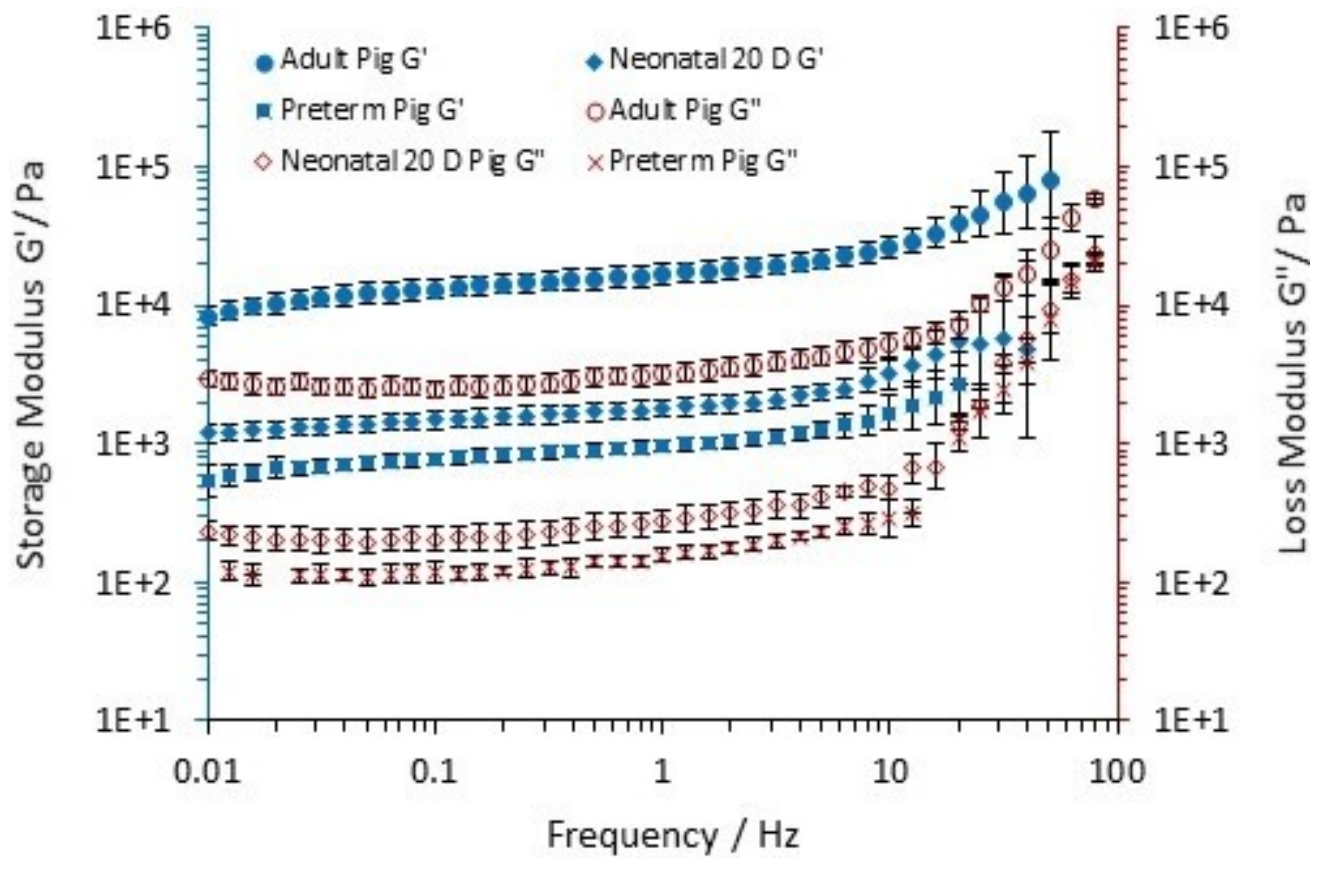

Figure 3-5. Storage and loss moduli of scleral tissues at preterm, neonatal and adult stages of development under frequency-sweep. 


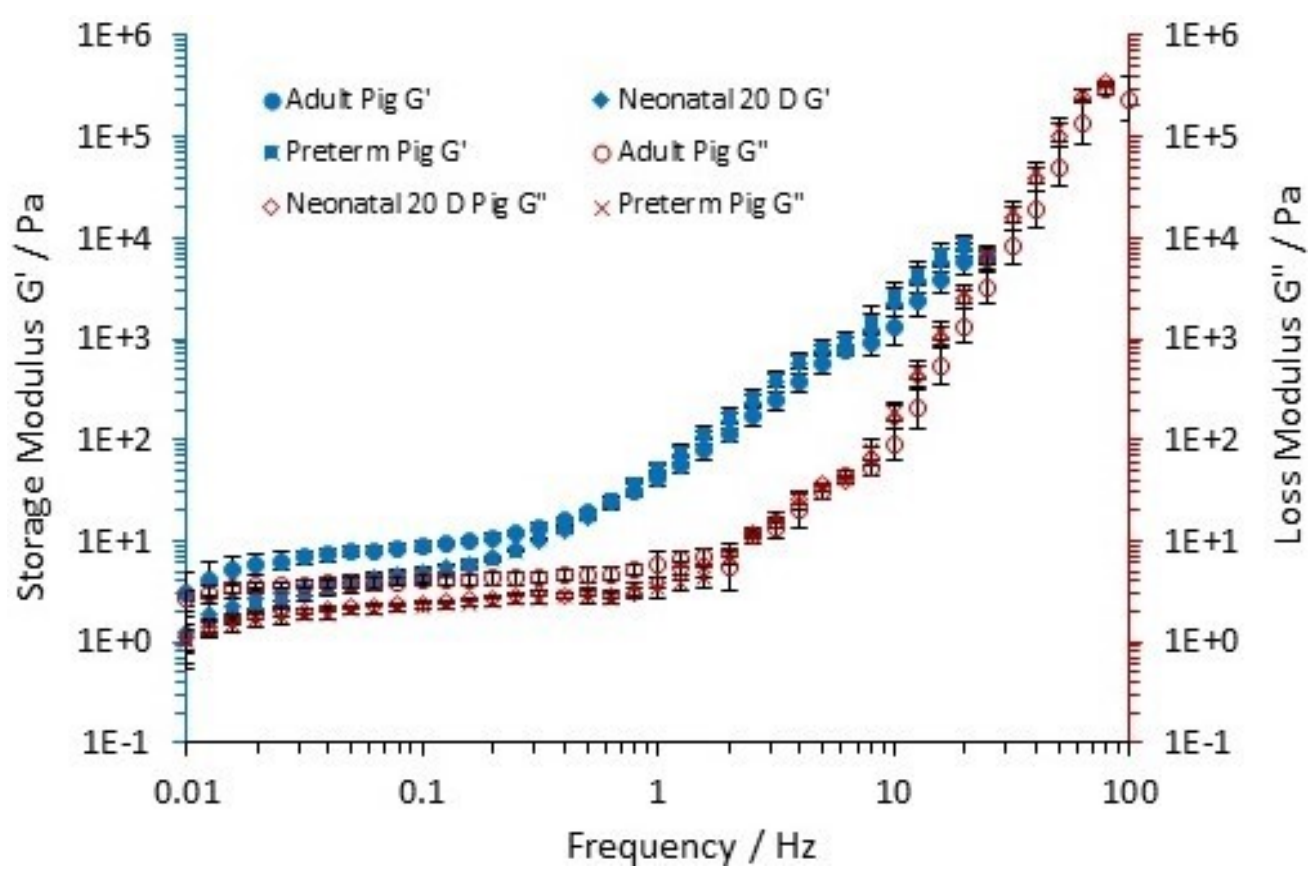

Figure 3-6. Storage and Loss moduli of vitreous humor at preterm, neonatal and adult stages of development under frequency-sweep.

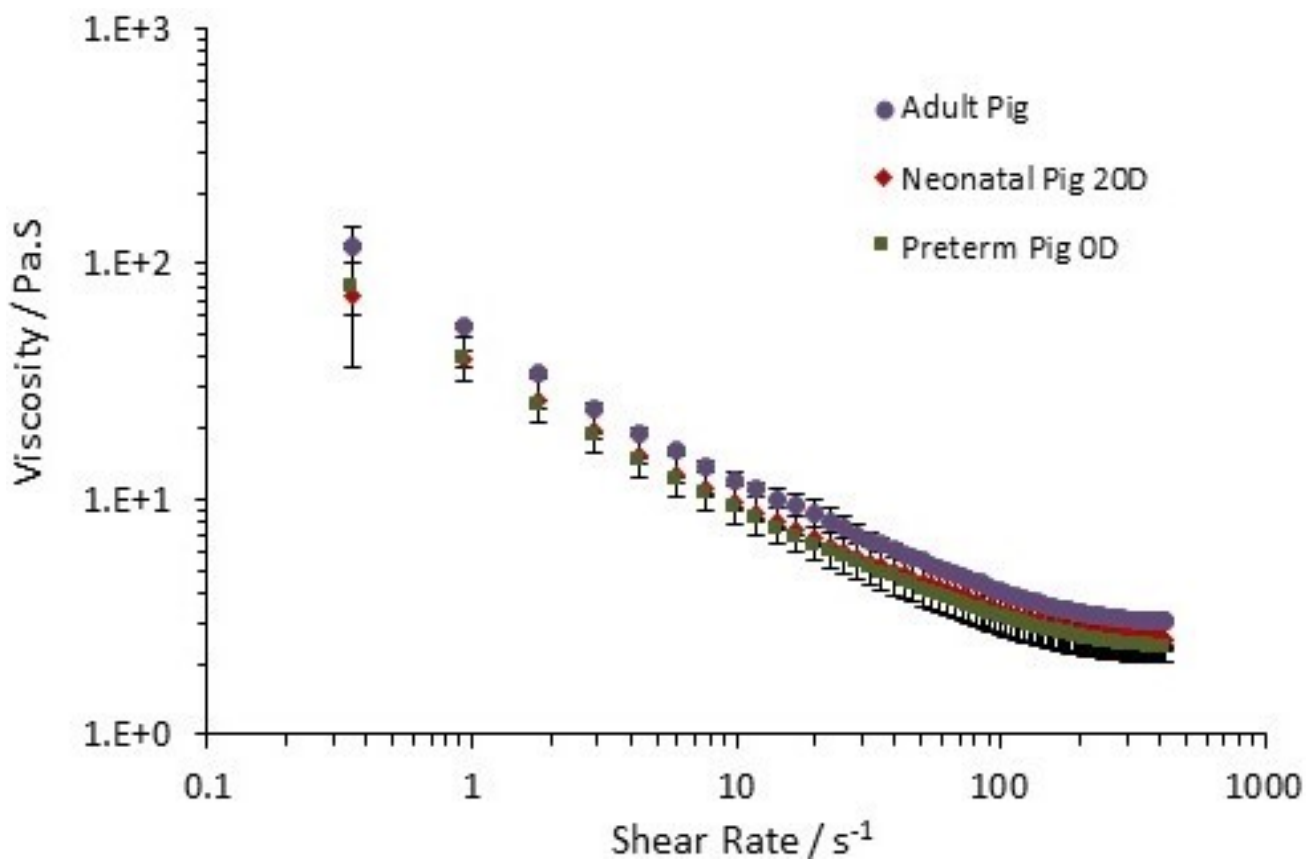

Figure 3-7. The viscosity of vitreous humor with the shear rate at preterm, neonatal and adult stages of development. 


\section{Conclusions}

This research presented the data on the effects of shear strain sweep and frequency sweep on rheological properties of the porcine ocular tissues, and compared the differences in tissues at different stages of development. Storage and loss modulus of porcine ocular tissues (cornea, sclera and vitreous) differed at different stages of development (adult, neonatal and preterm), adult tissues being on the higher end of $\mathrm{G}^{\prime}$ and $G^{\prime \prime}$. Nevertheless, future studies are required to fully characterize the mechanical behaviors of the ocular tissues at different stages of development covering the entire age range, and with different diseases. A thorough understanding of the shear properties of the ocular tissues would facilitate in developing better treatments for complex diseases or abnormalities. 


\section{CHAPTER 4. CONCLUSIONS}

A series of biodegradable hydrogels were synthesized by photopolymerization of NIPAAm monomer and hydrolytically degradable oligolactate DEX-Lactate-HEMA or HA-AEMA macromers. The thermoresponsive, rheological and biodegradable properties of the hydrogels were strongly dependent on the reaction conditions and composition of the hydrogels. The higher the amount of the Irgacure 2959 initiator, the higher the UV intensity, the longer the reaction time, and the higher amounts of crosslinker used for the synthesis, the higher the yield of the synthesized hydrogels. The hydrogels were not cytotoxic to DPSCs and ADSCs at a concentration up to at least $15 \mathrm{mg} \cdot \mathrm{mL}^{-1}$, and have appropriate mechanical and biodegradable properties to promote DPSCs and ADSCs growth. Based on in vitro studies it was observed that DEX-gels and HA-gels appear to be suitable for encapsulation of DPSCs/ADSCs at optimum hydrogel concentration. The data confirmed that both DPSCs and ADSCs favorably adhered and proliferated within the biomaterials in vitro. Additionally, the current study confirmed that DPSCs and ADSCs have superior growth properties in HA-AEMA hydrogels compared to DEXLactate-HEMA hydrogels. The developed hydrogels have shown promising potential for encpaulsating DPSCs/ADSCs for tissue engineering aplications. However, further optimization is needed to have apropriate mechanical and degradation properties to cater as per DPSCs or ADSCs growth inside their matrices, and successful completion of this project will have a significant impact on dental and retinal tissue engineering fields.

This research presented the data on the effects of shear strain sweep and frequency sweep on rheological properties of the porcine ocular tissues, and compared the differences in tissues at different stages of development. Storage and loss modulus of porcine ocular tissues (cornea, sclera and vitreous) differed at different stages of development (adult, neonatal and preterm), adult tissues being on the higher end of $\mathrm{G}^{\prime}$ and $G^{\prime \prime}$. Nevertheless, future studies are required to fully characterize the mechanical behaviors of the ocular tissues at different stages of development covering the entire age range, and with different diseases. A thorough understanding of the shear properties of the ocular tissues would facilitate in developing better treatments for complex diseases or abnormalities. 


\section{LIST OF REFERENCES}

1. Kost, J. and R. Langer, Responsive polymeric delivery systems. Advanced drug delivery reviews, 2012. 64: p. 327-341.

2. Kretlow, J.D., L. Klouda, and A.G. Mikos, Injectable matrices and scaffolds for drug delivery in tissue engineering. Advanced drug delivery reviews, 2007. 59(4): p. 263-273.

3. Klouda, L. and A.G. Mikos, Thermoresponsive hydrogels in biomedical applications. European Journal of Pharmaceutics and Biopharmaceutics, 2008. 68(1): p. 34-45.

4. Huang, X. and T.L. Lowe, Biodegradable thermoresponsive hydrogels for aqueous encapsulation and controlled release of hydrophilic model drugs. Biomacromolecules, 2005. 6(4): p. 2131-2139.

5. Tan, H., et al., Thermosensitive injectable hyaluronic acid hydrogel for adipose tissue engineering. Biomaterials, 2009. 30(36): p. 6844-6853.

6. Ohya, S., Y. Nakayama, and T. Matsuda, Thermoresponsive artificial extracellular matrix for tissue engineering: hyaluronic acid bioconjugated with poly (N-isopropylacrylamide) grafts. Biomacromolecules, 2001. 2(3): p. 856-863.

7. Chen, J.-P. and T.-H. Cheng, Preparation and evaluation of thermo-reversible copolymer hydrogels containing chitosan and hyaluronic acid as injectable cell carriers. Polymer, 2009. 50(1): p. 107-116.

8. Wang, L.-Q., et al., Synthesis and characterization of temperature responsive graft copolymers of dextran with poly ( $N$-isopropylacrylamide). Reactive and Functional Polymers, 2002. 53(1): p. 19-27.

9. Morikawaand, N. and T. Matsuda, Thermoresponsive artificial extracellular matrix: N-isopropylacrylamide-graft-copolymerized gelatin. Journal of Biomaterials Science, Polymer Edition, 2002. 13(2): p. 167-183.

10. Ohya, S. and T. Matsuda, Poly (N-isopropylacrylamide)(PNIPAM)-grafted gelatin as thermoresponsive three-dimensional artificial extracellular matrix: molecular and formulation parameters vs. cell proliferation potential. Journal of Biomaterials Science, Polymer Edition, 2005. 16(7): p. 809-827.

11. Lee, S.B., et al., Temperature/pH-sensitive comb-type graft hydrogels composed of chitosan and poly ( $\mathrm{N}$-isopropylacrylamide). Journal of applied polymer science, 2004. 92(4): p. 2612-2620.

12. Janagam, D.R., Biodegradable Polymeric Biomaterials in Different Forms for Long-acting Contraception and Drug Delivery to the Eye and Brain. 2017.

13. Jin, R., et al., Enzymatically crosslinked dextran-tyramine hydrogels as injectable scaffolds for cartilage tissue engineering. Tissue Engineering Part A, 2010. 16(8): p. 2429-2440.

14. Lévesque, S.G., R.M. Lim, and M.S. Shoichet, Macroporous interconnected dextran scaffolds of controlled porosity for tissue-engineering applications. Biomaterials, 2005. 26(35): p. 7436-7446.

15. Jin, R., et al., Enzymatically-crosslinked injectable hydrogels based on biomimetic dextran-hyaluronic acid conjugates for cartilage tissue engineering.

Biomaterials, 2010. 31(11): p. 3103-3113. 
16. Fricain, J.C., et al., A nano-hydroxyapatite-pullulan/dextran polysaccharide composite macroporous material for bone tissue engineering. Biomaterials, 2013. 34(12): p. 2947-2959.

17. Inuyama, Y., et al., Effects of hyaluronic acid sponge as a scaffold on odontoblastic cell line and amputated dental pulp. Journal of Biomedical Materials Research Part B: Applied Biomaterials, 2010. 92(1): p. 120-128.

18. Sasaki, T. and H. Kawamata-Kido, Providing an environment for reparative dentine induction in amputated rat molar pulp by high molecular-weight hyaluronic acid. Archives of oral biology, 1995. 40(3): p. 209-219.

19. Yoon, I.-S., et al., Proliferation and chondrogenic differentiation of human adipose-derived mesenchymal stem cells in porous hyaluronic acid scaffold. Journal of bioscience and bioengineering, 2011. 112(4): p. 402-408.

20. Dai, R., et al., Adipose-derived stem cells for tissue engineering and regenerative medicine applications. Stem cells international, 2016. 2016.

21. Geraghty, B., et al., Age-related variations in the biomechanical properties of human sclera. Journal of the mechanical behavior of biomedical materials, 2012. 16: p. 181-191.

22. Yan, D., et al., Microstructural differences in the human posterior sclera as a function of age and race. Investigative ophthalmology \& visual science, 2011. 52(2): p. 821-829.

23. Sebag, J., Age-related changes in human vitreous structure. Graefe's archive for clinical and experimental ophthalmology, 1987. 225(2): p. 89-93.

24. Elsheikh, A., et al., Assessment of corneal biomechanical properties and their variation with age. Current eye research, 2007. 32(1): p. 11-19.

25. Cartwright, N.E.K., J.R. Tyrer, and J. Marshall, Age-related differences in the elasticity of the human cornea. Investigative ophthalmology \& visual science, 2011. 52(7): p. 4324-4329.

26. Vedadghavami, R., Rheology of Vitreous Gel. 2015, University of California, Los Angeles.

27. Bishop, P.N., Structural macromolecules and supramolecular organisation of the vitreous gel. Progress in retinal and eye research, 2000. 19(3): p. 323-344.

28. Elsheikh, A., D. Alhasso, and P. Rama, Biomechanical properties of human and porcine corneas. Experimental eye research, 2008. 86(5): p. 783-790.

29. Basu, S., et al., Corneal permeability to and ocular metabolism of phenyl substituted prostaglandin esters in vitro. Prostaglandins, Leukotrienes and Essential Fatty Acids (PLEFA), 1994. 50(4): p. 161-168.

30. Scholz, M., et al., Pilocarpine permeability across ocular tissues and cell cultures: influence of formulation parameters. Journal of ocular pharmacology and therapeutics, 2002. 18(5): p. 455-468.

31. Worthington, K.S., et al., Mechanical properties of murine and porcine ocular tissues in compression. Experimental eye research, 2014. 121: p. 194-199.

32. Barber, A.C., et al., Repair of the degenerate retina by photoreceptor transplantation. Proceedings of the National Academy of Sciences, 2013. 110(1): p. 354-359. 
33. Gonzalez-Cordero, A., et al., Photoreceptor precursors derived from threedimensional embryonic stem cell cultures integrate and mature within adult degenerate retina. Nature biotechnology, 2013. 31(8): p. 741-747.

34. Huang, G. and F. Garcia-Godoy, Stem cells and dental tissue reconstruction. Material-Tissue Interfacial Phenomena: Contributions from Dental and Craniofacial Reconstructions, 2016: p. 325.

35. Klassen, H., D.S. Sakaguchi, and M.J. Young, Stem cells and retinal repair. Progress in retinal and eye research, 2004. 23(2): p. 149-181.

36. MacLaren, R.E., et al., Retinal repair by transplantation of photoreceptor precursors. Nature, 2006. 444(7116): p. 203-207.

37. Shastri, P. and I. Martin, Tissue engineering by cell transplantation, in Stem Cell Transplantation and Tissue Engineering. 2002, Springer. p. 29-45.

38. Bianco, P. and P.G. Robey, Stem cells in tissue engineering. Nature, 2001. 414(6859): p. 118-121.

39. Hutmacher, D.W., Scaffolds in tissue engineering bone and cartilage. Biomaterials, 2000. 21(24): p. 2529-2543.

40. Vacanti, J.P. and C.A. Vacanti, The history and scope of tissue engineering. Principles of tissue engineering, 2000. 3: p. 3-6.

41. Parveen, S., K. Krishnakumar, and S. Sahoo, New era in health care: tissue engineering. Journal of stem cells \& regenerative medicine, 2006. 1(1): p. 8.

42. Yang, S., et al., The design of scaffolds for use in tissue engineering. Part I. Traditional factors. Tissue engineering, 2001. 7(6): p. 679-689.

43. Marler, J.J., et al., Transplantation of cells in matrices for tissue regeneration. Advanced drug delivery reviews, 1998. 33(1): p. 165-182.

44. O'brien, F.J., Biomaterials \& scaffolds for tissue engineering. Materials today, 2011. 14(3): p. 88-95.

45. Karp, J.M., P.D. Dalton, and M.S. Shoichet, Scaffolds for tissue engineering. MRS bulletin, 2003. 28(4): p. 301-306.

46. Freed, L.E., et al., Biodegradable polymer scaffolds for tissue engineering. Nature Biotechnology, 1994. 12(7): p. 689-693.

47. Neel, E.A.A., et al., Tissue engineering in dentistry. Journal of dentistry, 2014. 42(8): p. 915-928.

48. Huang, G.T.-J., et al., Stem/progenitor cell-mediated de novo regeneration of dental pulp with newly deposited continuous layer of dentin in an in vivo model. Tissue Engineering Part A, 2009. 16(2): p. 605-615.

49. Huang, G.T., Pulp and dentin tissue engineering and regeneration: current progress. Regenerative medicine, 2009. 4(5): p. 697-707.

50. Khanna-Jain, R., Isolation, characterization and osteogenic differentiation of dental stem cells in vitro for bone tissue engineering. 2012: Tampere University Press.

51. Huang, G.-J., S. Gronthos, and S. Shi, Mesenchymal stem cells derived from dental tissues vs. those from other sources: their biology and role in regenerative medicine. Journal of dental research, 2009. 88(9): p. 792-806.

52. Trese, M., C.V. Regatieri, and M.J. Young, Advances in retinal tissue engineering. Materials, 2012. 5(1): p. 108-120. 
53. Mead, B., et al., Stem cell treatment of degenerative eye disease. Stem cell research, 2015. 14(3): p. 243-257.

54. Redenti, S., et al., Retinal tissue engineering using mouse retinal progenitor cells and a novel biodegradable, thin-film poly (e-caprolactone) nanowire scaffold. Journal of ocular biology, diseases, and informatics, 2008. 1(1): p. 19-29.

55. Rajashekhar, G., et al., Regenerative therapeutic potential of adipose stromal cells in early stage diabetic retinopathy. PloS one, 2014. 9(1): p. e84671.

56. Traktuev, D.O., et al., A population of multipotent CD34-positive adipose stromal cells share pericyte and mesenchymal surface markers, reside in a periendothelial location, and stabilize endothelial networks. Circulation research, 2008. 102(1): p. 77-85.

57. Maumus, M., et al., Native human adipose stromal cells: localization, morphology and phenotype. International journal of obesity, 2011. 35(9): p. 11411153.

58. Wankhade, U.D., et al., Advances in adipose-derived stem cells isolation, characterization, and application in regenerative tissue engineering. Stem cells international, 2016. 2016.

59. Tomita, M., et al., Biodegradable polymer composite grafts promote the survival and differentiation of retinal progenitor cells. Stem Cells, 2005. 23(10): p. 15791588.

60. Ballios, B.G., et al., A hydrogel-based stem cell delivery system to treat retinal degenerative diseases. Biomaterials, 2010. 31(9): p. 2555-2564.

61. Burdick, J.A. and G. Vunjak-Novakovic, Engineered microenvironments for controlled stem cell differentiation. Tissue Engineering Part A, 2008. 15(2): p. 205-219.

62. Collins, M.N. and C. Birkinshaw, Hyaluronic acid based scaffolds for tissue engineering-A review. Carbohydrate polymers, 2013.92(2): p. 1262-1279.

63. El-Sherbiny, I.M. and M.H. Yacoub, Hydrogel scaffolds for tissue engineering: Progress and challenges. Global Cardiology Science and Practice, 2013: p. 38.

64. Webber, M.J., et al., A perspective on the clinical translation of scaffolds for tissue engineering. Annals of biomedical engineering, 2015. 43(3): p. 641-656.

65. Ambrosio, A., et al., A novel amorphous calcium phosphate polymer ceramic for bone repair: I. Synthesis and characterization. Journal of Biomedical Materials Research Part A, 2001. 58(3): p. 295-301.

66. Mooney, D.J., et al., Engineering Dental Pulp-like Tissue in Vitro. Biotechnology Progress, 1996. 12(6): p. 865-868.

67. Bohl, K.S., et al., Role of synthetic extracellular matrix in development of engineered dental pulp. Journal of Biomaterials Science, Polymer Edition, 1998. 9(7): p. 749-764.

68. Nör, J.E., et al., Engineering and characterization of functional human microvessels in immunodeficient mice. Laboratory investigation, 2001. 81(4): p. 453-463.

69. Sakai, V., et al., SHED differentiate into functional odontoblasts and endothelium. Journal of dental research, 2010. 89(8): p. 791-796. 
70. Young, C.S., et al., Tissue engineering of complex tooth structures on biodegradable polymer scaffolds. Journal of dental research, 2002. 81(10): p. 695700.

71. Duailibi, S., et al., Bioengineered dental tissues grown in the rat jaw. Journal of dental research, 2008. 87(8): p. 745-750.

72. Im, G.-I., H.-J. Kim, and J.H. Lee, Chondrogenesis of adipose stem cells in a porous PLGA scaffold impregnated with plasmid DNA containing SOX trio (SOX5,-6 and-9) genes. Biomaterials, 2011. 32(19): p. 4385-4392.

73. Safaeijavan, R., et al., Comparison of random and aligned PCL nanofibrous electrospun scaffolds on cardiomyocyte differentiation of human adipose-derived stem cells. Iranian journal of basic medical sciences, 2014. 17(11): p. 903.

74. Rowlands, A., et al., Polyurethane/poly (lactic-co-glycolic) acid composite scaffolds fabricated by thermally induced phase separation. Biomaterials, 2007. 28(12): p. 2109-2121.

75. Oh, S.H., et al., Fabrication and characterization of hydrophilic poly (lactic-coglycolic acid)/poly (vinyl alcohol) blend cell scaffolds by melt-molding particulate-leaching method. Biomaterials, 2003. 24(22): p. 4011-4021.

76. Alshehadat, S.A., et al., Scaffolds for dental pulp tissue regeneration: A review. Int Dent Med J Adv Res, 2016. 2: p. 1-12.

77. Liu, H., E.B. Slamovich, and T.J. Webster, Less harmful acidic degradation of poly (lactic-co-glycolic acid) bone tissue engineering scaffolds through titania nanoparticle addition. International journal of nanomedicine, 2006. 1(4): p. 541.

78. Park, S.-J., et al., Glycol Chitin-based Thermoresponsive Hydrogel Scaffold Supplemented with Enamel Matrix Derivative Promotes Odontogenic Differentiation of Human Dental Pulp Cells. Journal of endodontics, 2013. 39(8): p. 1001-1007.

79. Matsunaga, T., et al., Chitosan monomer promotes tissue regeneration on dental pulp wounds. Journal of Biomedical Materials Research Part A, 2006. 76(4): p. 711-720.

80. Gao, S., et al., Differentiation of human adipose-derived stem cells into neuronlike cells which are compatible with photocurable three-dimensional scaffolds. Tissue Engineering Part A, 2014. 20(7-8): p. 1271-1284.

81. Cheng, N.-C., S. Wang, and T.-H. Young, The influence of spheroid formation of human adipose-derived stem cells on chitosan films on stemness and differentiation capabilities. Biomaterials, 2012. 33(6): p. 1748-1758.

82. Dobie, K., et al., Effects of alginate hydrogels and TGF- $\beta 1$ on human dental pulp repair in vitro. Connective tissue research, 2002. 43(2-3): p. 387-390.

83. KUMABE, S., et al., Human dental pulp cell culture and cell transplantation with an alginate scaffold. Okajimas folia anatomica Japonica, 2006. 82(4): p. 147-156.

84. Yao, R., et al., Alginate and alginate/gelatin microspheres for human adiposederived stem cell encapsulation and differentiation. Biofabrication, 2012. 4(2): p. 025007.

85. Gruene, M., et al., Adipogenic differentiation of laser-printed 3D tissue grafts consisting of human adipose-derived stem cells. Biofabrication, 2011. 3(1): p. 015005 . 
86. Gotlieb, E.L., et al., An ultrastructural investigation of tissue-engineered pulp constructs implanted within endodontically treated teeth. The Journal of the American dental association, 2008. 139(4): p. 457-465.

87. Zhang, W., et al., The performance of human dental pulp stem cells on different three-dimensional scaffold materials. Biomaterials, 2006. 27(33): p. 5658-5668.

88. Friess, W. and M. Schlapp, Sterilization of gentamicin containing collagen/PLGA microparticle composites. European journal of pharmaceutics and biopharmaceutics, 2006. 63(2): p. 176-187.

89. Wu, W., et al., Engineering of human tracheal tissue with collagen-enforced polylactic-glycolic acid non-woven mesh: a preliminary study in nude mice. British Journal of Oral and Maxillofacial Surgery, 2007. 45(4): p. 272-278.

90. Kopeček, J., Hydrogel biomaterials: a smart future? Biomaterials, 2007. 28(34): p. 5185-5192.

91. Drury, J.L. and D.J. Mooney, Hydrogels for tissue engineering: scaffold design variables and applications. Biomaterials, 2003. 24(24): p. 4337-4351.

92. Hoffman, A.S., Hydrogels for biomedical applications. Advanced drug delivery reviews, 2012. 64: p. 18-23.

93. Hunt, J.A., et al., Hydrogels for tissue engineering and regenerative medicine. Journal of Materials Chemistry B, 2014. 2(33): p. 5319-5338.

94. Sivashanmugam, A., et al., An overview of injectable polymeric hydrogels for tissue engineering. European Polymer Journal, 2015. 72: p. 543-565.

95. Ahmed, E.M., Hydrogel: Preparation, characterization, and applications: $A$ review. Journal of advanced research, 2015. 6(2): p. 105-121.

96. Taguchi, T., et al., Encapsulation of chondrocytes in injectable alkali-treated collagen gels prepared using poly (ethylene glycol)-based 4-armed star polymer. Biomaterials, 2005. 26(11): p. 1247-1252.

97. Hong, Y., et al., Covalently crosslinked chitosan hydrogel: properties of in vitro degradation and chondrocyte encapsulation. Acta biomaterialia, 2007. 3(1): p. 23-31.

98. Park, H., et al., Injectable chitosan hyaluronic acid hydrogels for cartilage tissue engineering. Acta biomaterialia, 2013. 9(1): p. 4779-4786.

99. Wang, L.-S., et al., Modulation of chondrocyte functions and stiffness-dependent cartilage repair using an injectable enzymatically crosslinked hydrogel with tunable mechanical properties. Biomaterials, 2014. 35(7): p. 2207-2217.

100. Yu, F., et al., An injectable hyaluronic acid/PEG hydrogel for cartilage tissue engineering formed by integrating enzymatic crosslinking and Diels-Alder "click chemistry”. Polymer Chemistry, 2014. 5(3): p. 1082-1090.

101. Elisseeff, J., et al., Photoencapsulation of chondrocytes in poly (ethylene oxide)based semi-interpenetrating networks. Journal of biomedical materials research, 2000. 51(2): p. 164-171.

102. Leone, G., et al., Amidic alginate hydrogel for nucleus pulposus replacement. Journal of Biomedical Materials Research Part A, 2008. 84(2): p. 391-401.

103. Pereira, C.L., et al., The effect of hyaluronan-based delivery of stromal cellderived factor-1 on the recruitment of MSCs in degenerating intervertebral discs. Biomaterials, 2014. 35(28): p. 8144-8153. 
104. Kumar, D., et al., Three-dimensional hypoxic culture of human mesenchymal stem cells encapsulated in a photocurable, biodegradable polymer hydrogel: a potential injectable cellular product for nucleus pulposus regeneration. Acta biomaterialia, 2014. 10(8): p. 3463-3474.

105. Frith, J.E., et al., An injectable hydrogel incorporating mesenchymal precursor cells and pentosan polysulphate for intervertebral disc regeneration. Biomaterials, 2013. 34(37): p. 9430-9440.

106. Lee, K.Y., E. Alsberg, and D.J. Mooney, Degradable and injectable poly (aldehyde guluronate) hydrogels for bone tissue engineering. Journal of Biomedical Materials Research Part A, 2001. 56(2): p. 228-233.

107. Alsberg, E., et al., Cell-interactive alginate hydrogels for bone tissue engineering. Journal of dental research, 2001. 80(11): p. 2025-2029.

108. Kim, H.K., et al., Injectable In Situ-Forming pH/Thermo-Sensitive Hydrogel for Bone Tissue Engineering. Tissue Engineering Part A, 2008. 15(4): p. 923-933.

109. Kim, J., et al., Bone regeneration using hyaluronic acid-based hydrogel with bone morphogenic protein-2 and human mesenchymal stem cells. Biomaterials, 2007. 28(10): p. 1830-1837.

110. Burdick, J.A. and K.S. Anseth, Photoencapsulation of osteoblasts in injectable RGD-modified PEG hydrogels for bone tissue engineering. Biomaterials, 2002. 23(22): p. 4315-4323.

111. Park, H., et al., Injectable biodegradable hydrogel composites for rabbit marrow mesenchymal stem cell and growth factor delivery for cartilage tissue engineering. Biomaterials, 2007. 28(21): p. 3217-3227.

112. Park, D.-J., et al., Injectable bone using chitosan-alginate gel/mesenchymal stem cells/BMP-2 composites. Journal of Cranio-Maxillofacial Surgery, 2005. 33(1): p. 50-54.

113. Jaikumar, D., et al., Injectable alginate-O-carboxymethyl chitosan/nano fibrin composite hydrogels for adipose tissue engineering. International journal of biological macromolecules, 2015. 74: p. 318-326.

114. Halberstadt, C., et al., A hydrogel material for plastic and reconstructive applications injected into the subcutaneous space of a sheep. Tissue engineering, 2002. 8(2): p. 309-319.

115. Loebsack, A., et al., In vivo characterization of a porous hydrogel material for use as a tissue bulking agent. Journal of Biomedical Materials Research Part A, 2001. 57(4): p. 575-581.

116. Christman, K.L., et al., Fibrin glue alone and skeletal myoblasts in a fibrin scaffold preserve cardiac function after myocardial infarction. Tissue engineering, 2004. 10(3-4): p. 403-409.

117. Christman, K.L., et al., Injectable fibrin scaffold improves cell transplant survival, reduces infarct expansion, and induces neovasculature formation in ischemic myocardium. Journal of the American College of Cardiology, 2004. 44(3): p. 654-660.

118. Wu, J., et al., Infarct stabilization and cardiac repair with a VEGF-conjugated, injectable hydrogel. Biomaterials, 2011. 32(2): p. 579-586. 
119. Yi, X., et al., A novel, biodegradable, thermoresponsive hydrogel attenuates ventricular remodeling and improves cardiac function following myocardial infarction-a review. Current pharmaceutical design, 2014. 20(12): p. 2040-2047.

120. Li, Z., et al., Differentiation of cardiosphere-derived cells into a mature cardiac lineage using biodegradable poly ( $N$-isopropylacrylamide) hydrogels.

Biomaterials, 2011. 32(12): p. 3220-3232.

121. Rossi, C.A., et al., In vivo tissue engineering of functional skeletal muscle by freshly isolated satellite cells embedded in a photopolymerizable hydrogel. The FASEB Journal, 2011. 25(7): p. 2296-2304.

122. Ding, K., et al., Injectable thermosensitive chitosan/ $\beta$-glycerophosphate/collagen hydrogel maintains the plasticity of skeletal muscle satellite cells and supports their in vivo viability. Cell biology international, 2013. 37(9): p. 977-987.

123. Fuoco, C., et al., Injectable polyethylene glycol-fibrinogen hydrogel adjuvant improves survival and differentiation of transplanted mesoangioblasts in acute and chronic skeletal-muscle degeneration. Skeletal muscle, 2012. 2(1): p. 24.

124. Kuraitis, D., et al., A stromal cell-derived factor-1 releasing matrix enhances the progenitor cell response and blood vessel growth in ischaemic skeletal muscle. Eur Cell Mater, 2011. 22(109): p. e23.

125. Lu, W.-N., et al., Functional improvement of infarcted heart by co-injection of embryonic stem cells with temperature-responsive chitosan hydrogel. Tissue Engineering Part A, 2008. 15(6): p. 1437-1447.

126. Cavalcanti, B.N., B.D. Zeitlin, and J.E. Nör, A hydrogel scaffold that maintains viability and supports differentiation of dental pulp stem cells. Dental Materials, 2013. 29(1): p. 97-102.

127. Compton, K.B., Synthesis and Characterization of Methacrylated HyaluronanBased Hydrogels for Tissue Engineering. 2014: The University of Tennessee Health Science Center.

128. Misra, G.P., et al., Subconjunctivally implantable hydrogels with degradable and thermoresponsive properties for sustained release of insulin to the retina.

Biomaterials, 2009. 30(33): p. 6541-6547.

129. Meyvis, T.K., et al., A comparison between the use of dynamic mechanical analysis and oscillatory shear rheometry for the characterisation of hydrogels. International journal of pharmaceutics, 2002. 244(1): p. 163-168.

130. Janagam, D.R., L. Wu, and T.L. Lowe, Nanoparticles for drug delivery to the anterior segment of the eye. Advanced Drug Delivery Reviews, 2017.

122(Supplement C): p. 31-64.

131. Hatami-Marbini, H., Viscoelastic shear properties of the corneal stroma. Journal of biomechanics, 2014. 47(3): p. 723-728.

132. Murthy, K.R., et al., Proteomic analysis of human vitreous humor. Clinical proteomics, 2014. 11(1): p. 29.

133. Colter, J., et al., Age-related changes in dynamic moduli of ovine vitreous. Journal of the mechanical behavior of biomedical materials, 2015. 41: p. 315-324.

134. O'Brien, W. and H. Edelhauser, The corneal penetration of trifluorothymidine, adenine arabinoside, and idoxuridine: a comparative study. Investigative ophthalmology \& visual science, 1977. 16(12): p. 1093-1103. 
135. Geerligs, M., et al., Linear shear response of the upper skin layers. Biorheology, 2011. 48(3-4): p. 229-245.

136. Nickerson, C.S., Engineering the mechanical properties of ocular tissues. 2006, California Institute of Technology.

137. Moelbert, S. and P. De Los Rios, Chaotropic effect and preferential binding in a hydrophobic interaction model. The Journal of chemical physics, 2003. 119(15): p. 7988-8001.

138. Iatridis, J.C., et al., Shear mechanical properties of human lumbar annulus fibrosus. Journal of Orthopaedic Research, 1999. 17(5): p. 732-737.

139. Zhu, W., K.Y. Chern, and M. van C, Anisotropic viscoelastic shear properties of bovine meniscus. Clinical orthopaedics and related research, 1994. 306: p. 34-45.

140. Zhu, W., et al., Viscoelastic shear properties of articular cartilage and the effects of glycosidase treatments. Journal of Orthopaedic Research, 1993. 11(6): p. 771781.

141. Silva, A.F., M.A. Alves, and M.S. Oliveira, Rheological behaviour of vitreous humour. Rheologica Acta, 2017. 56(4): p. 377-386.

142. Maleki, A., A.-L. Kjøniksen, and B. Nyström, Anomalous viscosity behavior in aqueous solutions of hyaluronic acid. Polymer Bulletin, 2007. 59(2): p. 217-226. 


\section{APPENDIX. RHEOLOGY DATA OF HYDROGELS AND PORCINE OCULAR TISSUES}

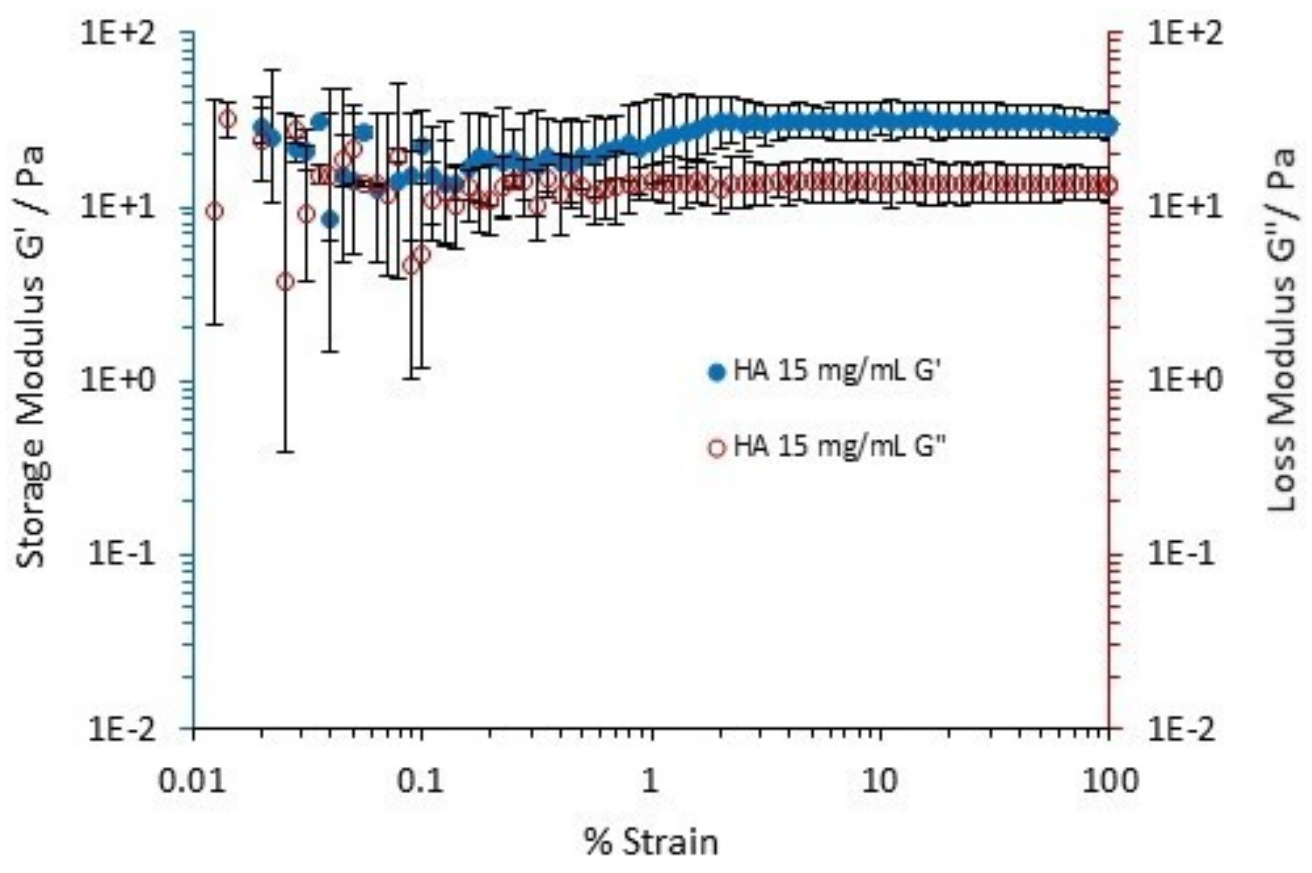

Figure A-1. Representative shear storage modulus $\left(G^{\prime}\right)$ and shear loss modulus $\left(G^{\prime \prime}\right)$ as a function of oscillatory strain sweep for the HA-based $15 \mathbf{m g} \cdot \mathbf{m L}^{-1}$ hydrogel. 


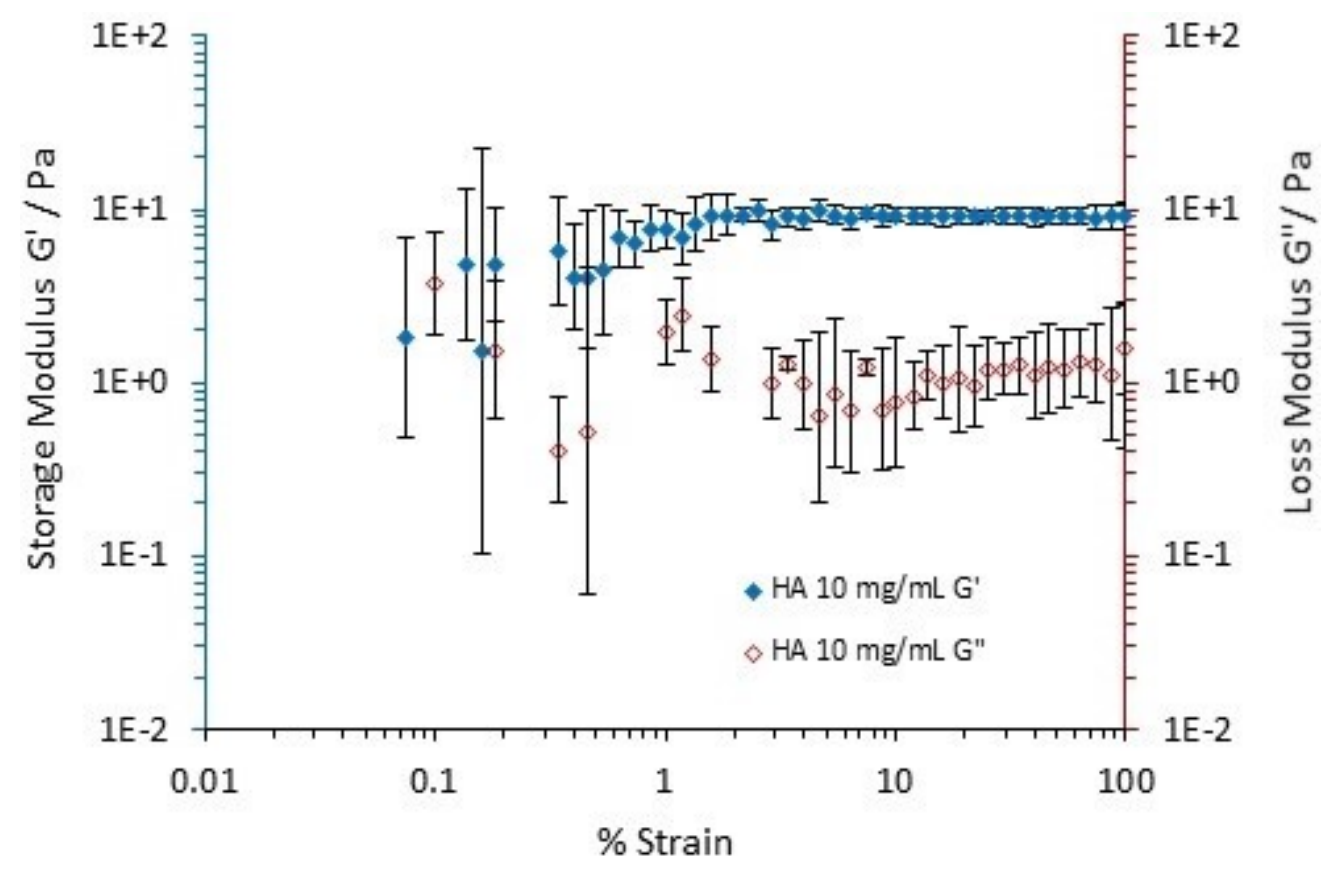

Figure A-2. Representative shear storage modulus $\left(G^{\prime}\right)$ and shear loss modulus $\left(G^{\prime \prime}\right)$ as a function of oscillatory strain sweep for the $\mathrm{HA}$-based $10 \mathrm{mg} \cdot \mathrm{mL}^{-1}$ hydrogel. 


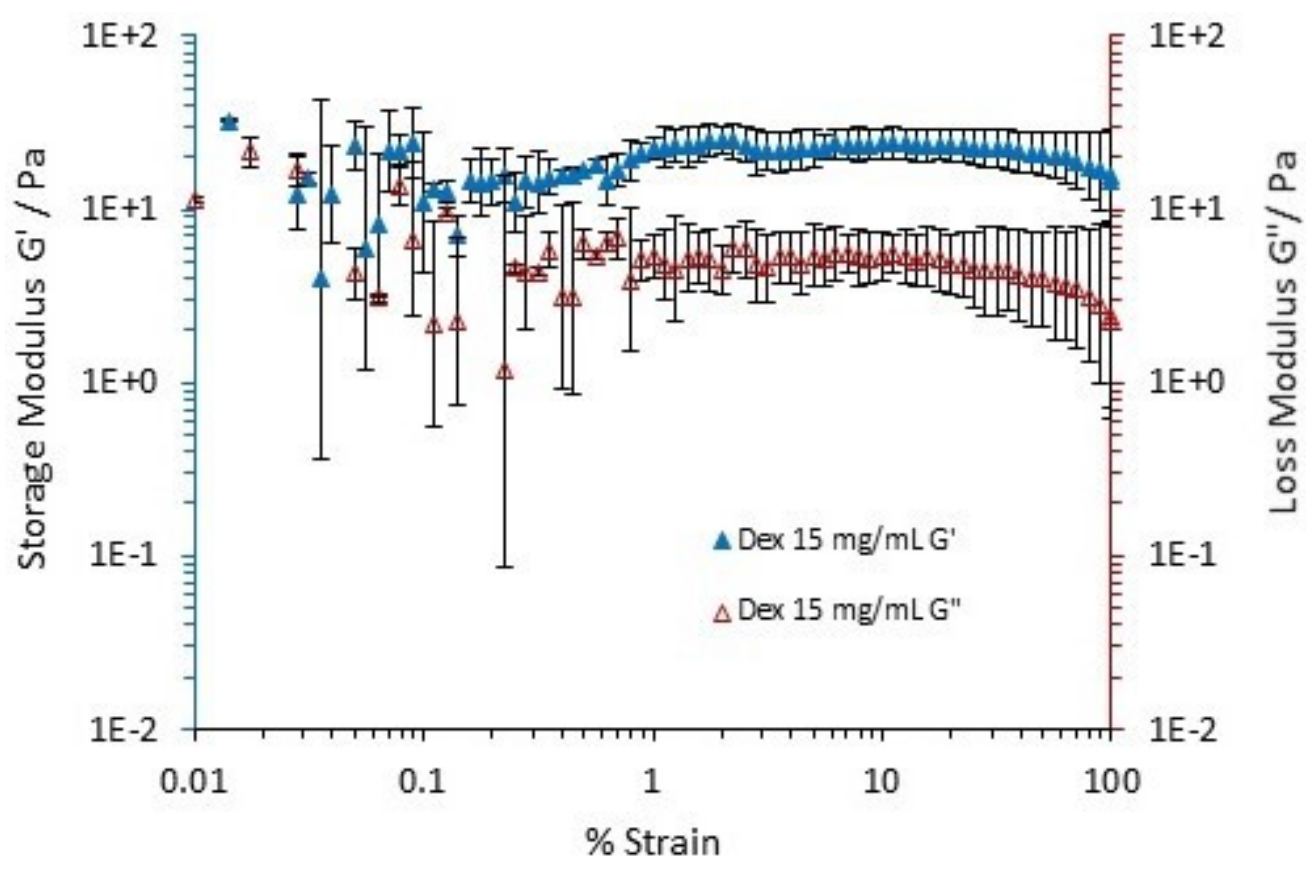

Figure A-3. Representative shear storage modulus $\left(G^{\prime}\right)$ and shear loss modulus $\left(G^{\prime \prime}\right)$ as a function of oscillatory strain sweep for the Dex-based $15 \mathrm{mg} \cdot \mathrm{mL}^{-1}$ hydrogel. 


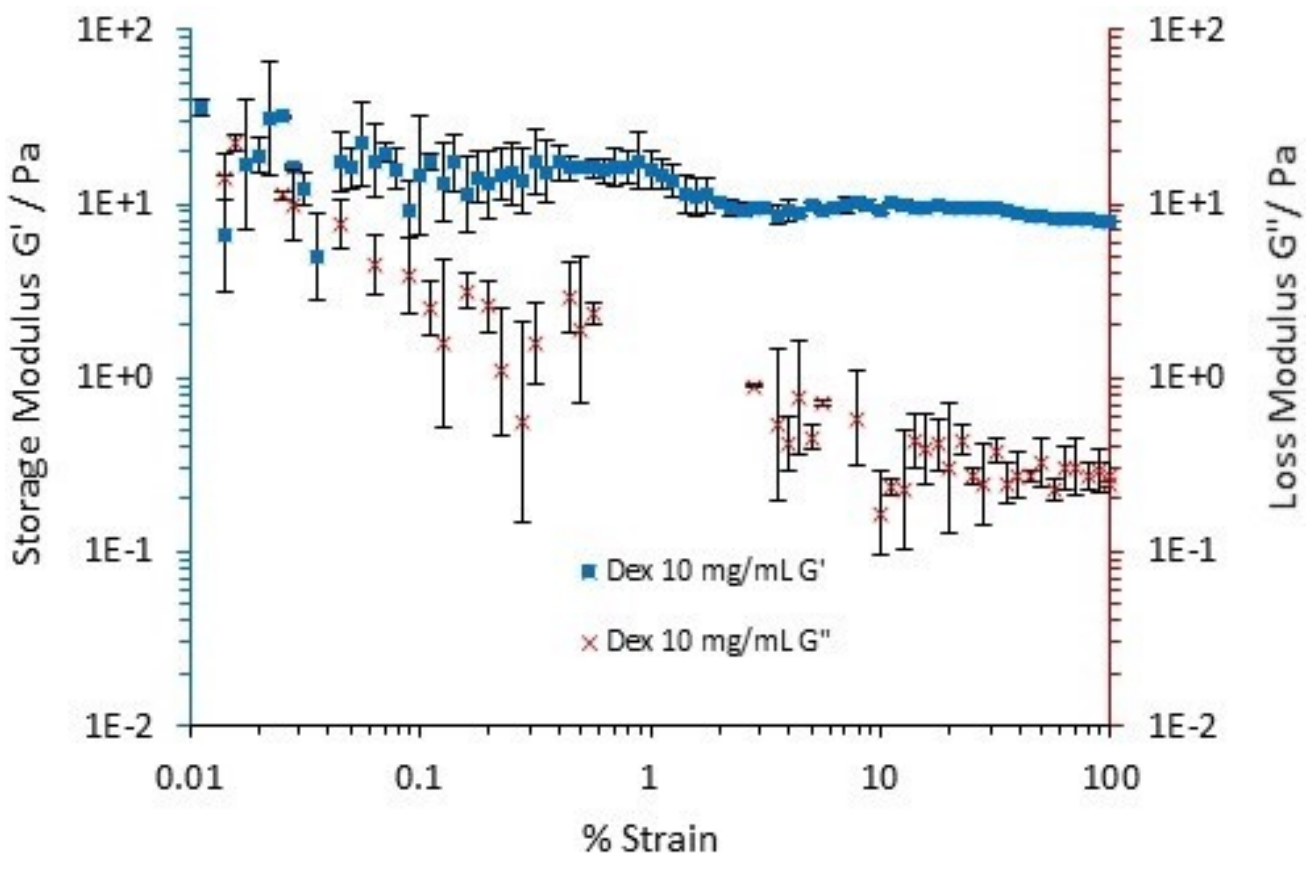

Figure A-4. Representative shear storage modulus $\left(G^{\prime}\right)$ and shear loss modulus $\left(G^{\prime \prime}\right)$ as a function of oscillatory strain sweep for the Dex-based $10 \mathrm{mg} \cdot \mathrm{mL}^{-1}$ hydrogel. 


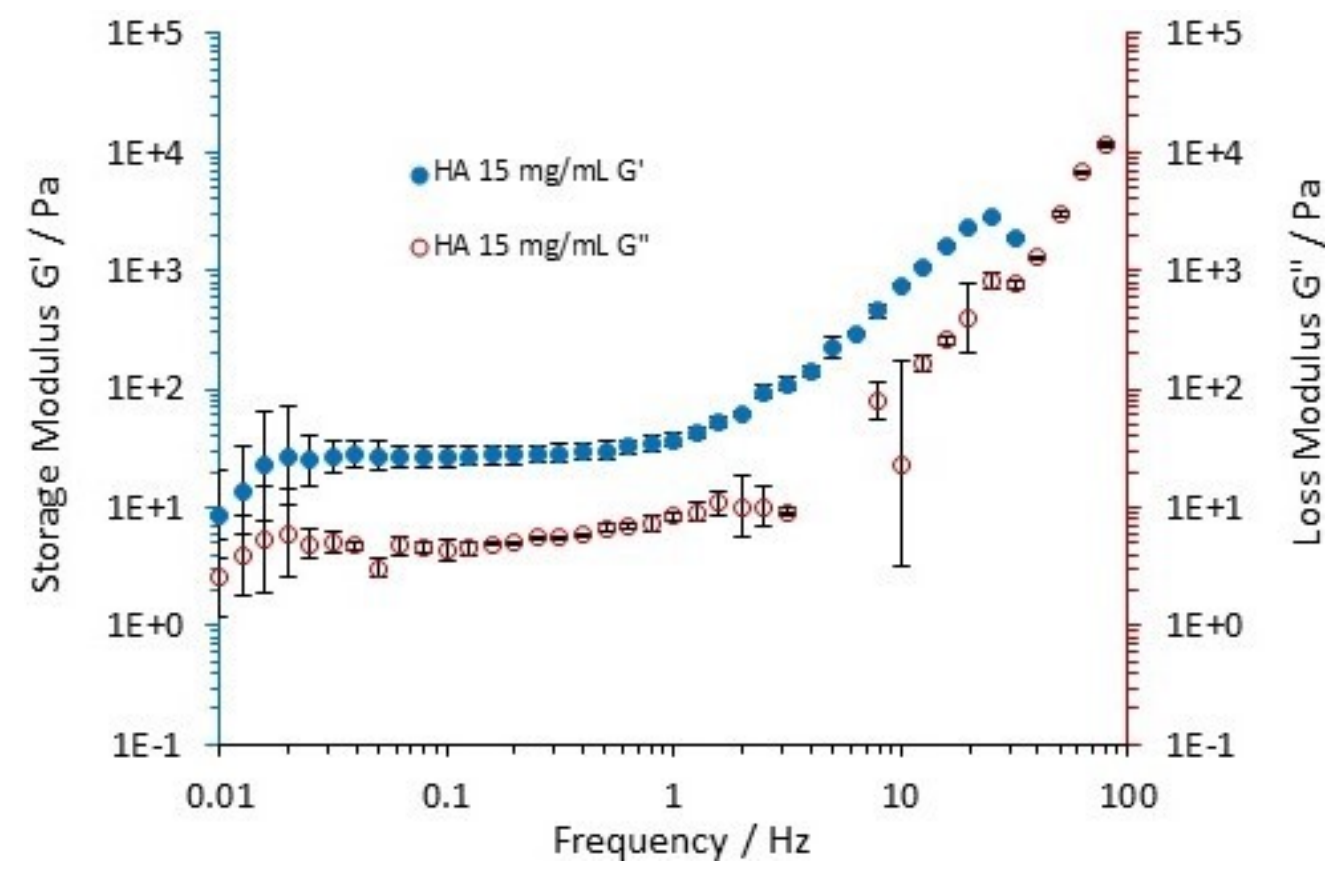

Figure A-5. Representative shear storage modulus $\left(G^{\prime}\right)$ and shear loss modulus $\left(G^{\prime \prime}\right)$ as a function of frequency for the HA-based $15 \mathrm{mg} \cdot \mathrm{mL}^{-1} \mathrm{hydrogel}$. 


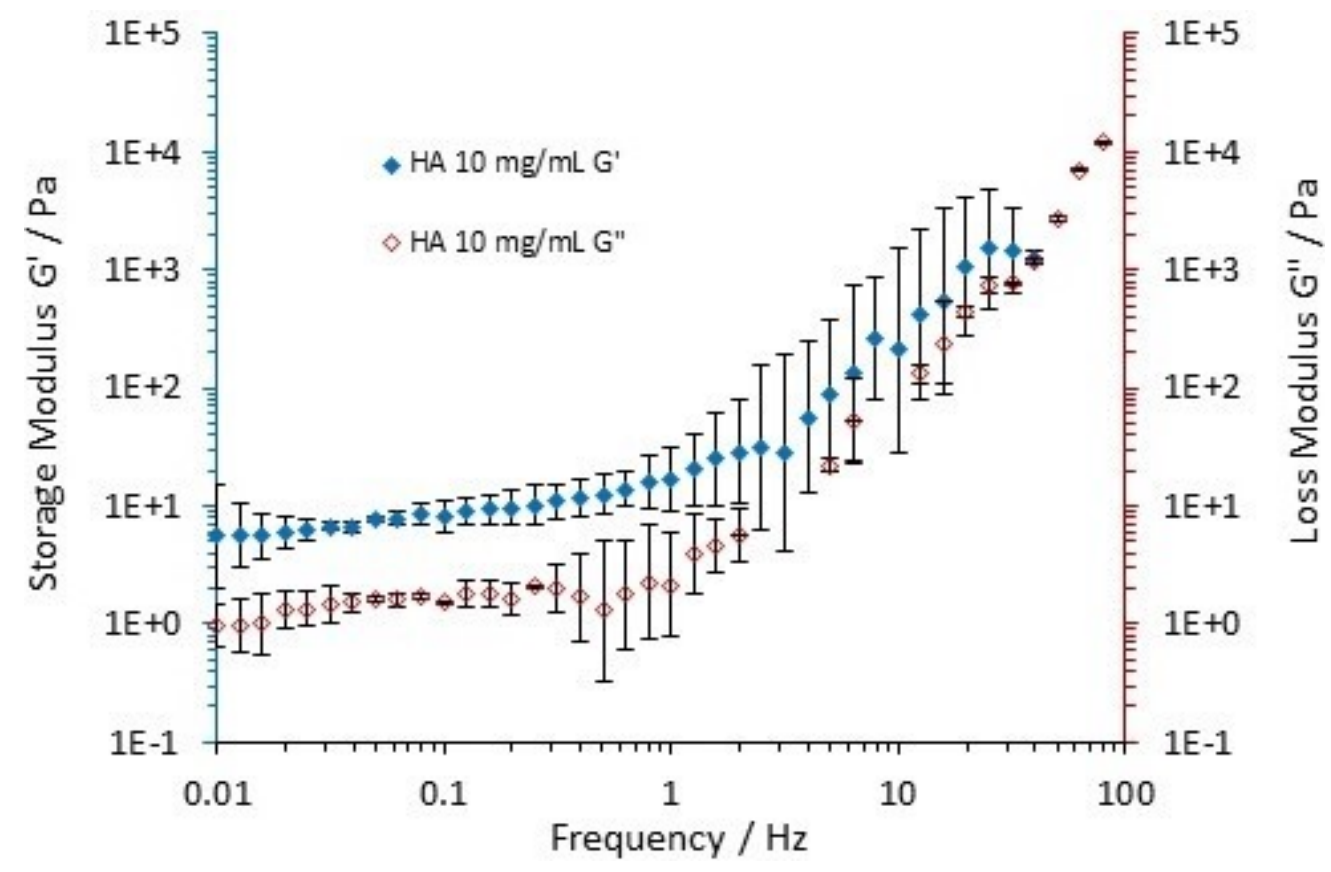

Figure A-6. Representative shear storage modulus $\left(G^{\prime}\right)$ and shear loss modulus $\left(G^{\prime \prime}\right)$ as a function of frequency for the HA-based $10 \mathrm{mg} \cdot \mathrm{mL}^{-1} \mathrm{hydrogel}$. 


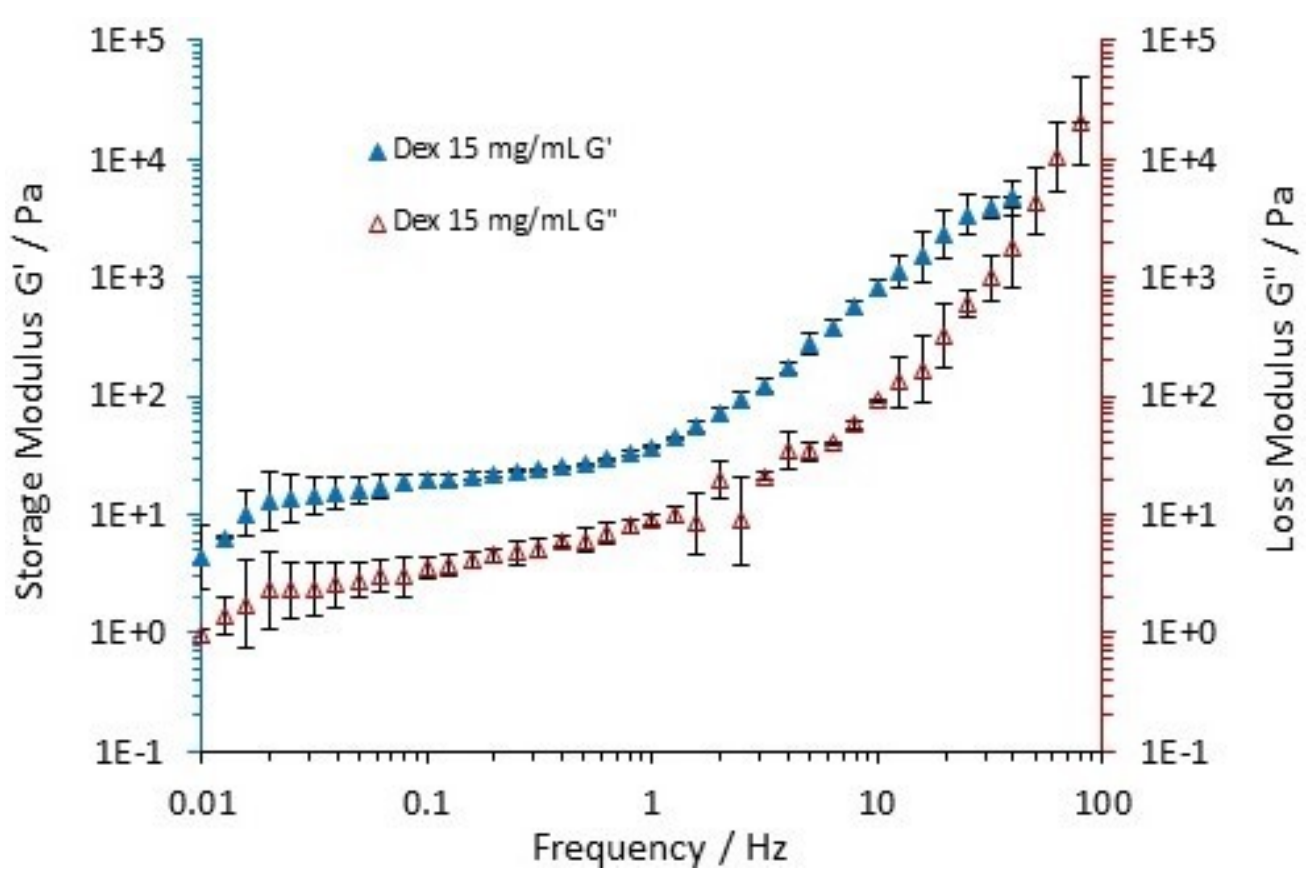

Figure A-7. Representative shear storage modulus $\left(G^{\prime}\right)$ and shear loss modulus $\left(G^{\prime \prime}\right)$ as a function of frequency for the Dex-based $15 \mathrm{mg} \cdot \mathrm{mL}^{-1}$ hydrogel. 


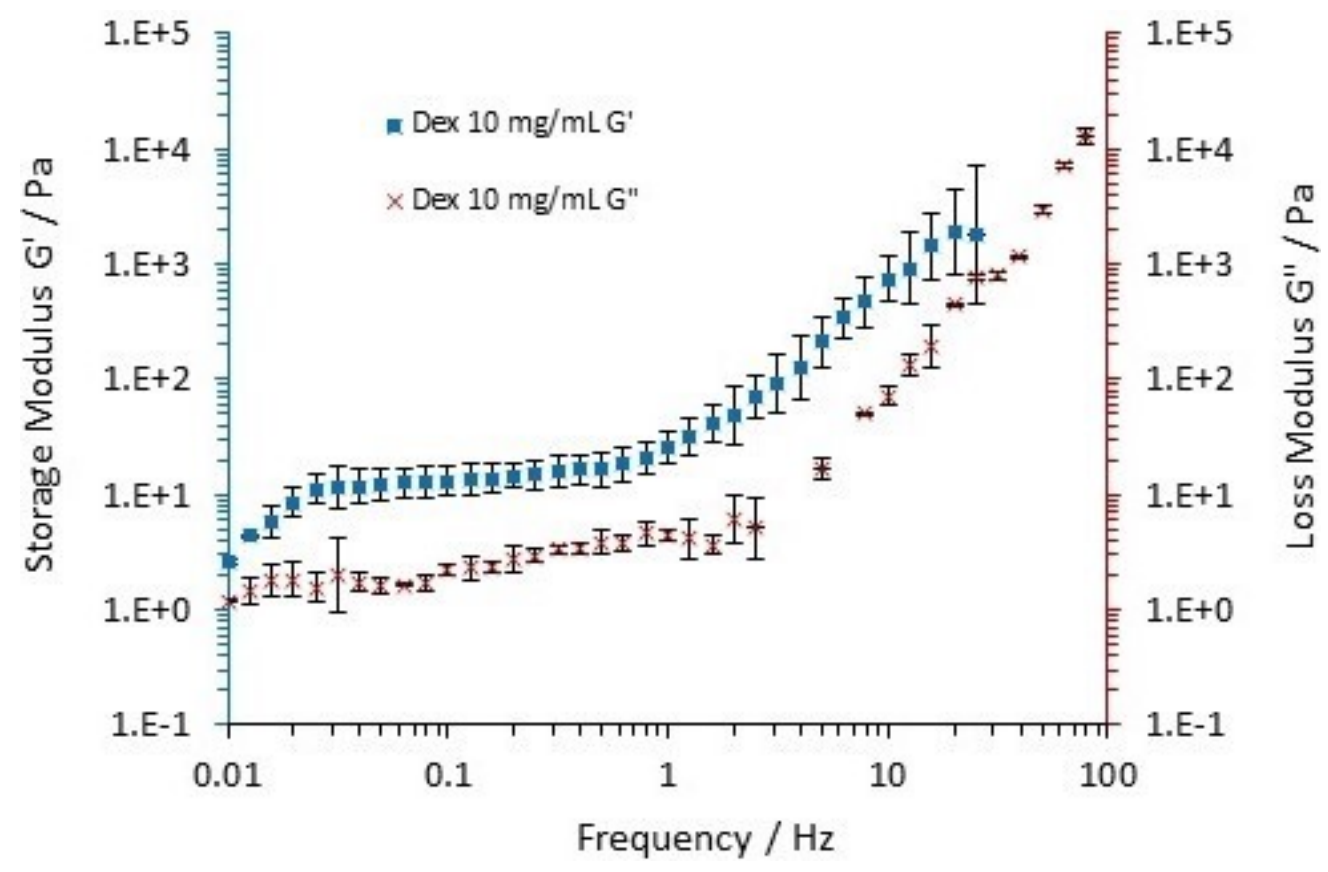

Figure A-8. Representative shear storage modulus $\left(G^{\prime}\right)$ and shear loss modulus $\left(G^{\prime \prime}\right)$ as a function of frequency for the Dex-based $10 \mathrm{mg} \cdot \mathrm{mL}^{-1}$ hydrogel. 


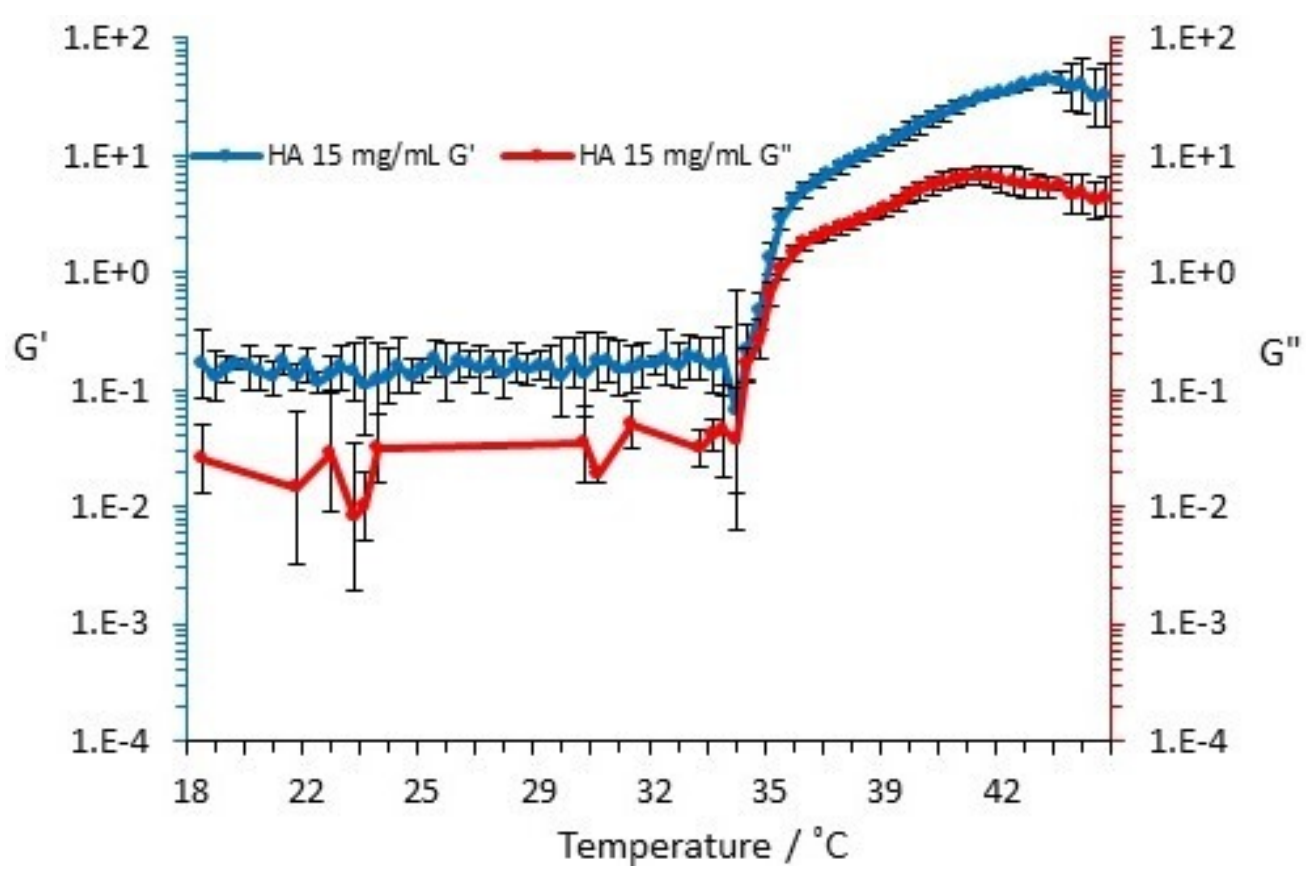

Figure A-9. Thermoresponsive phase transition and representative change in shear storage modulus $\left(G^{\prime}\right)$ and shear loss modulus $\left(G^{\prime \prime}\right)$ as a function of temperature ramp for the $\mathrm{HA}$-based $15 \mathrm{mg} \cdot \mathrm{mL}^{-1}$ hydrogel. 


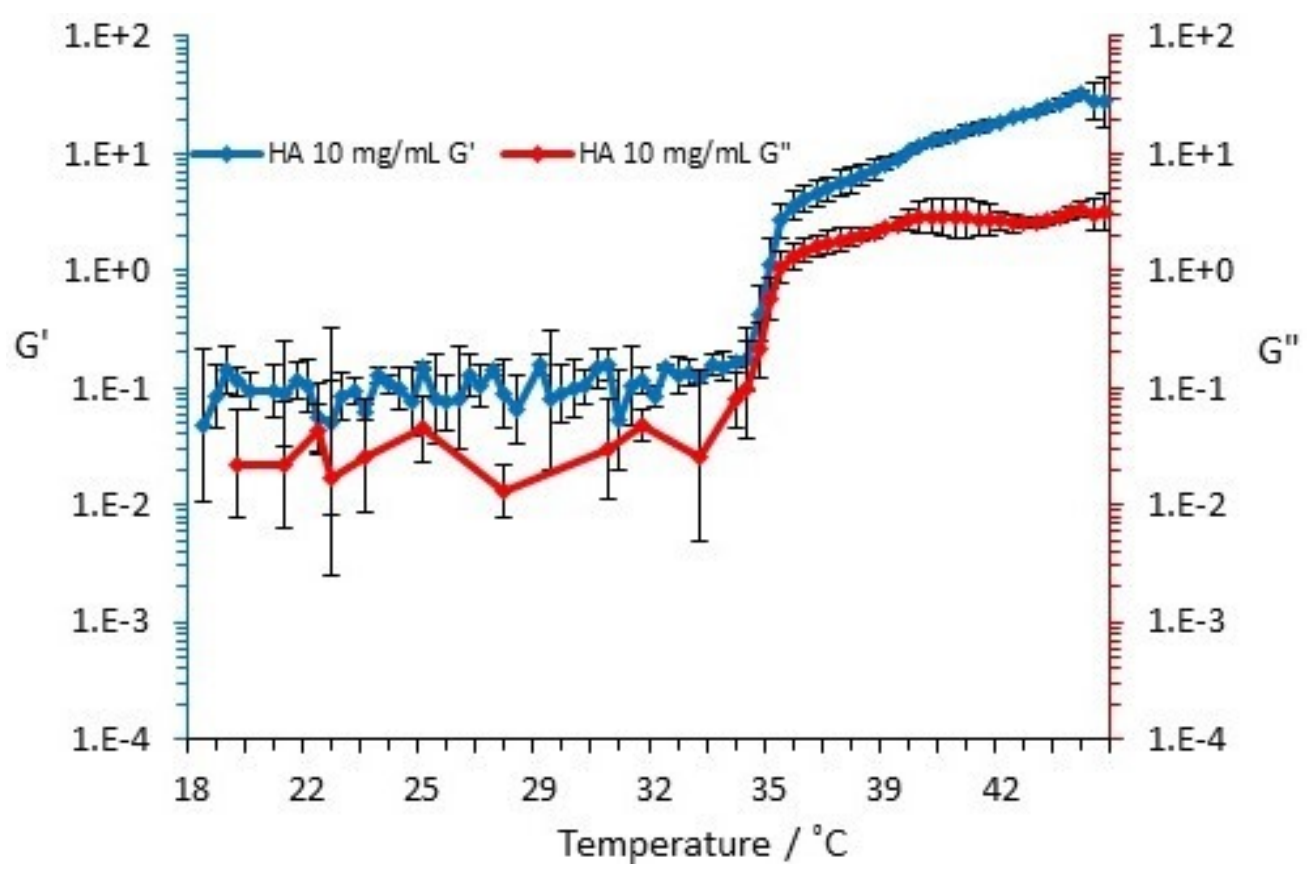

Figure A-10. Thermoresponsive phase transition and representative change in shear storage modulus $\left(G^{\prime}\right)$ and shear loss modulus $\left(G^{\prime \prime}\right)$ as a function of temperature ramp for the $\mathrm{HA}$-based $10 \mathrm{mg} \cdot \mathrm{mL}^{-1}$ hydrogel. 


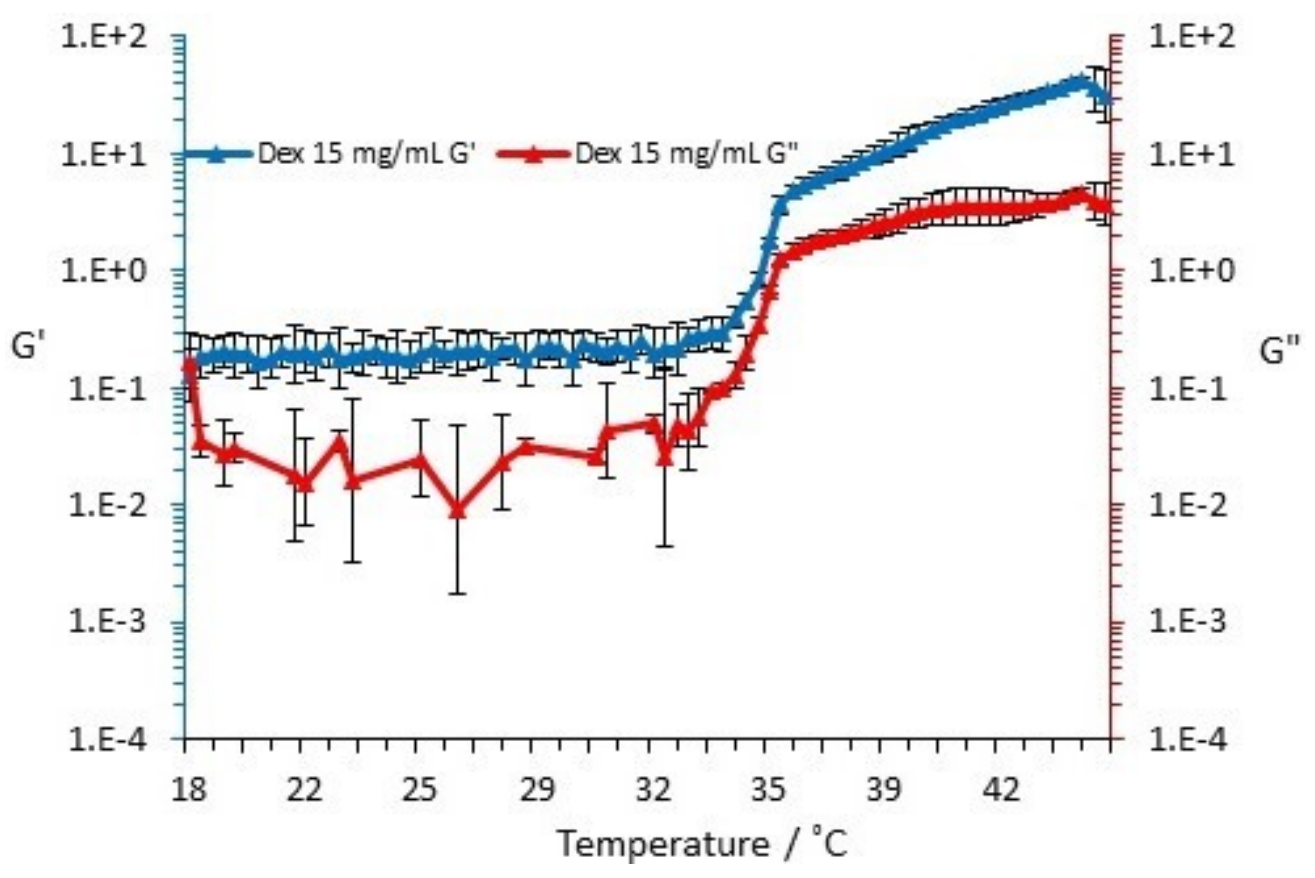

Figure A-11. Thermoresponsive phase transition and representative change in shear storage modulus $\left(G^{\prime}\right)$ and shear loss modulus $\left(G^{\prime \prime}\right)$ as a function of temperature ramp for the Dex-based $15 \mathrm{mg} \cdot \mathrm{mL}^{-1}$ hydrogel. 


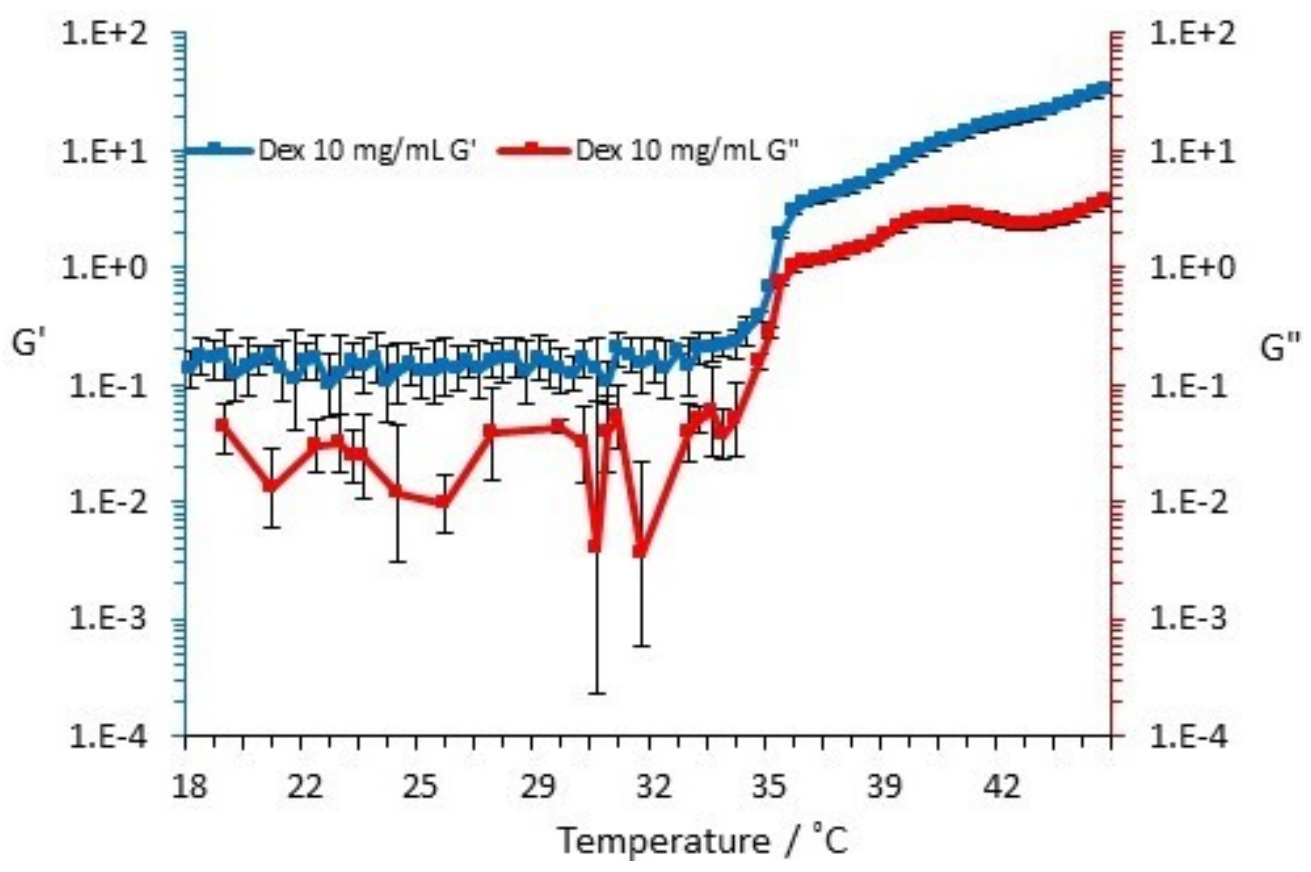

Figure A-12. Thermoresponsive phase transition and representative change in shear storage modulus $\left(G^{\prime}\right)$ and shear loss modulus $\left(G^{\prime \prime}\right)$ as a function of temperature ramp for the Dex-based $10 \mathrm{mg} \cdot \mathrm{mL}^{-1}$ hydrogel. 


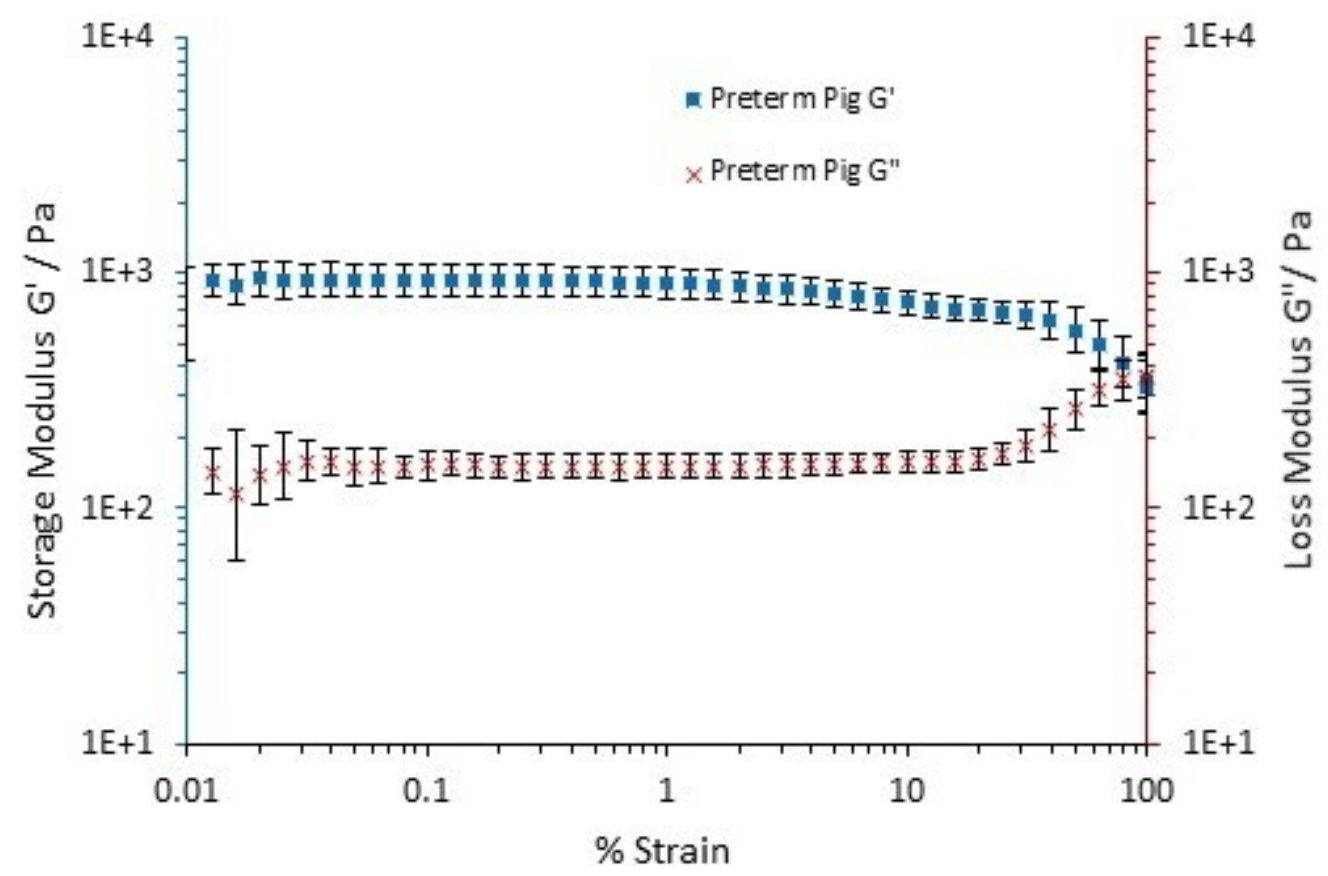

Figure A-13. Storage and loss moduli of corneal tissues at preterm stage of development under strain-sweep. 


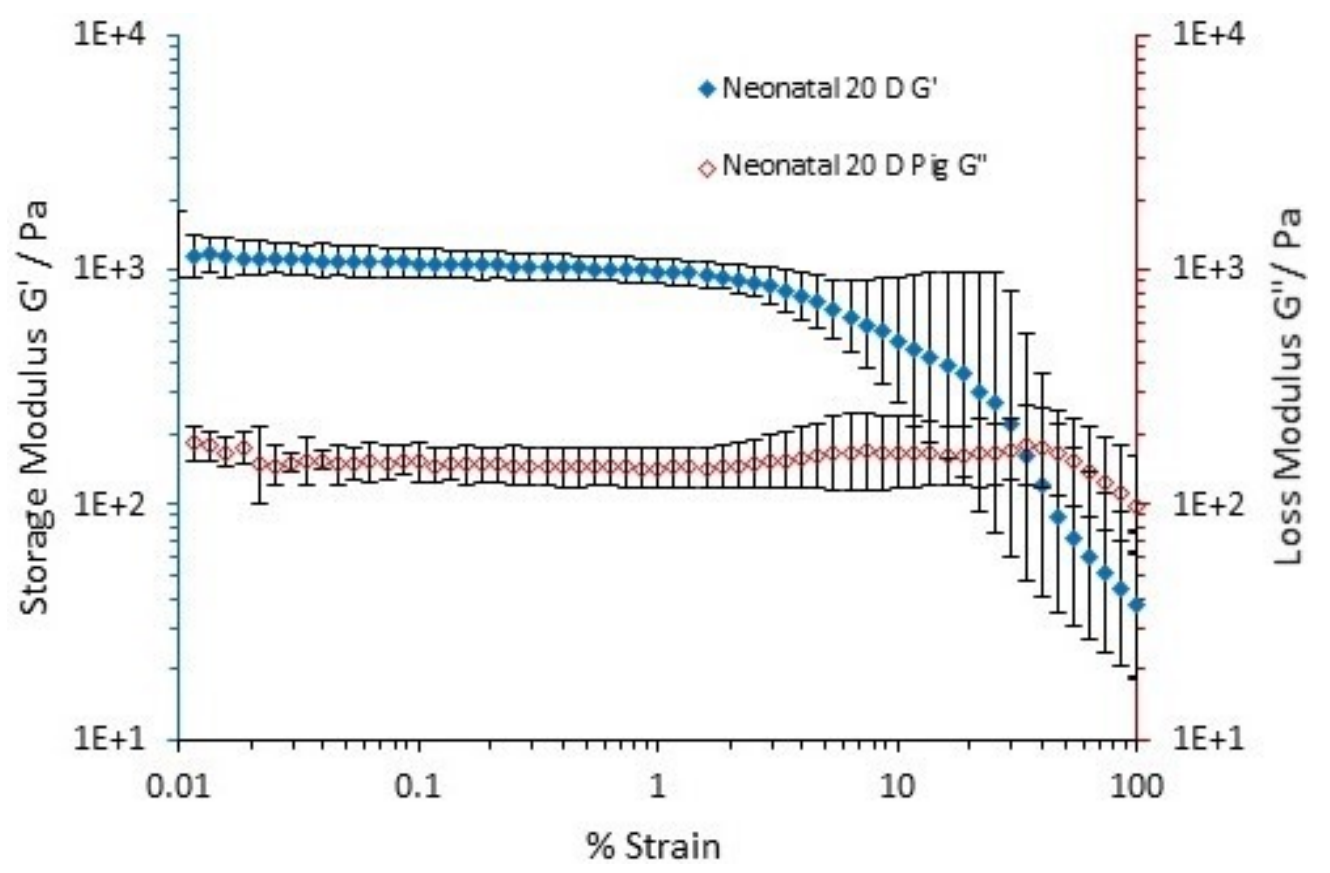

Figure A-14. Storage and loss moduli of corneal tissues at neonatal stage of development under strain-sweep. 


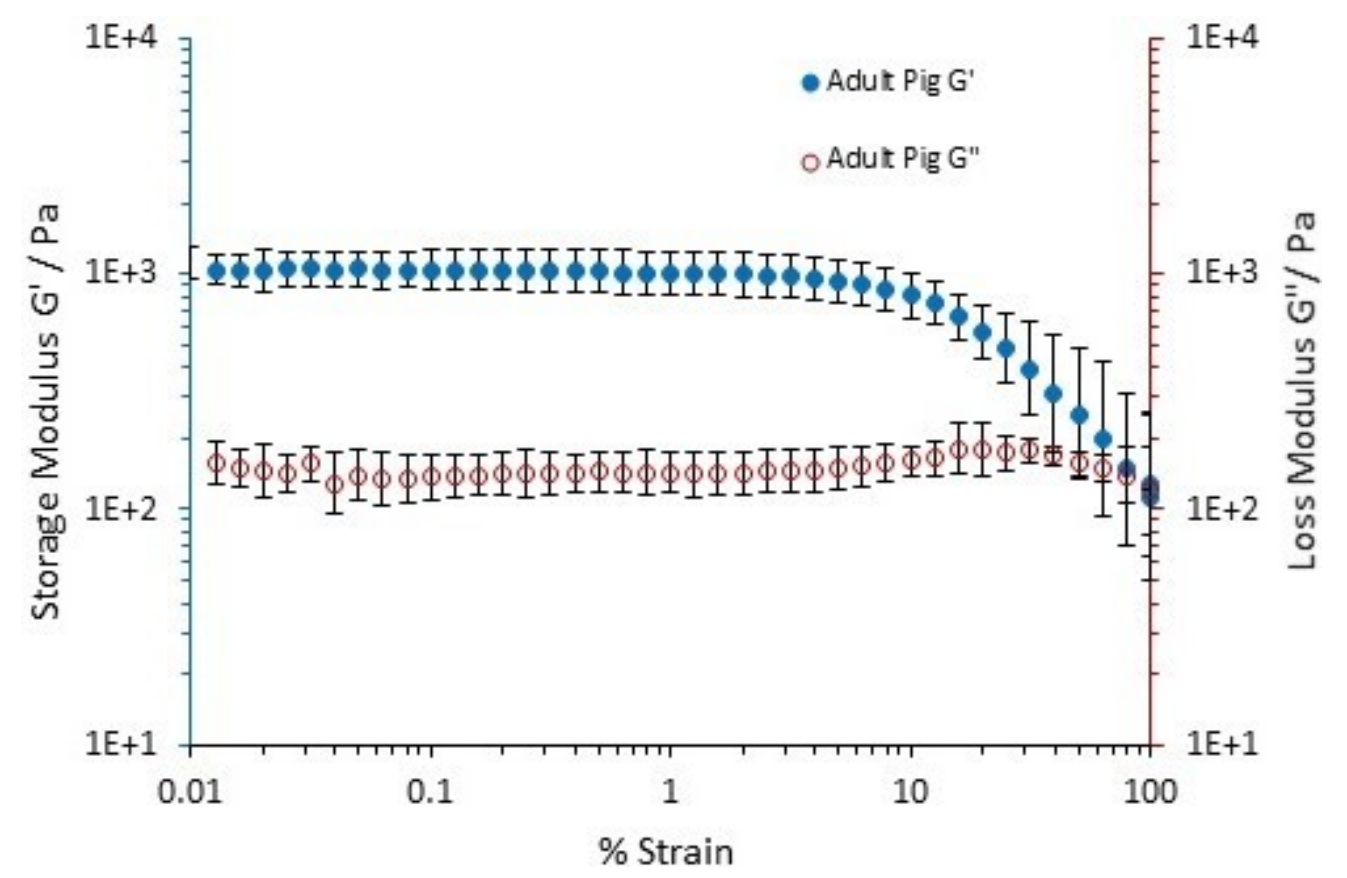

Figure A-15. Storage and loss moduli of corneal tissues at adult stage of development under strain-sweep. 


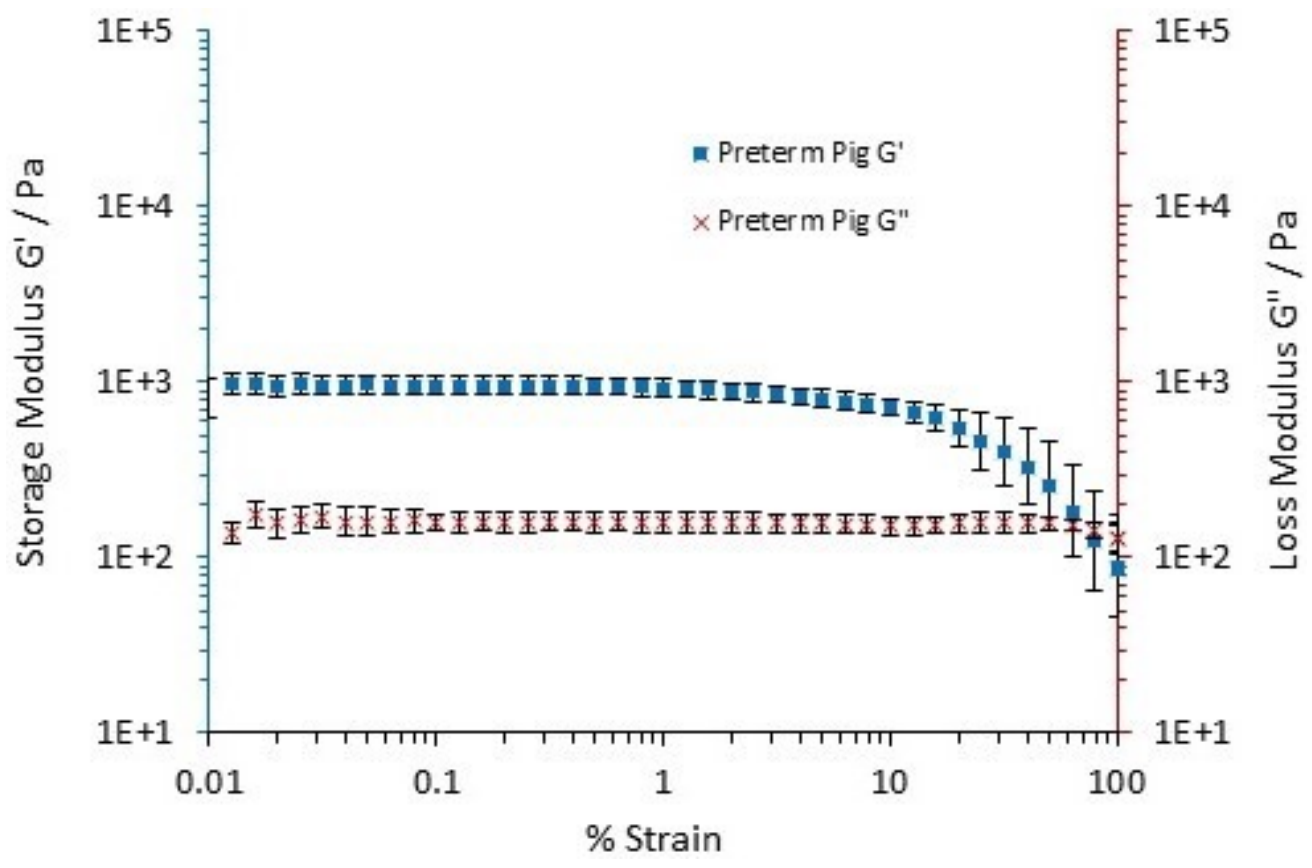

Figure A-16. Storage and loss moduli of scleral tissues at preterm stage of development under strain-sweep. 


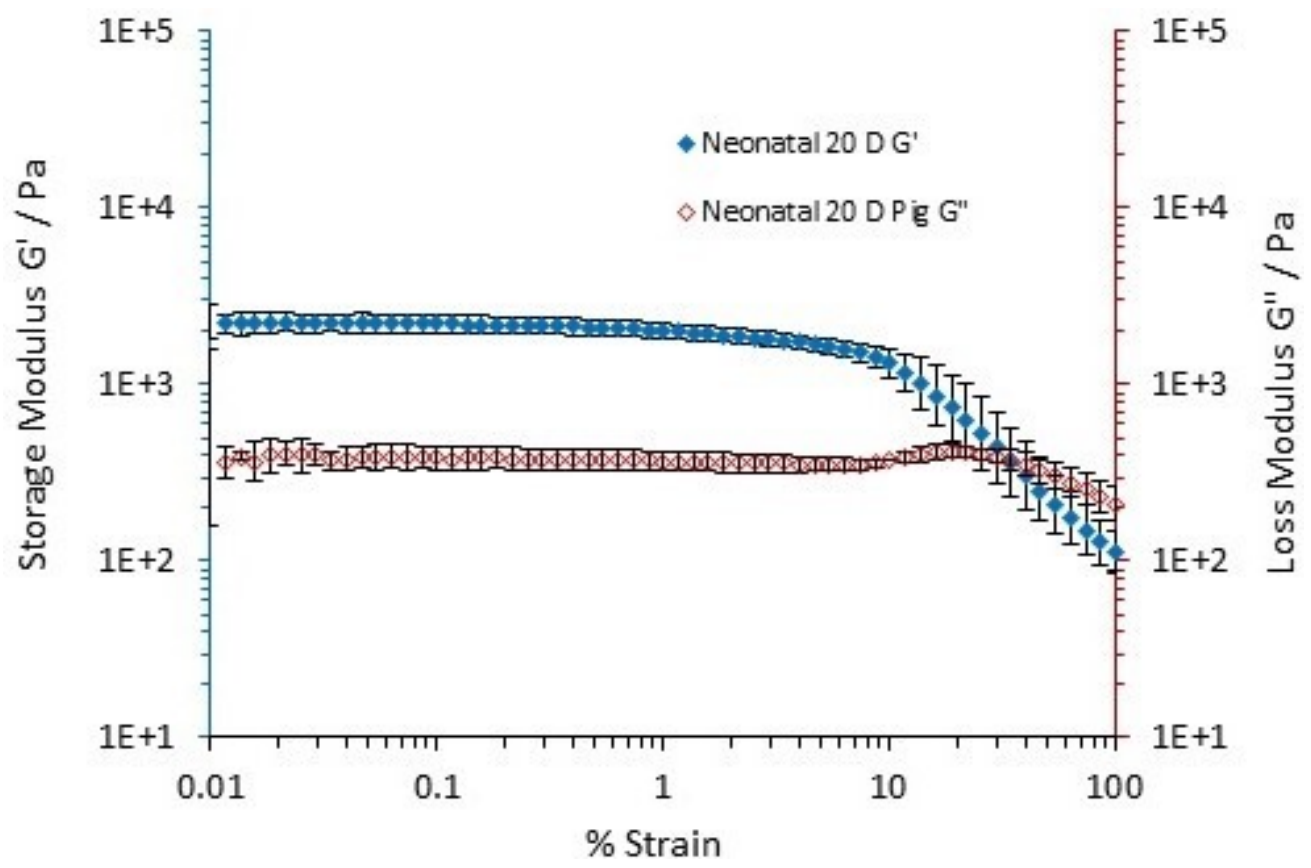

Figure A-17. Storage and loss moduli of scleral tissues at neonatal stage of development under strain-sweep. 


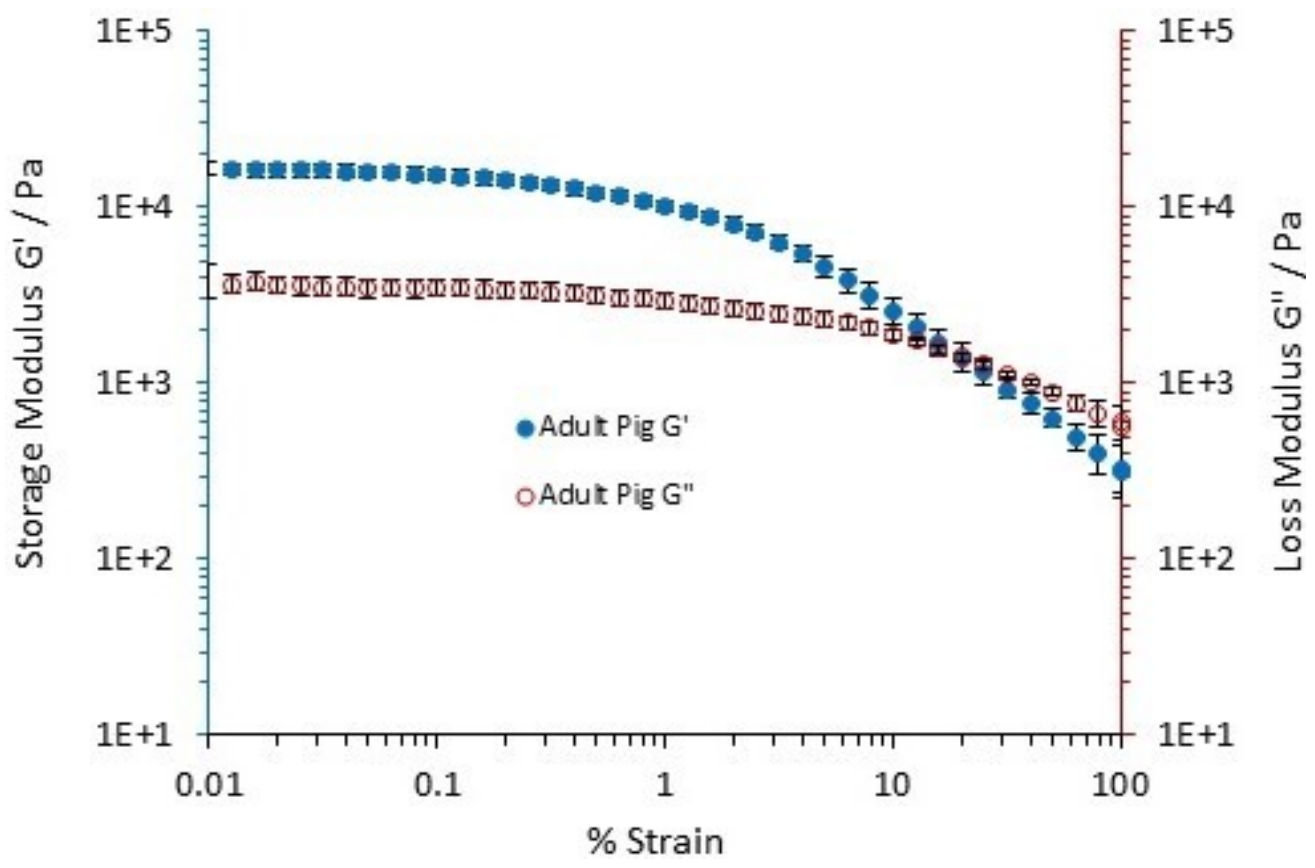

Figure A-18. Storage and loss moduli of scleral tissues at adult stage of development under strain-sweep. 


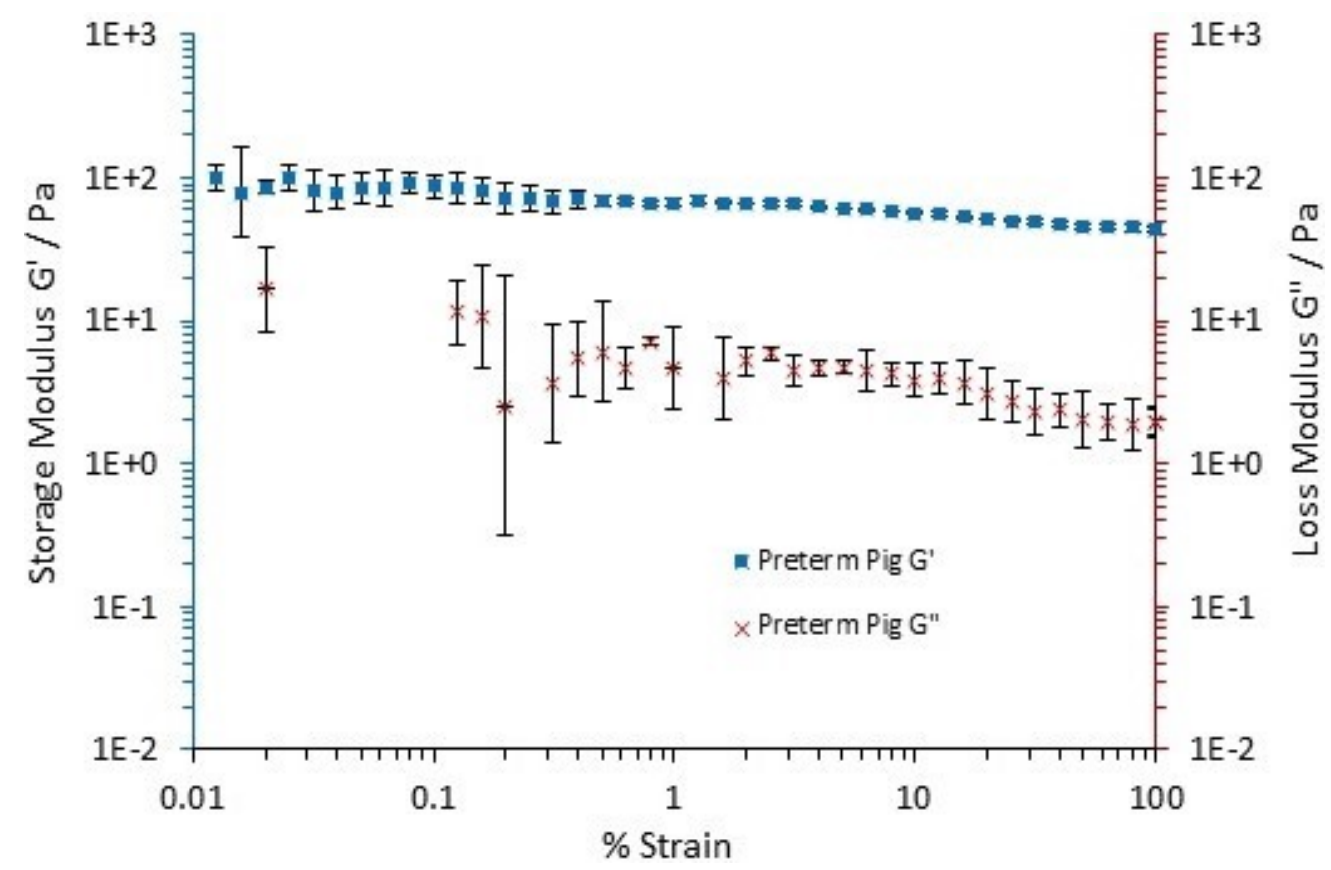

Figure A-19. Storage and Loss moduli of vitreous humor at preterm stage of development under strain-sweep. 


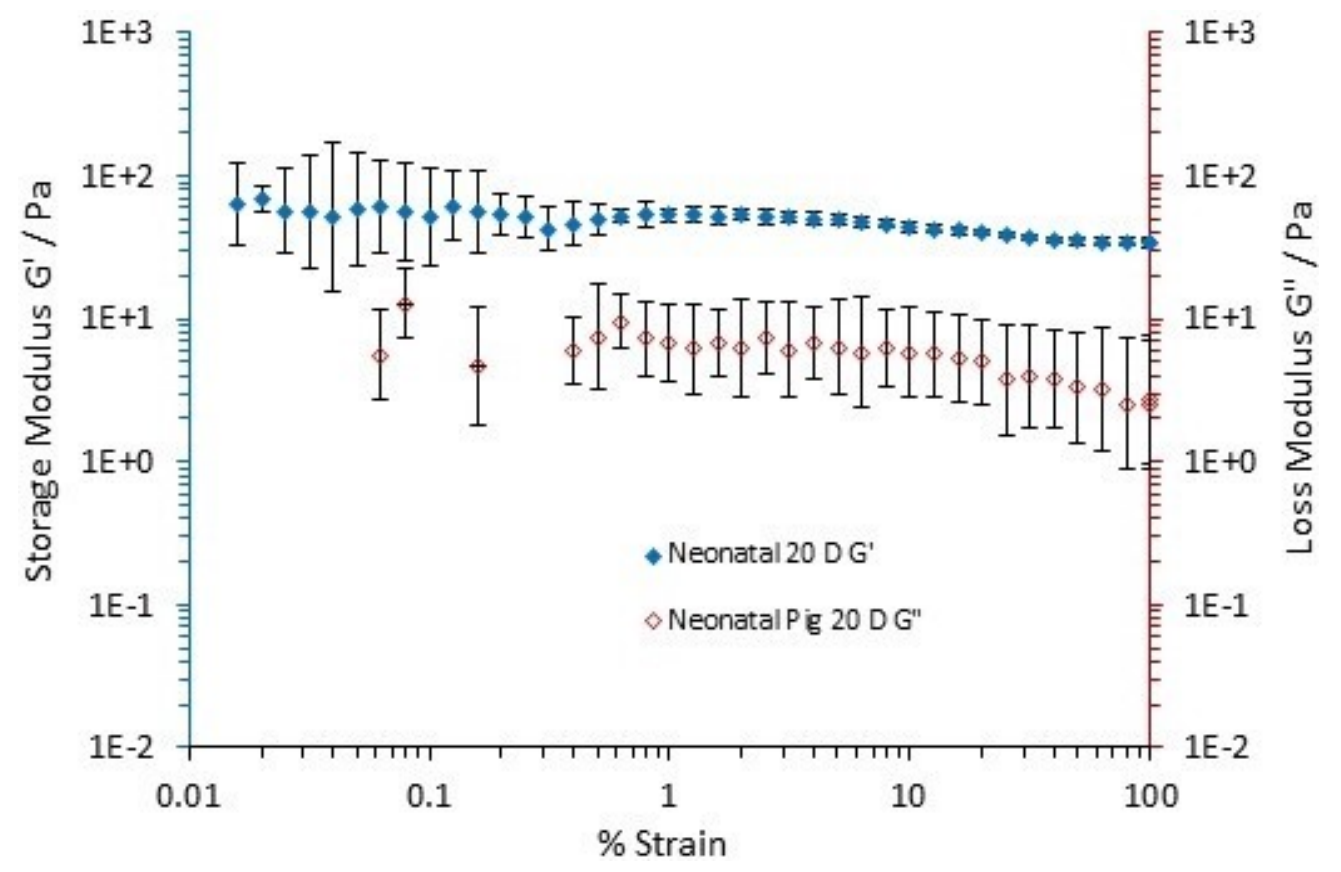

Figure A-20. Storage and Loss moduli of vitreous humor at neonatal stage of development under strain-sweep. 


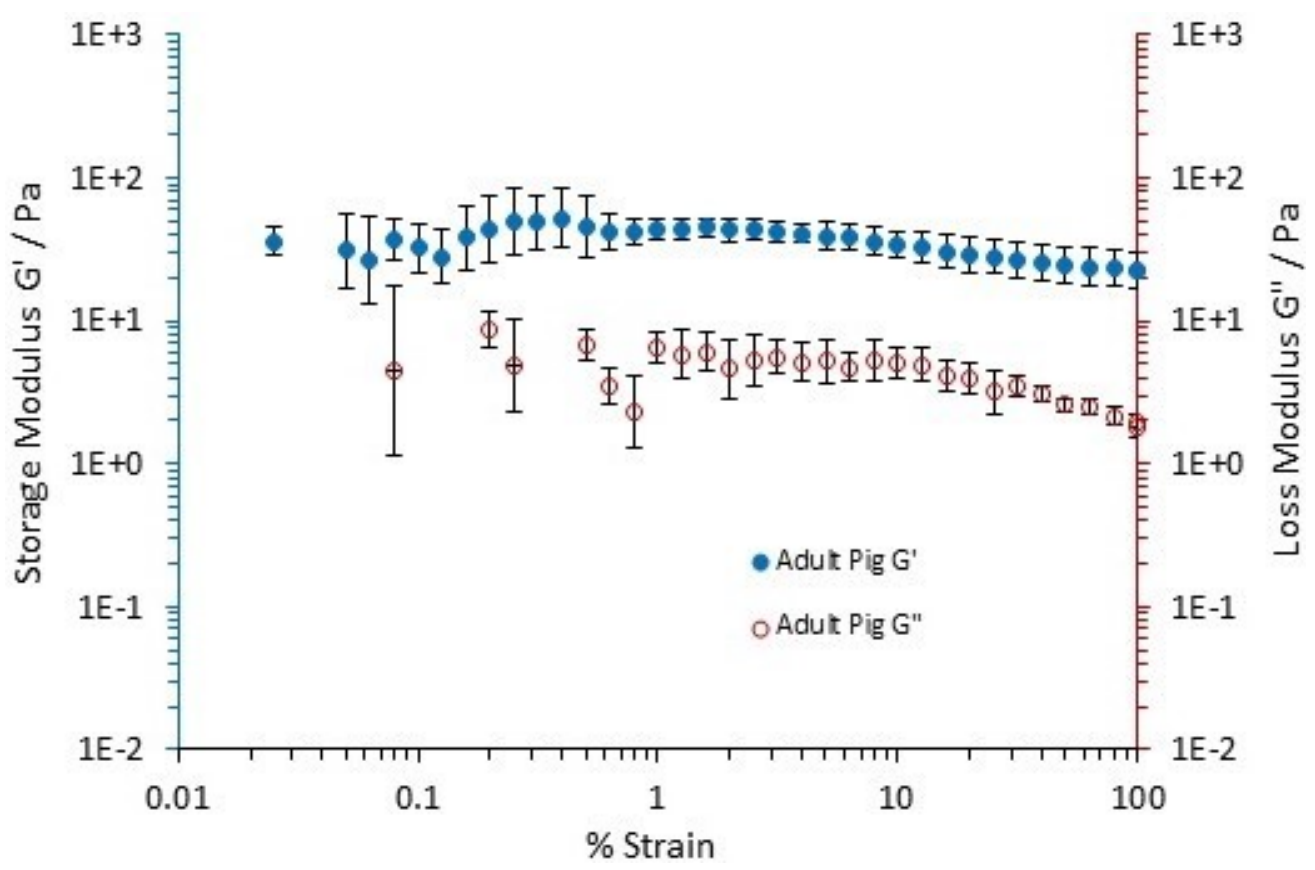

Figure A-21. Storage and Loss moduli of vitreous humor at adult stage of development under strain-sweep. 


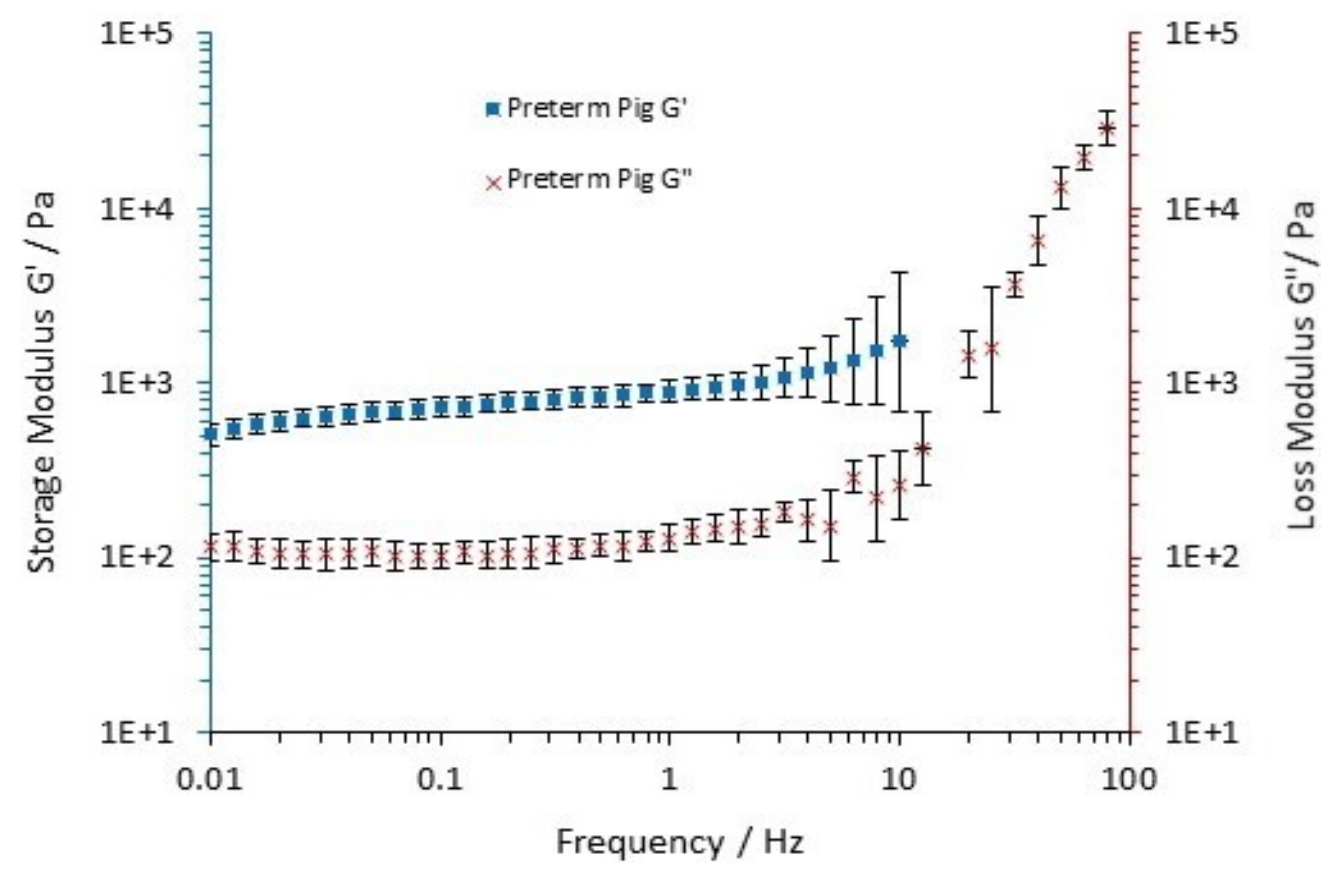

Figure A-22. Storage and loss moduli of corneal tissues at preterm stage of development under frequency-sweep. 


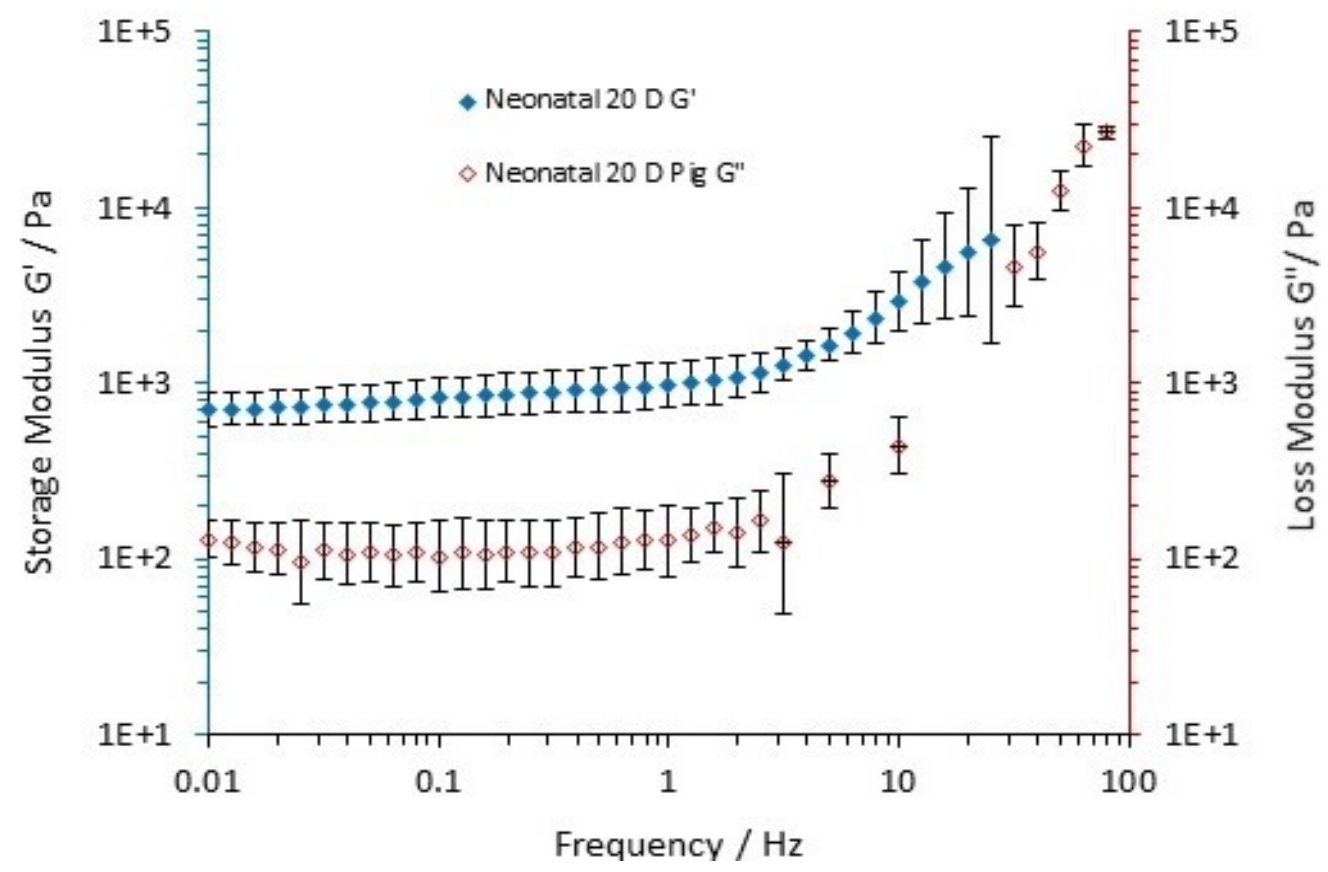

Figure A-23. Storage and loss moduli of corneal tissues at neonatal stage of development under frequency-sweep. 


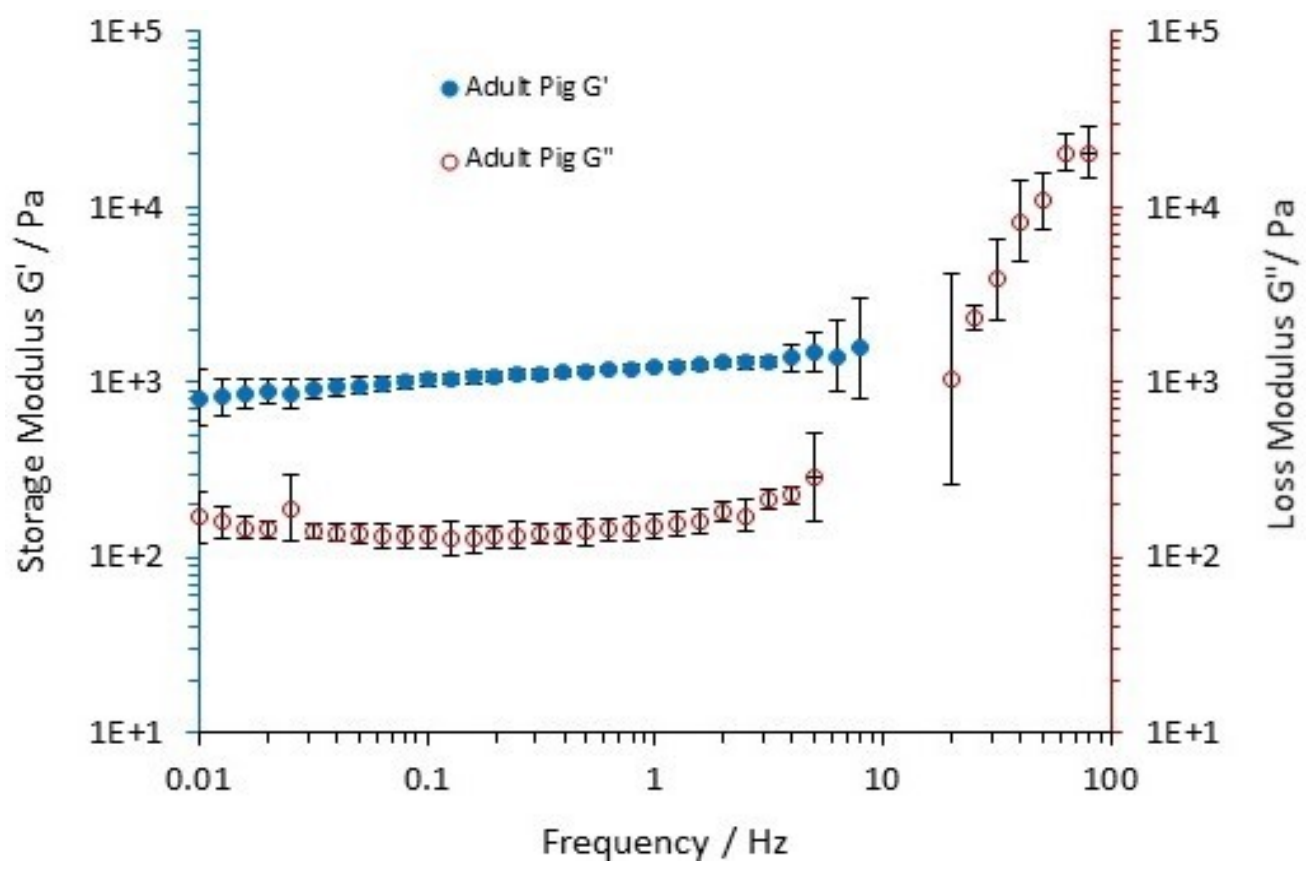

Figure A-24. Storage and loss moduli of corneal tissues at adult stage of development under frequency-sweep. 


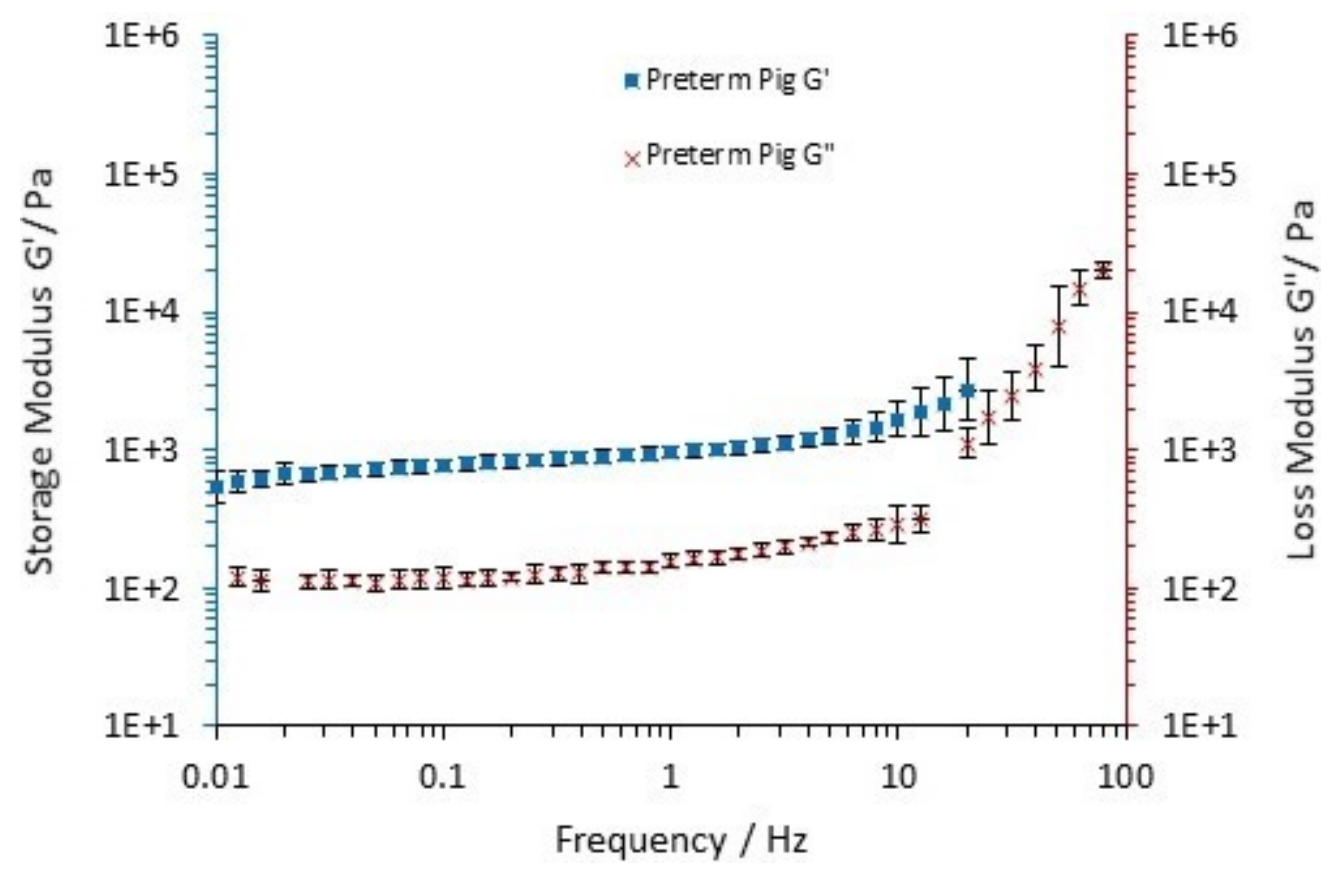

Figure A-25. Storage and loss moduli of scleral tissues at preterm stage of development under frequency-sweep. 


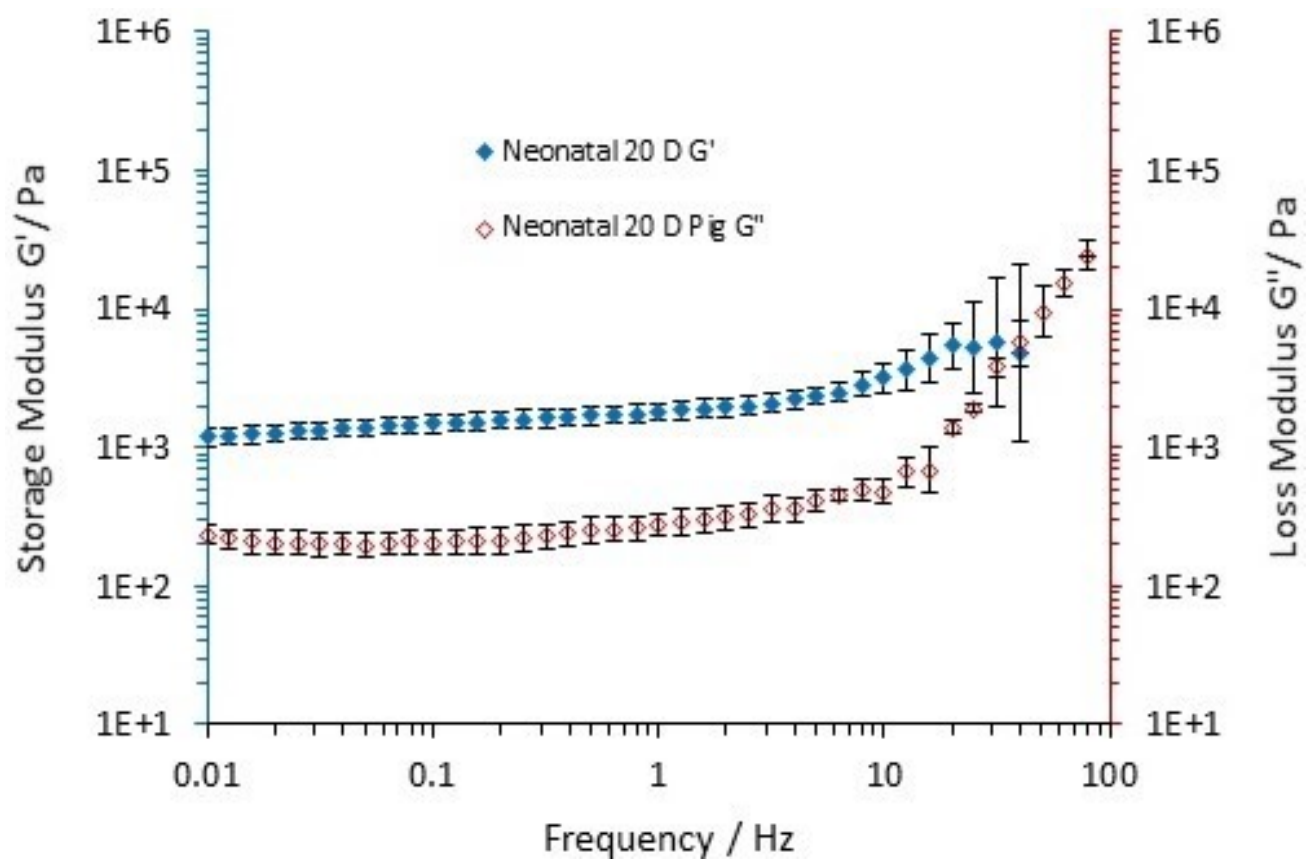

Figure A-26. Storage and loss moduli of scleral tissues at neonatal stage of development under frequency-sweep. 


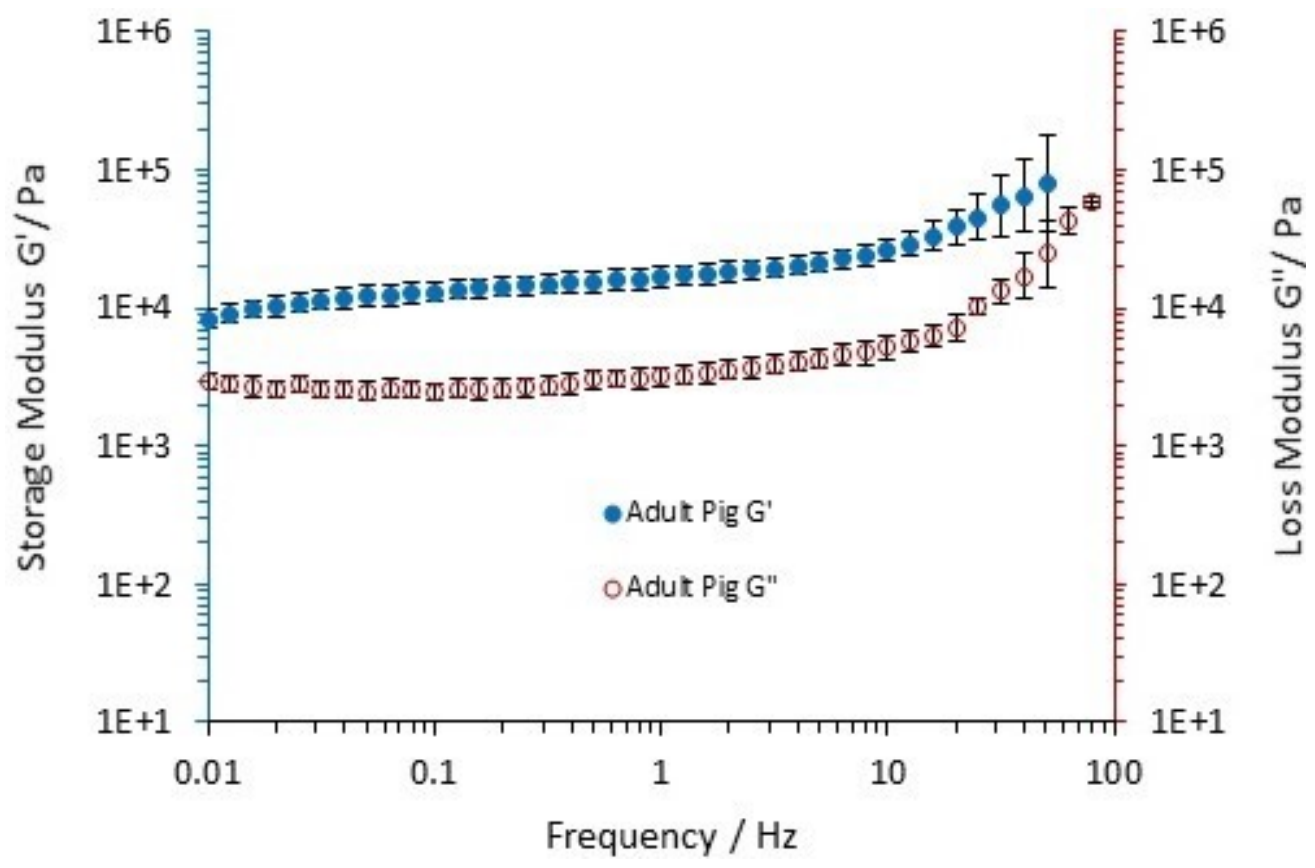

Figure A-27. Storage and loss moduli of scleral tissues at adult stage of development under frequency-sweep. 


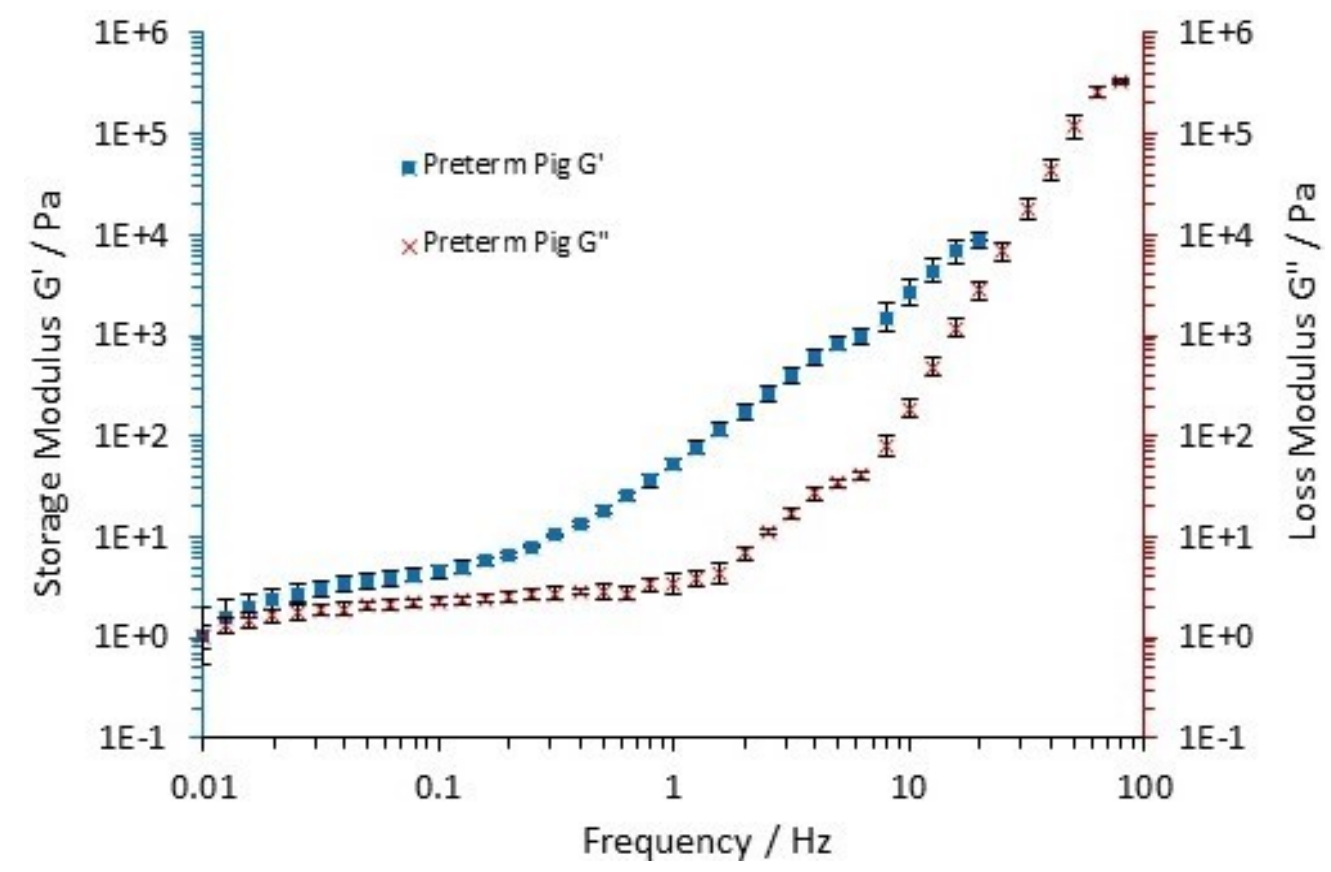

Figure A-28. Storage and Loss moduli of vitreous humor at preterm stage of development under Frequency-sweep. 


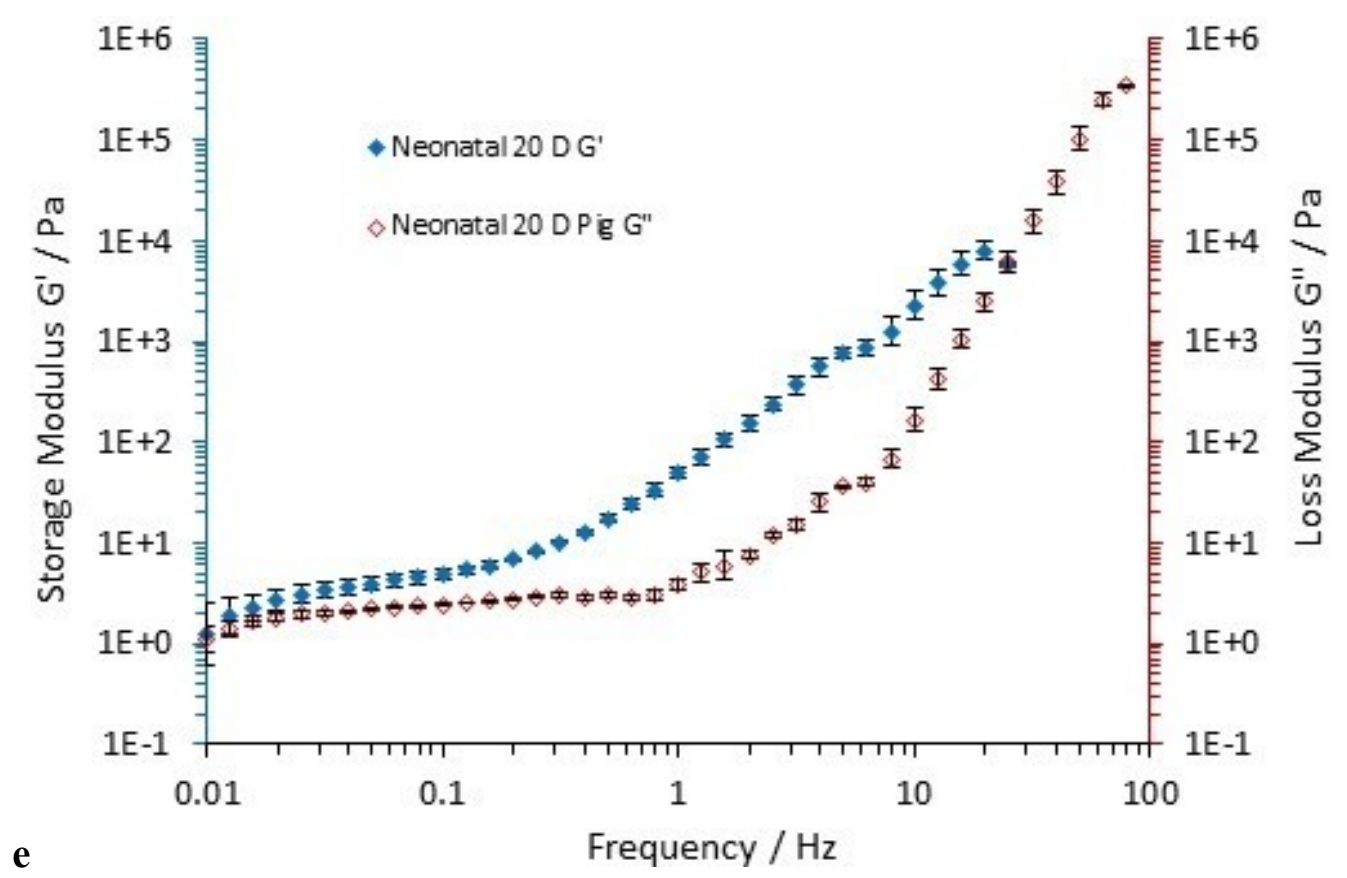

Figure A-29. Storage and Loss moduli of vitreous humor at neonatal stage of development under Frequency-sweep. 


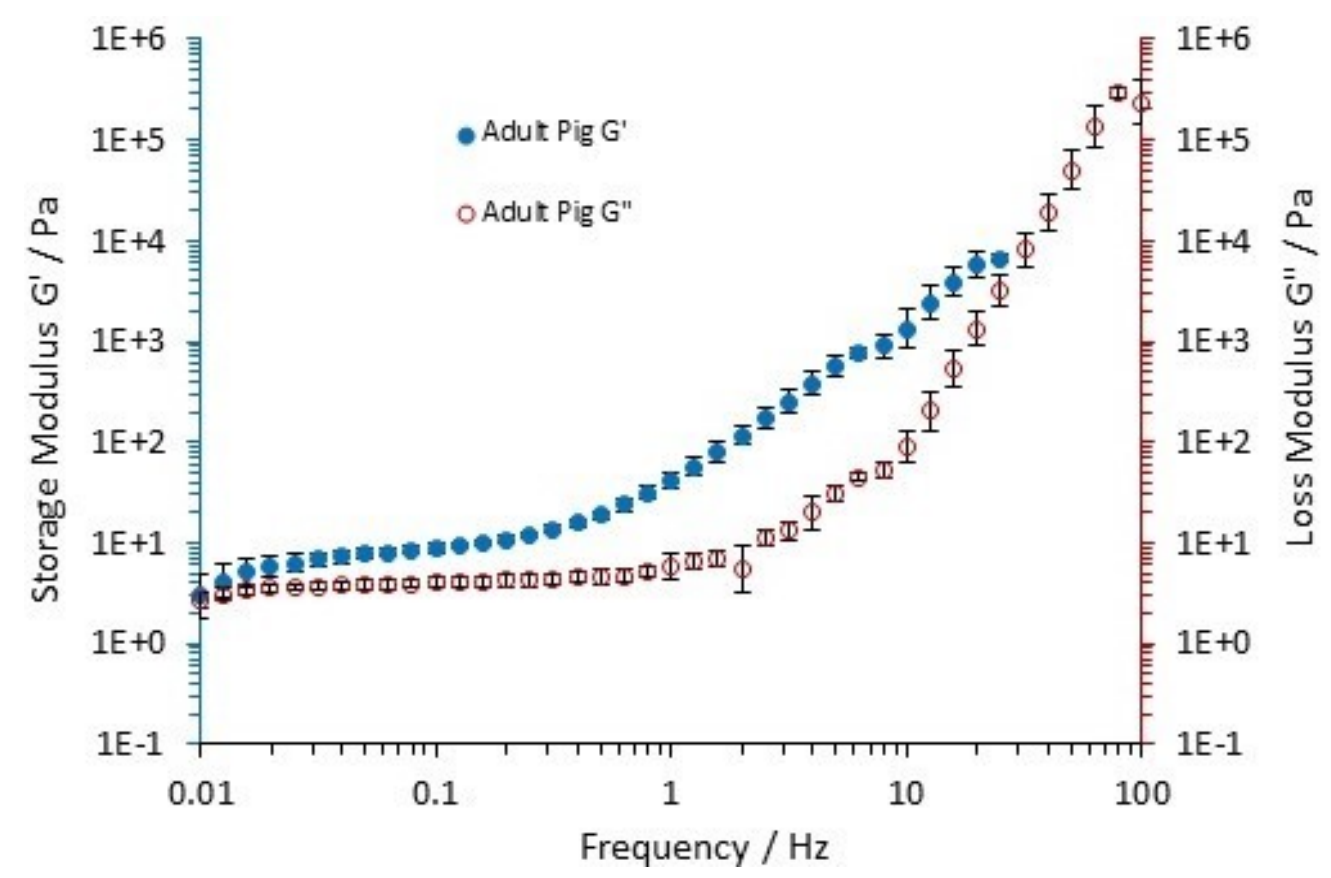

Figure A-30. Storage and Loss moduli of vitreous humor at adult stage of development under Frequency-sweep. 


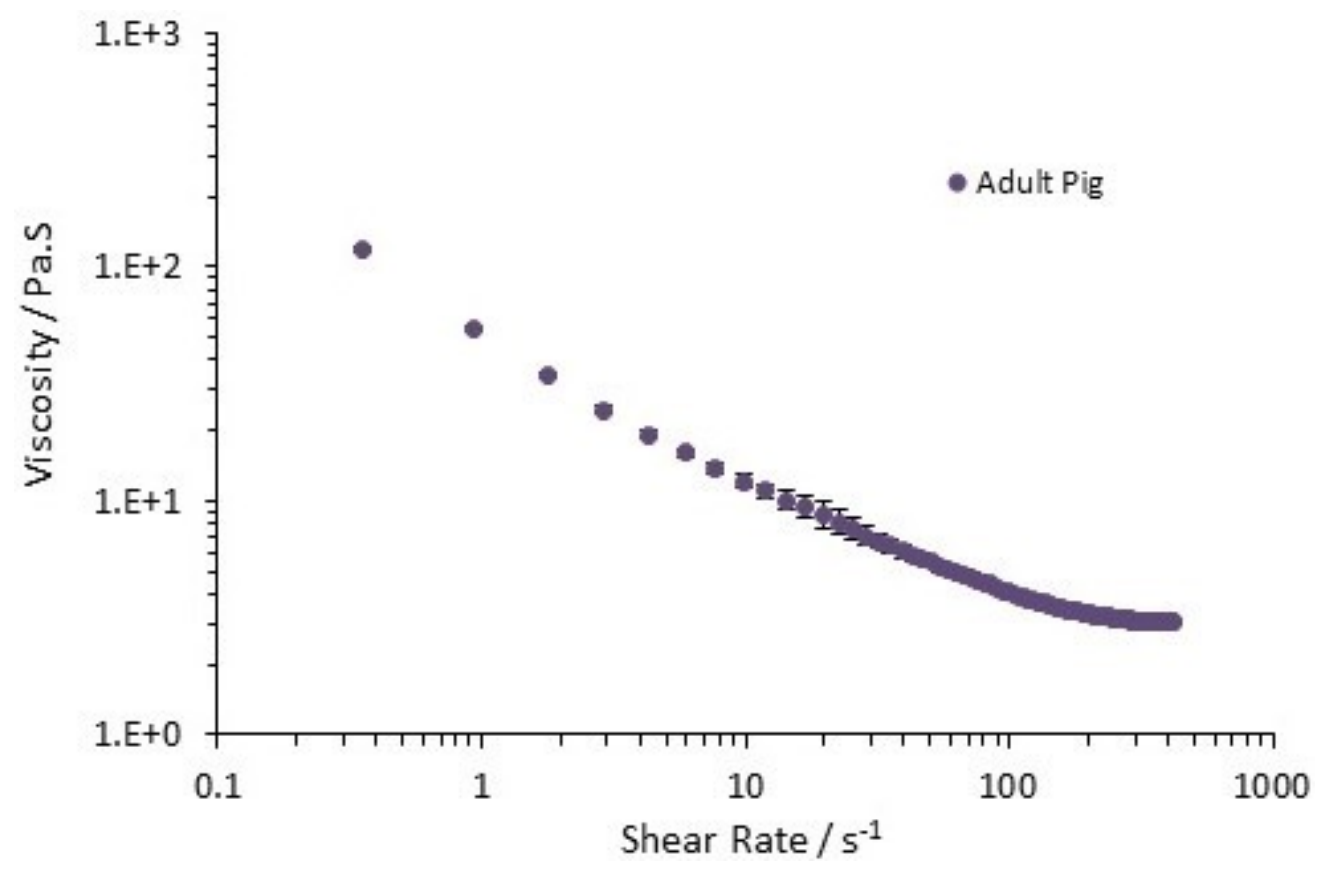

Figure A-31. The viscosity of vitreous humor with the shear rate at preterm stage of development. 


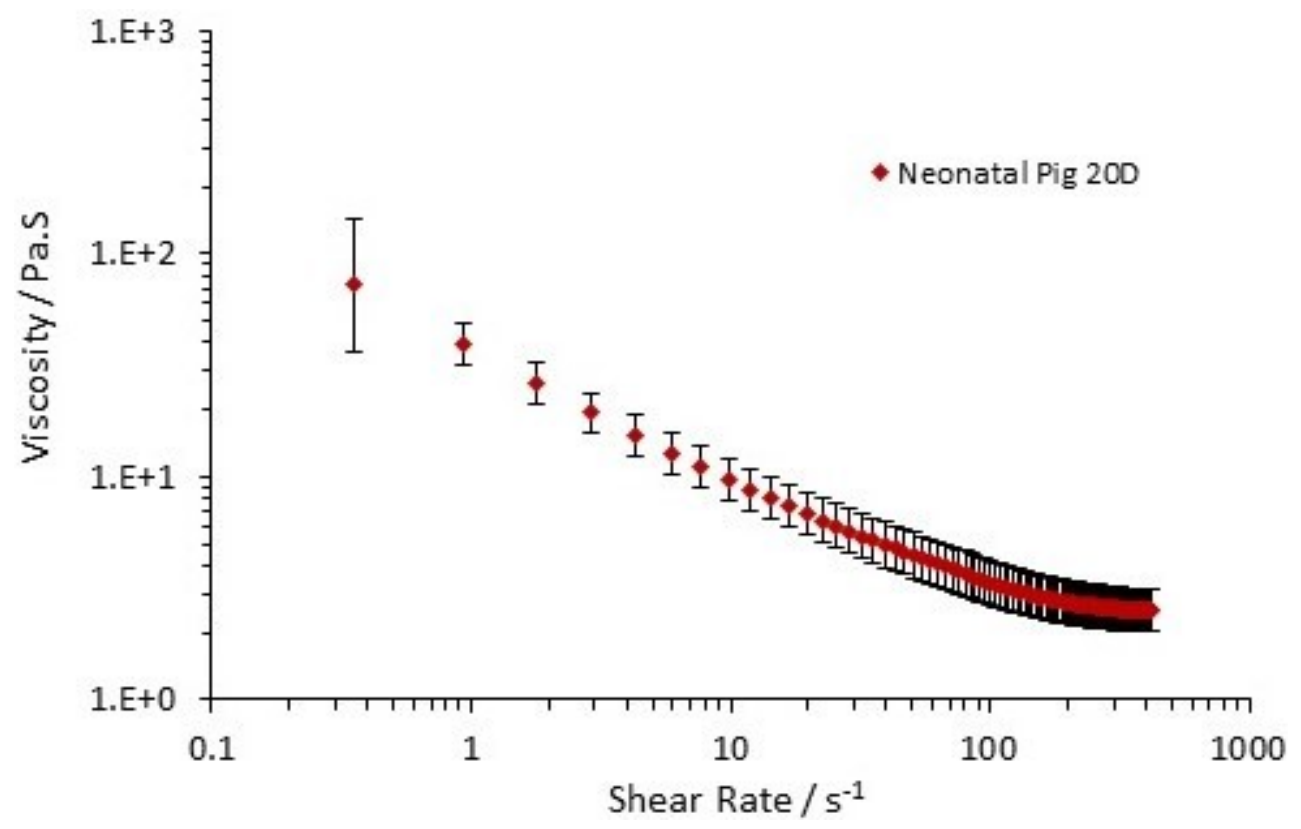

Figure A-32. The viscosity of vitreous humor with the shear rate at neonatal stage of development. 


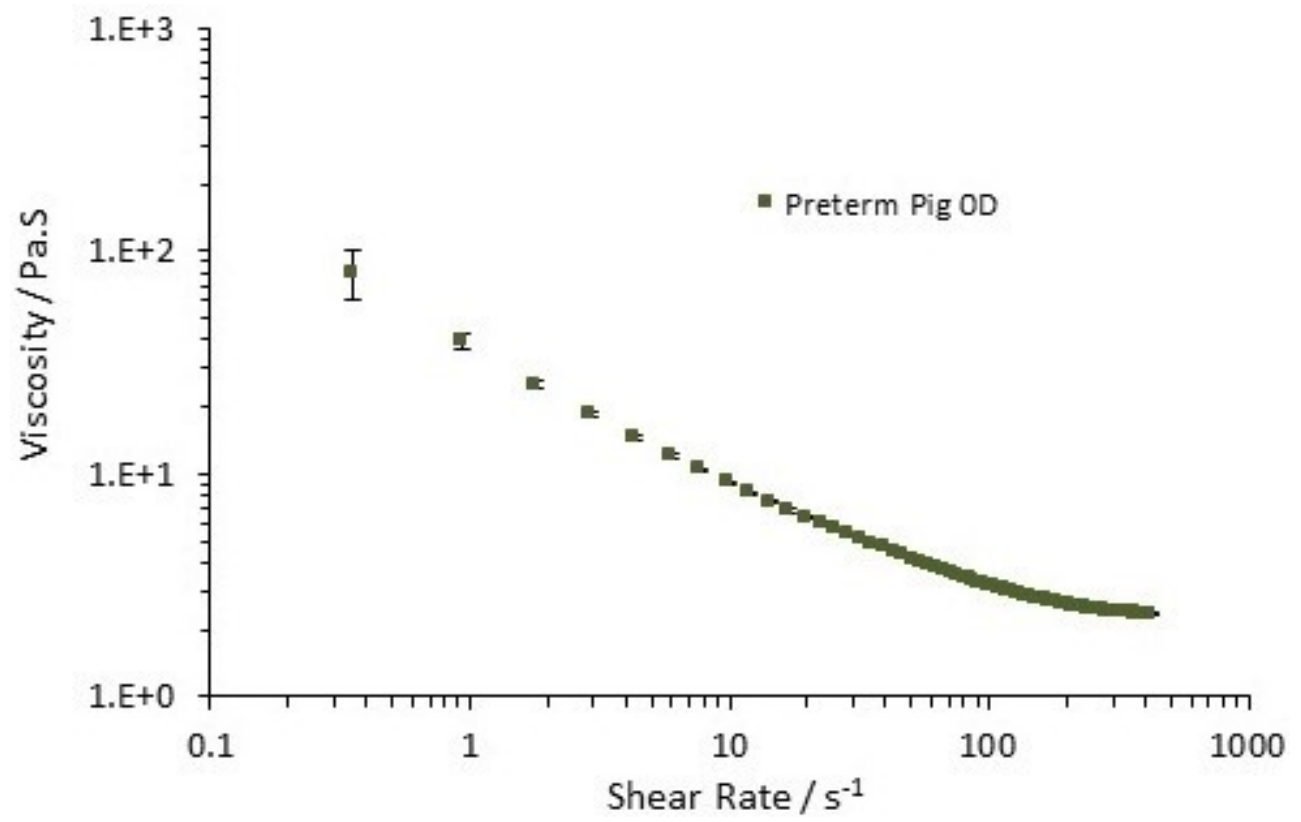

Figure A-33. The viscosity of vitreous humor with the shear rate at adult stage of development. 


\section{VITA}

Mrs. Sri Chandana Reddy Damera was born in Karimnagar District, Telangana, India in 1990. She received her Bachelor of Pharmacy degree from Teegala Ram Reddy College of Pharmacy, Jawaharlal Nehru Technological University in 2011. She received her Masters in Pharmaceutical Chemistry degree in 2013 from Osmania University. After the acceptance of this thesis, she will have earned a Master's Degree in Pharmaceutical Sciences. During her time at UTHSC, she has presented her work in conferences including AAPS, BMES, and ARVO. She also served as Secretary for AAPS UTHSC Student Chapter (Aug 2016 - May 2017) 